Aus der Abteilung Neurogenetik

(Leiter: Prof. Dr. rer. nat. K. A. Nave)

des Max-Planck-Instituts für Experimentelle Medizin in Göttingen

\title{
Myelinisierung des peripheren Nervensystems in Endothelin-Rezeptor-B-defizienten Ratten
}

\section{INAUGURAL - DISSERTATION}

zur Erlangung des Doktorgrades

der Medizinischen Fakultät

der Georg-August-Universität zu Göttingen

vorgelegt von

Naureen Kerić

aus Rabwah (Pakistan)

Göttingen 2010 
Dekan: Prof. Dr. med. C. Frömmel

I. Berichterstatter: PD. Dr. med. M. W. Sereda

II. Berichterstatter/in: Prof. Dr. med. M. Simons

III. Berichterstatter/in:

Tag der mündlichen Prüfung: 01.08.2011 


\section{Inhaltsverzeichnis}

1 EINLEITUNG _ 1

1.1 ENDOTHELINE 2

1.1.1 Endotheline und ihre Rezeptoren

1.1.2 Physiologische und pathophysiologische Bedeutung der Endotheline ___ 4

1.1.3 Signalkaskaden der Endothelinrezeptoren __ 5

1.1.4 ET $T_{B}$-Rezeptor-defiziente Ratten___ ${ }^{7}$

1.2 Das Periphere NerVENSYSTEM __ 9

1.2.1 Die Neuralleiste _ 9

1.2.2 Entwicklung und Differenzierung der Schwannzellen __ 9

1.2.3 Signale, die das Überleben der Schwannzellen beeinflussen ___ 11

1.2.4 Das Myelin__ 12

1.2.5 Die Myelinisierung im peripheren Nervensystem ___ 13

1.2.6 Die Rolle der Endotheline im Nervensystem___ 16

1.3 ZIELSETZUNG DER ARBEIT __ 18

2 MATERIAL UND METHODEN__ 19

2.1 MATERIAL 19

2.1.1 Chemikalien und Bioreagenzien __ 19

2.1.2 Verbrauchsmaterial __ 20

2.1 .3 Geräte_ 20

2.1.4 Lösungen und Puffer _ 22

2.1.4.1 Molekularbiologie __ 22

2.1.4.2 Histologie _ 23

2.1.5 Enzyme und Reaktionskomplettsysteme _ 25

2.1.5.1 Enzyme_ 25

2.1.5.2 Reaktionskomplettsysteme 25

2.1.6 Nukleinsäuren und Nukleotide 25

2.1.6.1 Primer zur Genotypisierung mutanter Ratten 225

2.1.7 Tiere 25

2.1.8 Computersoftware__ 25

2.2 METHODEN__ 27

2.2.1 Zucht und Analyse von Ratten___ 27

2.2.1.1 Tiere 27

2.2.1.2 Tierhaltung _ 27

2.2.1.3 Identifikation der Tiere und Schwanzbiopsien __ 27

2.2.1.4 Narkotisierung und Tötung der Tiere_ 28

2.2.1.5 Präparation von Ischiasnerven, spinalen Nervenwurzeln (DRG's) und Rückenmarksabschnitten _ 28

2.2.2 Histologische Methoden __ 29

2.2.2.1 Ganzkörperfixation von Ratten durch Perfusion ___ 29

2.2.2.2 Einbettung der Gewebeproben in Kunstharz __ 29

2.2.2.3 Semidünnschnitte von in Kunstharz eingebetteten Gewebeproben 30

2.2.2.4 Methylenblaufärbung von Semidünnschnitten 30

2.2.2.5 Ultradünnschnitte von in Kunstharz eingebetteten Nerven _ 30

2.2.2.6 Paraffinschnitte von den entnommenen Gewebeproben 31

2.2.3 Immunhistochemie _ 31

2.2.3.1 Dako-LSAB2 System an Paraffinschnitten __ 31

2.2.3.2 Histologische Analyse von Ischiasnerven 32

2.2.3.3 Histologische Analyse des Rückenmarks 34

2.2.3.4 Histologische Analyse der dorsalen spinalen Nervenwurzeln 
2.2.4 Molekularbiologische Methoden

2.2.4.1 Präparation von DNA und Genotypisierung

3.1 MORPHOLOGIE DES N. ISCHIADICUS AUF LICHTMIKROSKOPISCHER EBENE _ 38

3.1.1 Anzahl myelinisierter Axone im N. ischiadicus___ 38

3.1.2 Gesamtanzahl von Zellkernen im N. ischiadicus _ 39

3.1.3 Die Myelindicke, "g-ratio"___ 41

3.2 ELEKTRONENMIKROSKOPISCHE UNTERSUCHUNG DES N. ISCHIADICUS BEI P1__ 43

3.2.1 Anzahl myelinisierter Axone __ 43

3.2.2 Axonale Dichte im N. ischiadicus bei P1__ 44

3.3 Histologische ANALYSE DES RÜCKENMARKS UND DER DRG's _ 45

3.3.1 TUNEL Färbungen DRG's und Rückenmark ___ 46

3.3.2 Dichte der DRG-Neuronen___ 47

3.3.3 Anzahl von $\alpha$-Motoneuronen im Vorderhorn des Rückenmarks___ 49

3.4 ZUSAMMENFASSUNG DER ERGEBNISSE___ 51

4 DISKUSSION —

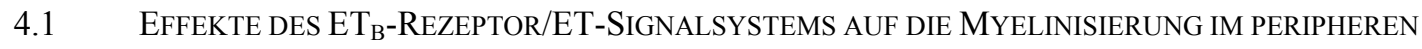
NERVENSYSTEM (PNS)

4.1.1 Erhöhte Anzahl myelinisierter Axone im Ischiasnerven der sl/sl-Ratten bei P1 53

4.1.2 Verminderte Anzahl von myelinisierten Axonen und Schwannzellen in sl/sl-Ratten bei P6 und P18

4.1.3 Hypomyelinisierung kleiner Axone in sl/sl-Ratten bei P6__ 55

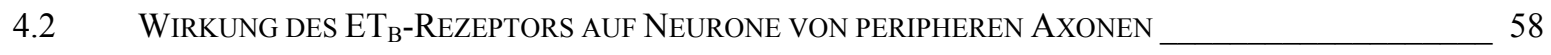

5 ZUSAMMENFASSUNG__ 60

6 LITERATURVERZEICHNIS

7 ABKÜRZUNGSVERZEICHNIS_ 73

8 ABBILDUNGSVERZEICHNIS $\quad 75$ 


\section{Einleitung}

Das Nervensystem ist für die Wahrnehmung, Verarbeitung und Weiterleitung von Signalen zuständig. Es ermöglicht eine schnelle und integrative Kommunikation zwischen einzelnen Organen des Körpers. Es wird in das zentrale Nervensystem (ZNS), Gehirn und Rückenmark, und in das periphere Nervensystem (PNS), periphere Nerven und Ganglien (Nervenknoten) unterteilt. Das enterische Nervensystem (ENS), die Nervenplexus des Intestinaltraktes, bildet einen autonomen Teil des PNS. Auf zellulärer Ebene besteht das Nervensystem von Vertebraten aus zwei Komponenten, den Neuronen und den Gliazellen. Neurone bestehen aus einem Zellsoma (Perikaryon), das den Nukleus enthält, und aus einem oder mehreren Fortsätzen. Die Fortsätze werden in Dendriten, die dem Erregungsempfang dienen, und in Axone unterteilt, die der Erregungsweiterleitung dienen. Oligodendrozyten, Astrozyten und Mikrogliazellen sind die Gliazellen des zentralen, Schwannzellen die des peripheren Nervensystems. Bei Neuronen, deren axonaler Durchmesser über einem $\mu \mathrm{m}$ liegt, wickeln im PNS die Schwannzellen viele konzentrische Zellmembranschichten um einen Axonabschnitt die so genannte Myelin- oder Markscheide. Sie wirkt als Isolator für Ionenströme, wodurch die Entstehung von Aktionspotentialen auf nicht myelinisierte Axonabschnitte (Nodien oder Ranviersche Schnürringe) beschränkt wird und eine schnelle, saltatorische Erregungsleitung im Axon ermöglicht wird.

Schwannzellen entstehen aus pluripotenten Stammzellen der Neuralleiste (neural crest stem

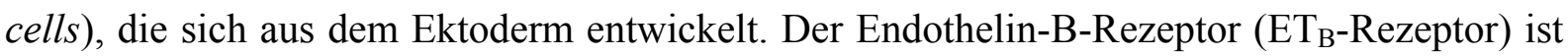
ein wichtiger Faktor für die Entwicklung der Neuralleistenzellen. Bei Ratten führt ein Defekt des $\mathrm{ET}_{\mathrm{B}}$-Rezeptorgens $\mathrm{zu}$ einem Entwicklungsdefekt von Neuralleistenzellen und zu kongenitaler Aganglionose des kaudalen Darmabschnitts. Diese natürlich mutanten Tiere dienen als Modellsystem für den menschlichen Morbus Hirschsprung.

Da der $\mathrm{ET}_{\mathrm{B}}$-Rezeptor auch die embryonale Entwicklung von Schwannzellen beeinflusst, soll in der vorliegenden Arbeit anhand des Rattenmodells der mögliche Einfluss des $\mathrm{ET}_{\mathrm{B}^{-}}$ Rezeptors auf die frühe, postnatale Myelinisierung des PNS untersucht werden. 


\title{
1.1 Endotheline
}

\subsubsection{Endotheline und ihre Rezeptoren}

Endotheline (ET-1, ET-2, ET-3) sind Peptide aus jeweils 21 Aminosäuren, einem hydrophoben C-Terminus und zwei Disulfidbrücken im N-terminalen Ende (Abbildung 1). Sie sind in den verschiedensten Zellen und Organsystemen weit verbreitet und vermitteln sehr unterschiedliche, physiologische Effekte. ET-2 und ET-3 werden in Nieren, Nebennieren und Darmtrakt gebildet. ET-3 findet sich in hoher Konzentration im Gehirn und scheint spezifisch für neuronales Gewebe zu sein, während ET-1 die einzige Isoform in menschlichen Endothelzellen ist. Weiterhin wird ET-1 vor allem in Gefäßmuskelzellen, aber auch in nicht vaskulärem Gewebe wie Gehirn, Nieren und Lunge synthetisiert. Peptide ähnlicher Struktur, die Sarafotoxine, finden sich im Schlangengift von Atractaspis engaddensis (Takasaki et al. 1988).
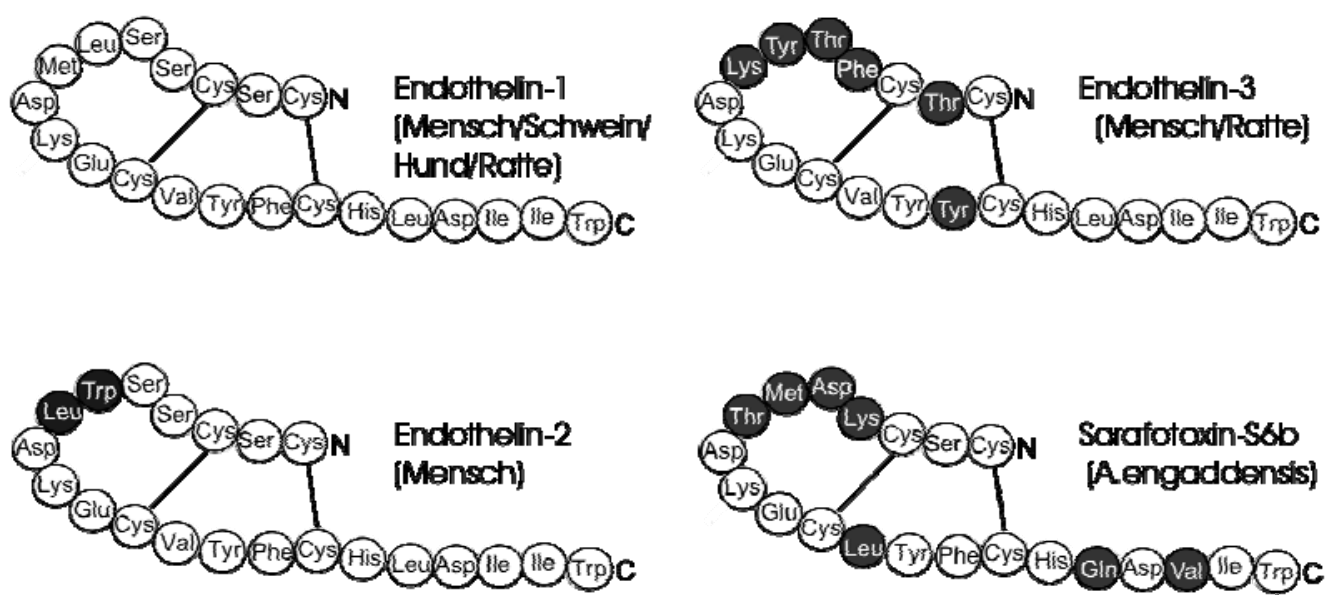

\begin{abstract}
Abbildung 1: Struktur der Endotheline und des Sarafotoxin-S6b
Schwarz markierte Aminosäuren zeigen Unterschiede in der Aminosäuresequenz zum Endothelin-1 (Modifiziert nach Nayler
\end{abstract} 1990, S. 97).

ET-1 ist der potenteste heute bekannte Vasokonstriktor. Er wird in Endothelzellen gebildet und wirkt sich auf die umliegenden Gefäßmuskelzellen stark kontrahierend aus (Vanhoute und Houston 1985). Erst 1988 konnte dieses Peptid aus den Überständen von kultivierten Gefäßendothelzellen der Schweineaorta isoliert und schließlich sequenziert werden (Yanagisawa et al. 1988). Durch Endopeptidasen entsteht aus dem Prä-pro-ET-1 mit 212 Aminosäuren das Big-ET mit 39 Aminosäuren (Abbildung 2, S. 3). Big-ET-1 wird durch eine 
membrangebundene Zink-Metallopeptidase, das Endothelin-Conversions-Enzym-1 (ECE-1), erst kurz vor seiner Sekretion in das aktive ET-1 umgewandelt (Harrison et al. 1995).

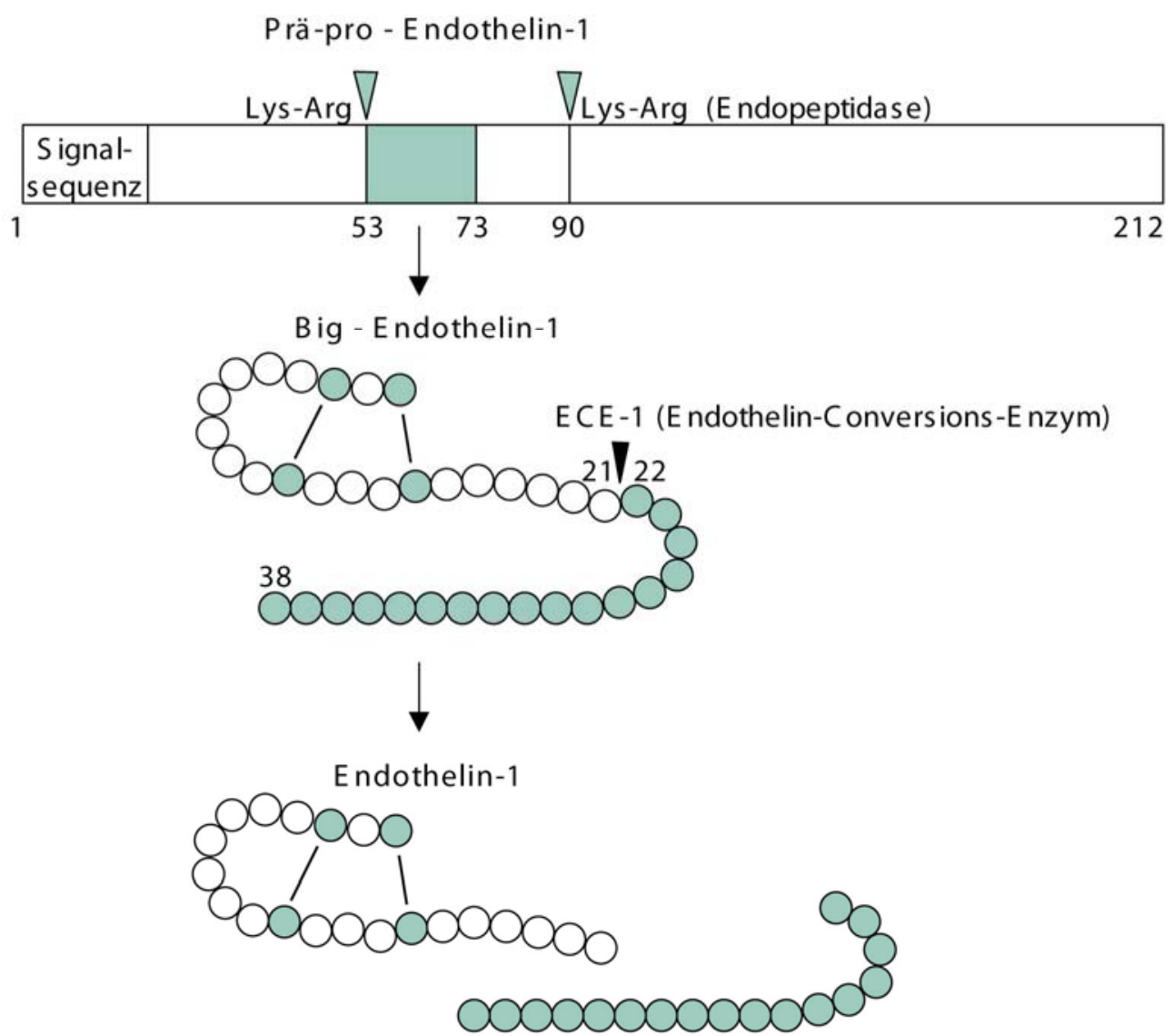

\section{Abbildung 2: Enzymatische Prozessierung von Endothelin-1}

Endothelin-1 ist etwa 100-fach stärker wirksam als Big-ET-1. Nur ein kleiner Teil des in der Endothelzelle gebildeten Endothelin-1 wird in das Gefäßlumen sezerniert, der größte Teil gelangt zu den Gefäßmuskelzellen und wird dort an Endothelin-Rezeptoren gebunden (Modifiziert nach Vane und Botting 1994, S. 514 ).

Zelluläre Effekte der Endotheline werden durch spezifische G-Protein-gekoppelte Rezeptoren (GPCR's; Abbildung 3, S. 4) vermittelt. Es wurden zwei Isoformen des humanen Endothelinrezeptors $\mathrm{A}$ ( $\mathrm{ET}_{\mathrm{A}}$-Rezeptor) und $\mathrm{B}$ ( $\mathrm{ET}_{\mathrm{B}}$-Rezeptor) kloniert, die auf den Chromosomen 4 und 13 lokalisiert sind (Arai et al. 1990; Sakurai et al. 1990; Hosoda et al. 1992). Ein weiterer Rezeptorsubtyp, der ET $_{C}$-Rezeptor, wurde bisher nur im Krallenfrosch Xenopus laevis nachgewiesen (Karne et al. 1993). Für den $\mathrm{ET}_{\mathrm{B}}$-Rezeptor konnten zwei mRNA-Spleißvarianten identifiziert werden, die für veränderte zytoplasmatische Domänen kodieren. Diese zeigen trotz unveränderter Bindungseigenschaften keine Aktivierung der GProteine mehr (Shyamala et al. 1994; Elshourbagy et al. 1996). 


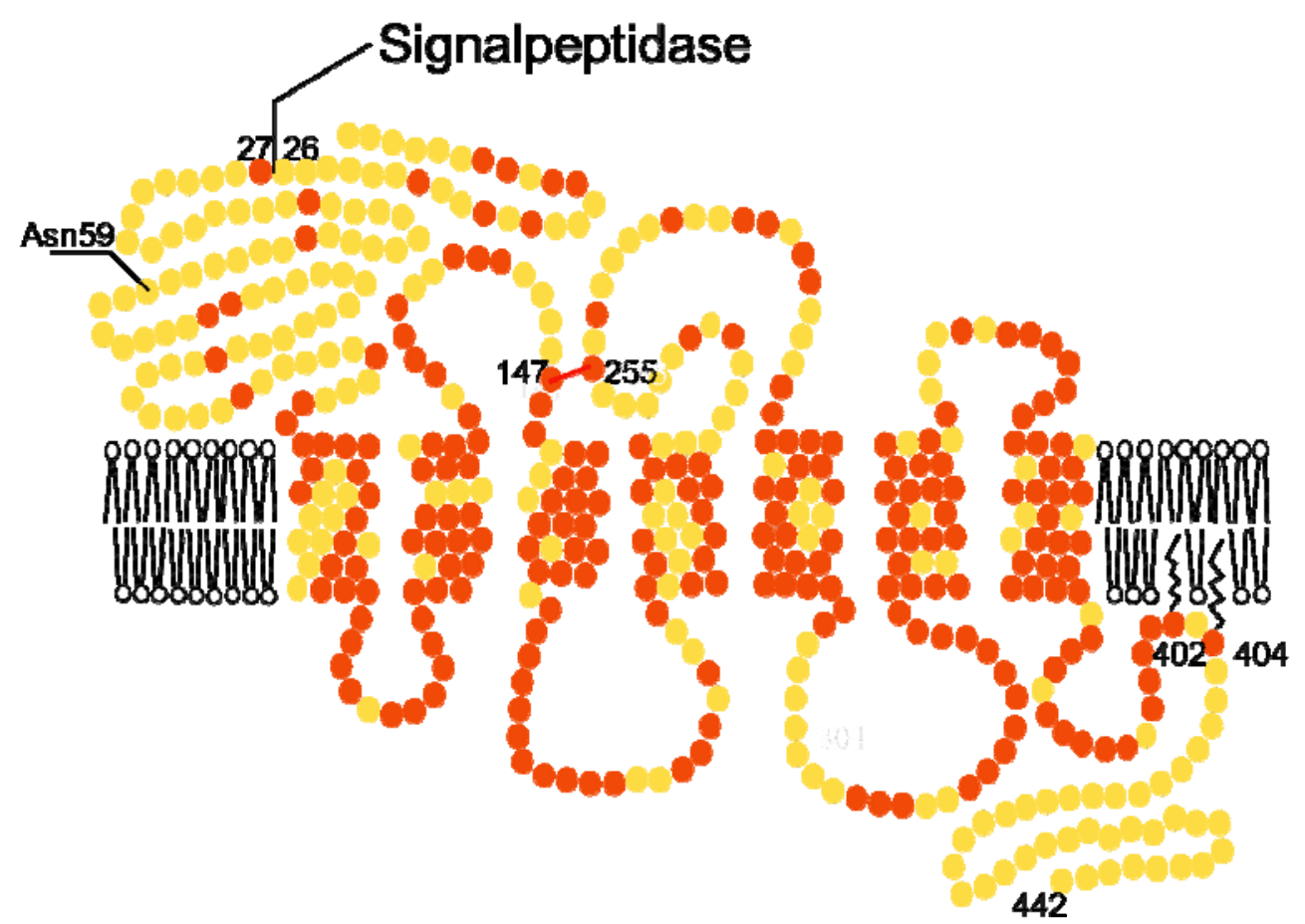

\begin{abstract}
Abbildung 3: Struktur des humanen ETB-Rezeptors
Homologe Bereiche zum $\mathrm{ET}_{\mathrm{A}}$-Rezeptor sind dunkel hervorgehoben. Die ersten 26 Aminosäuren können von einer Signalpeptidase abgespalten werden und dienen möglicherweise als Erkennungssequenz. Das Asparagin 59 kann glykosiliert werden. Der lange, prolinreiche N-Terminus sowie der C-Terminus des $\mathrm{ET}_{\mathrm{B}}$-Rezeptors weisen eine geringe Homologie zum $\mathrm{ET}_{\mathrm{A}}$ - Rezeptor auf (Modifiziert nach Adachi et al. 1991, S. 1268).
\end{abstract}

Zwischen den verschiedenen Spezies sind die Isoformen A und B hoch homolog. So ist der humane $\mathrm{ET}_{\mathrm{A}}$-Rezeptor zu dem $\mathrm{ET}_{\mathrm{A}}$-Rezeptor der Ratte zu 93\% und zu dem des Rindes zu 94\% identisch (Adachi et al. 1991). Der humane $\mathrm{ET}_{\mathrm{B}}$-Rezeptor stimmt mit dem $\mathrm{ET}_{\mathrm{B}}$-Rezeptor der Ratte zu 88\% überein (Sakamoto et al. 1991). Hingegen besteht zwischen dem humanen $\mathrm{ET}_{\mathrm{A}}$-Rezeptor und $\mathrm{ET}_{\mathrm{B}}$-Rezeptor nur eine Sequenzhomologie von 64\% (Adachi et al. 1991). Die strukturellen Unterschiede zwischen den humanen Endothelin-Rezeptoren sind die Ursache für die verschiedenartigen Bindungsprofile und Signalkaskaden. Der $\mathrm{ET}_{\mathrm{A}}$-Rezeptor ist Isopeptid-selektiv, d.h. er bindet ET-1 und ET-2 mit gleicher, ET-3 jedoch mit 1000-fach geringerer Affinität, während der $\mathrm{ET}_{\mathrm{B}}$-Rezeptor für alle Endotheline nahezu identische Bindungseigenschaften besitzt.

\title{
1.1.2 Physiologische und pathophysiologische Bedeutung der Endotheline
}

Die Beteiligung des Endothelinsystems an der Blutdruckregulation ist weitestgehend unverstanden. Da die Konzentration von ET-1 im Blutkreislauf nur sehr gering ist, wird eher 
eine lokale Einflussnahme im Sinne einer para- bzw. autokrinen Regulation vermutet. ET-1 führt an Endothelzellen zur Freisetzung gefäßrelaxierender Faktoren wie Stickstoffmonoxid (NO) und Prostacyclin (Prostaglandin $\mathrm{I}_{2} ; \mathrm{PGI}_{2}$ ), während es an glatten Gefäßmuskelzellen konstriktorisch wirkt. Somit stellt sich die Frage, ob ET-1 ein relaxierender oder kontrahierender Faktor ist. Mäuse, die heterozygot für das ET-1-Gen sind (Maemura et al. 1995) sowie Mäuse mit einer stark verminderten $\mathrm{ET}_{\mathrm{B}}$ - Rezeptor- Expression weisen einen erhöhten Ruheblutdruck auf. Dies ist vermutlich auf die fehlende ET $_{\mathrm{B}}$-Rezeptor-vermittelte Freisetzung von Prostacyclin zurückzuführen (Ohuchi et al. 1999). Auch beim Menschen wurde der Einfluss des Endothelinsystems auf den Blutdruck gezeigt. Eine intravenöse Infusion des $\mathrm{ET}_{\mathrm{A}}$-Rezeptor-Antagonisten $\mathrm{BQ}-123$ führt bei normotensiven Probanden zur Erhöhung des Blutflusses infolge einer Gefäßrelaxation, während $\mathrm{ET}_{\mathrm{B}}$-RezeptorAntagonisten einen anhaltenden Blutdruckanstieg bewirken (Haynes und Webb 1994). Bei zahlreichen Krankheitszuständen, wie beispielsweise der chronischen Herzinsuffizienz, der pulmonalen Hypertension, dem Schlaganfall, der Gehirnblutung und der Niereninsuffizienz, ist eine stark erhöhte ET-1-Plasmakonzentration nachweisbar. EndothelinrezeptorAntagonisten zeigen oftmals eine deutliche Inhibition dieser fortschreitenden pathologischen Prozesse und damit eine Verbesserung des Krankheitszustandes. ET-1 zeigt bei einigen Zellen stark mitogene Eigenschaften und induziert die Expression einiger Protoonkogene, wie beispielsweise c-fos, c-jun und c-myc (Battistini et al. 1993). Hier könnte ein Zusammenhang mit der Entwicklung von zellulärer Hypertrophie/Hyperplasie gesehen werden. Diese Effekte können in pathologischen Vorgängen, wie z.B. der Hypertonie oder der Herzinsuffizienz, allmählich zu einer Veränderung der kardiovaskulären Strukturen führen. Ebenso ist ET-1 durch proliferative Effekte auf Astrozyten an Wundheilungsstörungen im Gehirn beteiligt. ET-3-defiziente bzw. ET $_{\mathrm{B}}$-Rezeptor -defiziente Mäuse und Ratten zeigen den Phänotyp von Morbus Hirschsprung infolge fehlender Ausbildung von Ganglien im Darmbereich (Hosoda et al. 1994; Baynash et al. 1994).

\subsubsection{Signalkaskaden der Endothelinrezeptoren}

Nach der Bindung des Liganden an den Rezeptor werden infolge von Konformationsänderungen heterotrimere G-Proteine aktiviert. Zumeist können GPCR's unterschiedliche Signalwege aktivieren. Dies wird durch Bindung verschiedener G-Proteine an einen Rezeptor bzw. über Wechselwirkungen ihrer hydrolysierten $\beta \gamma$-Untereinheiten vermittelt (Milligan 1999). So konnte in zahlreichen heterologen Expressionssystemen auch für ligandenaktivierte Endothelinrezeptoren ein ausgeprägtes, vernetztes Effektorsystem 
gezeigt werden. Der $\mathrm{ET}_{\mathrm{A}}$-Rezeptor stimuliert über ein Gas-Protein die Adenylatzyklase (AC), was zur Erhöhung der Konzentration des sekundären Botenstoffs cAMP führt (Takuwa et al. 1990), während der $\mathrm{ET}_{\mathrm{B}}$-Rezeptor über Pertussistoxin (PTX)-sensitive Gaq-Proteine eine Aktivierung der Phospholipase C $\beta$ (PLC- $\beta$ ) bewirkt (Sokolovsky 1995). Aktivierte PLC- $\beta$ spaltet Phosphatidylinositolbisphosphat $\left(\mathrm{PIP}_{2}\right) \mathrm{zu}$ 1,4,5-Inositoltriphosphat $\left(\mathrm{IP}_{3}\right)$ und 1,2 Diacylglycerol (DAG). $\mathrm{IP}_{3}$ setzt aus intrazellulären Speichern $\mathrm{Ca}^{2+}$ frei und erhöht so die zytoplasmatische $\mathrm{Ca}^{2+}$-Konzentration. Membranständiges DAG aktiviert zusammen mit $\mathrm{Ca}^{2+}$ die Proteinkinase C (PKC) (Nishizuka 1992), was u.a. zu einer Serin/ThreoninProteinphosphorylierung einer großen Anzahl unterschiedlicher Substrate führt. Beide Endothelinrezeptoren können über Gaq die Phospholipase $\mathrm{A}_{2}\left(\mathrm{PLA}_{2}\right)$ aktivieren und somit Arachidonsäure aus der Zellmembran freisetzen, aus welcher Zelltyp-abhängig Prostaglandine gebildet werden (Schramek et al. 1994; Sokolovsky 1995). Weiterhin vermitteln Endotheline über komplexe Wege die Aktivierung von mitogenaktivierten Proteinkinasen (MAPK) und beeinflussen damit die Proliferation und Differenzierung in verschiedenen Geweben. Aktivierte Endothelinrezeptoren können in einem „Cross-talk“ mit Rezeptor-Tyrosinkinasen, wie für den EGF-Rezeptor gezeigt, die kleine Ras GTPase aktivieren (Daub et al. 1996). Ein anderer Weg wird von der $\beta \gamma$-Untereinheit des Gai- Proteins oder der $\alpha$ - Untereinheit von Gaq aktiviert (Hawes et al. 1995; Abbildung 4, S. 7). 


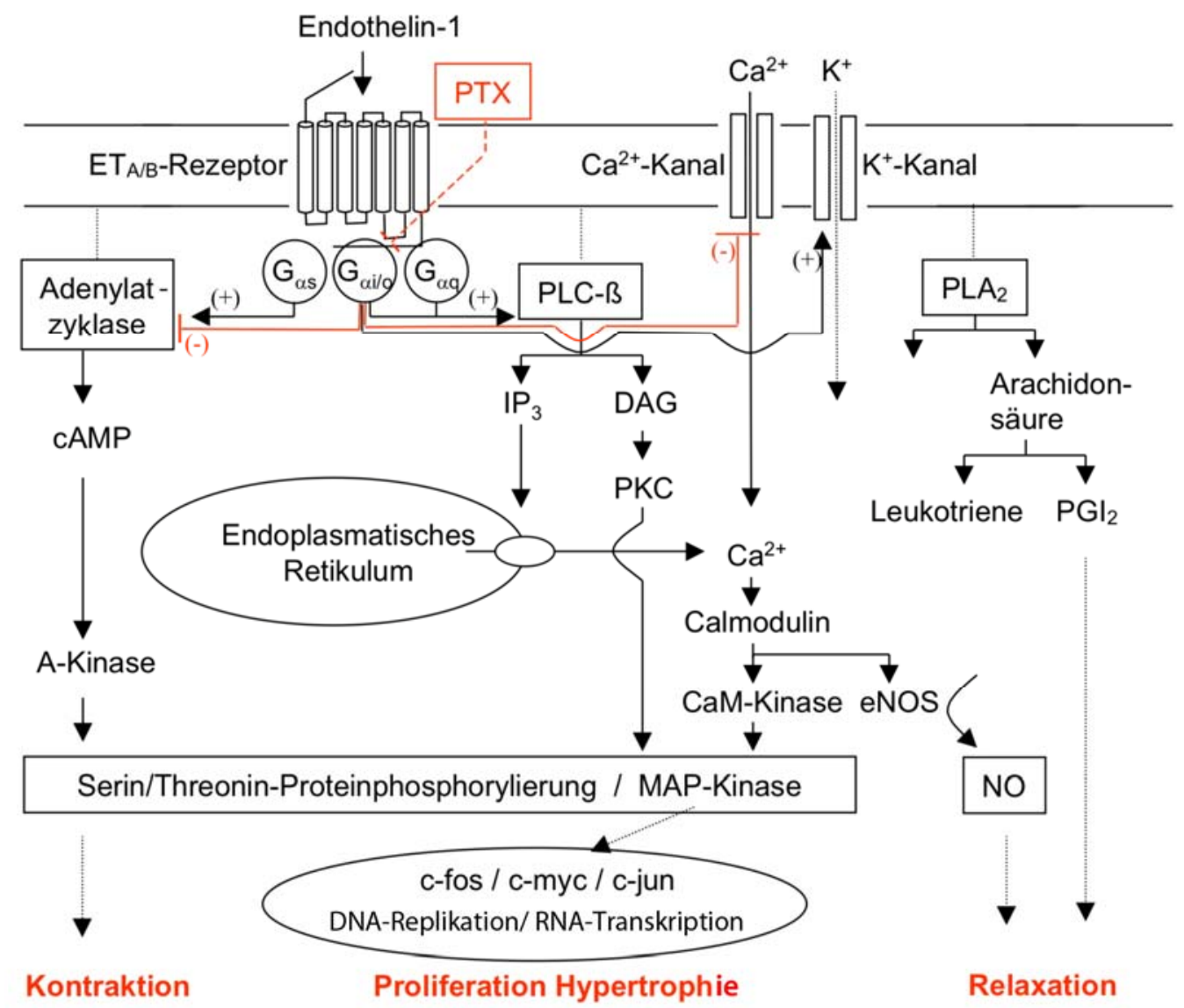

\section{Abbildung 4: Effektorsysteme der humanen Endothelin-Rezeptoren}

PLA $_{2}$ : Phospholipase $\mathrm{A}_{2}$; PLC- 3 : Phospholipase CB; PLD: Phospholipase D; IP ${ }_{3}$ : 1,4,5-Inositoltriphosphat; DAG: Diacylglycerol; eNOS: endotheliale NO-Synthase; NO: Stickoxid; $\mathrm{PGI}_{2}$ : Prostacyclin; MAP-Kinase: Mitogen-Aktivierte Protein-Kinase.

\subsubsection{ET $_{B}$-Rezeptor-defiziente Ratten}

Defekte im ETB-Rezeptor/ET-3-Signalsystem und der gesamte Verlust dieses Signalweges führen, wie bereits oben erwähnt, zu Entwicklungsdefekten in den enterischen Ganglien (Baynash et al. 1994; Hosoda et al. 1994). Mutationen im ETB-Rezeptorgen und im ET-3Gen wurden im Zebrafisch und Säugetieren (Ratte, Pferd, Maus und Mensch) entdeckt. Die kongenitale Aganglionose in Ratten, die mit einem weißen Fell einhergeht, weist einen Mangel an enterischen Ganglien und Melanozyten auf (McCabe et al. 1990; Gariepy et al. 1996; Abbildung 5, S. 9). Diese Ratten, die auch als "spotting lethal" (sl/sl) bezeichnet werden, haben eine Deletion von 301 Basenpaaren im ETB-Rezeptorgen. Diese rezessive Mutation führt zu einer aberranten Spleißvariante des ETB-Rezeptorproteins (Ceccherini et al. 1995; Gariepy et al. 1996; Kunieda et al. 1996). Eine andere Mutationsvariante ist die "lethal white foal'-Mutation, die zu einem Austausch von einem Isoleuzinrest durch einen Lysinrest 
in der ersten Transmembrandomäne des ETB-Rezeptorproteins führt (Metallinos et al. 1998; Yang et al. 1998).

In der Maus kodieren die "lethal spotting" und "piebald lethal" Loki ebenfalls das ET-3 und den $\mathrm{ET}_{\mathrm{B}}$-Rezeptor. Einige dieser Mutationen wurden als natürlich vorkommende Tiermodelle identifiziert, andere wurden durch genetische Manipulation generiert (siehe http://www.informatics.jax.org). All diese Genotypen haben einen sehr ähnlichen Phänotyp, der sich durch Melanozytenmangel in der Haut und einer Aganglionose im Dickdarm auszeichnet. Mildere Mutationen sind ebenfalls bekannt, wie z.B. in der piebald Maus, wobei lediglich ca. $20 \%$ der Haut weiß ist und sich nur ein milder Ganglienzellendefekt im Darm zeigt.
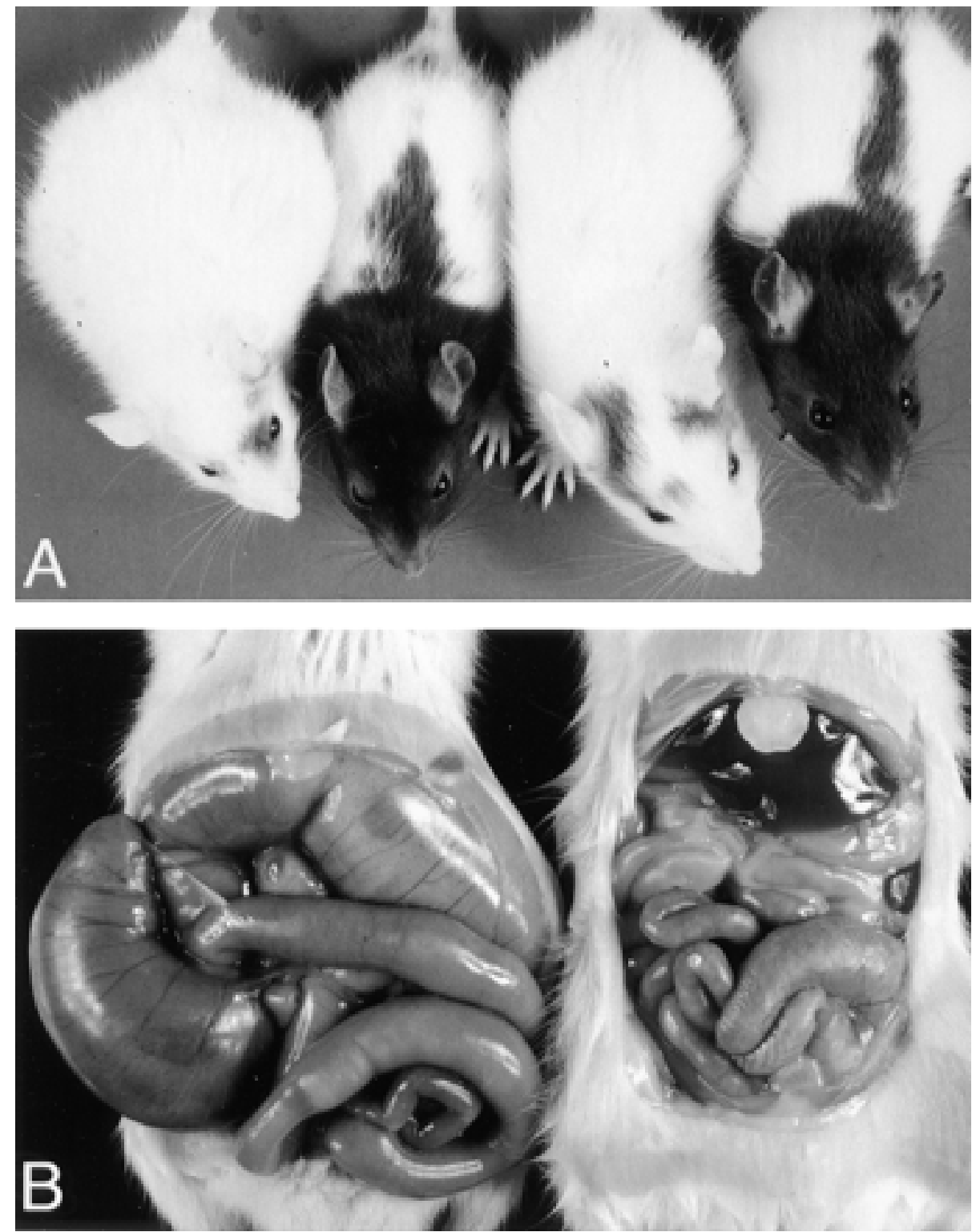
Abbildung 5: Äußerlicher Phänotyp und Morphologie des Darms bei sl/sl-Ratten und Wildtypratten

A) Von links erstes und drittes Tier sind homozygot für die sl Mutation (sl/sl) mit fast komplett weißem Fell. Von links das zweite und vierte Tier sind Wildtyptiere mit normal geflecktem Fell. B) Freiliegender Darm, bestehend aus Dünndarm, Dickdarm und dem Blinddarm. Der linke Dickdarm ist aufgeweitet und stenotisch vor der Aufweitung, Bild eines toxischen Megacolons bei einer sl/sl-Ratte. Der rechte Darm eines Wildtyptiers ist regelhaft.

\subsection{Das Periphere Nervensystem}

\subsubsection{Die Neuralleiste}

Das Ektoderm unterteilt sich zunächst in zwei Regionen. Der mediale Teil entwickelt sich während der Gastrulation zur Neuralplatte, die sich während der Neurulation einrollt und sich zum Neuralrohr entwickelt, dem Vorläufer des zentralen Nervensystems (Couly und Le Douarin, 1987). Der distale Teil des Ektoderms entwickelt sich zum Oberflächenektoderm, das nach dem Einrollen und Abschnüren des Neuralrohrs den gesamten Embryo als Epidermis umgibt. Vor der Neurulation bringt der Übergangsbereich zwischen dem späteren neuralen und epidermalen Ektoderm die Neuralleistenzellen hervor. Die Neuralleiste entsteht dann entlang der Körperachse in rostro-kaudaler Ausrichtung. Die Neuralleistenzellen lösen sich nach dem Schließen des Neuralrohrs aus dem Epithel des dorsalen Ektoderms und wandern durch den Embryo (LaBonne und Bronner-Faser, 1999). Aus diesen Zellen entsteht unter anderem das periphere Nervensystem, die Melanozyten sowie kraniofasziale Knochen- und Knorpelzellen (Ayer-Le Lievre und Le Douarin 1982).

\subsubsection{Entwicklung und Differenzierung der Schwannzellen}

Schwannzellen stammen von pluripotenten Vorläuferzellen der Neuralleiste ab. Aus diesen Zellen entwickeln sich nicht nur Neurone und Gliazellen des PNS, sondern auch Pigmentzellen der Haut und Bindegewebszellen (Le Douarin und Dupin 2003). Die Entwicklung einer Neuralleistenvorläuferzelle zu einer Schwannzelle ist ein komplexer Prozess, der über mehrere Stufen verläuft. Einzelne Entwicklungsstufen sind durch Expression spezifischer Proteine gekennzeichnet (Abbildung 6, S. 10). Der Transkriptionsfaktor Sox-10 ist für den Entwicklungsschritt von Neuralleistenvorläuferzellen zu Schwannzellvorläuferzellen notwendig. Dies wurde auch mit Hilfe von Sox-10-defizienten Mäusen gezeigt, denen diese frühen Gliazellen fehlen (Britsch et al. 2001). Schwannzellvorläuferzellen sind während der embryonalen Entwicklung ab dem Embryonaltag 14/15 (E14/15) in peripheren Nerven zu erkennen. Die Expression von GAP43 (,Growth associated protein 43“ = Wachstum-assoziiertes-Protein 43) und geringe 
mRNA-Mengen von P0 (Myelin Protein Null), PMP22 (peripheres Myelin Protein von 22kDa) und Oct-6 (Octamer-bindender Transkriptionsfaktor 6) unterscheidet sie von den Neuralleistenvorläuferzellen (Lobsiger et al. 2002).

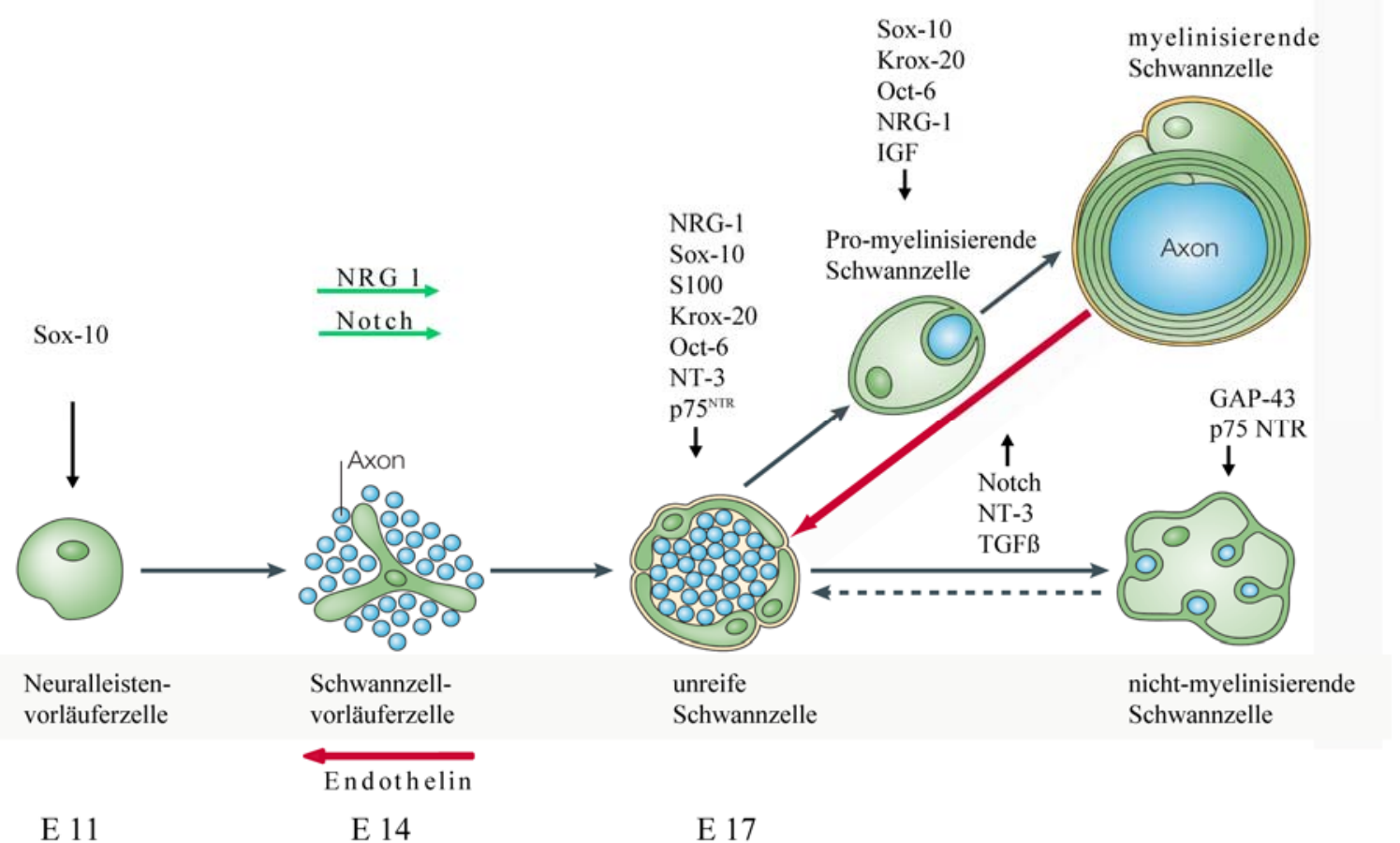

\section{Abbildung 6: Die Schwannzell-Entwicklungslinie}

Schematische Darstellung der wichtigsten Stadien, während der Entwicklung von einer Neuralleistenvorläuferzelle zu einer Schwannzelle. Gestrichelte Linien zeigen die Reversibilität des letzten postnatalen Entwicklungsschrittes, in welchem myelinisierende und nicht-myelinisierende Schwannzellen gebildet werden. Die embryonale Entwicklungsphase von Schwannzellen beinhaltet drei Übergangsformen von Zellpopulationen: Neuralleistenvorläuferzellen, Schwannzellvorläuferzellen und unreife Schwannzellen. Alle Entwicklungsstadien können durch spezifische Markerproteine identifiziert und voneinander unterschieden werden (Modifiziert nach Jessen und Mirsky 2005, S. 673).

Das Überleben von Schwannzellvorläuferzellen ist von axonalen Signalen abhängig (Mirsky et al. 2002). Eines dieser axonalen Signale ist Neuregulin-1 (NRG-1; Garratt et al. 2000). Neuregulin-1 ist außerdem wichtig bei der Differenzierung von Schwannzellvorläuferzellen in unreife Schwannzellen. Diese Entwicklung erfolgt schnell und synchronisiert zwischen E15 und E17. Die Differenzierung beginnt proximal in den Spinalganglien und endet in den Nervenenden (Lobsiger et al. 2002). Unreife Schwannzellen exprimieren S100 (ein Calcium bindendes Protein), Sox-10, den Neurotrophin-Rezeptor p75, Krox-20 („early growth response 2" EGR2) und Oct-6 (Bhatheja und Field 2006). Als Markerprotein zur Unterscheidung von Schwannzellvorläuferzellen und unreifen Schwannzellen kann S100 
verwendet werden, da dieser Faktor ausschließlich von unreifen Schwannzellen exprimiert wird (Brennan et al. 2000).

Der zeitliche Verlauf der Differenzierung wird durch mehrere bekannte Faktoren gesteuert. Eine Gruppe davon sind Endotheline (ET), die über den ETB-Rezeptor vermittelt werden (Abbildung 6, S. 10). Eine Rolle des ETB-Rezeptor/ET-3-Signalsystems bei der Schwannzelldifferenzierung wurde in in-vitro-Experimenten durch die Inkubation von Schwannzellvorläuferzellen mit ET-1 oder NRG-1 nachgewiesen. Kulturen mit rekombinantem NRG-1 enthielten 87\%, Kulturen mit Zusatz von rekombinanten ET-1 nur $16 \%$ unreife Schwannzellen (Brennan et al. 2000).

Inkubation der Schwannzellvorläuferzellen mit beiden Faktoren, ET-1 und NRG-1, ergab im Vergleich zu unbehandelten Kulturen hingegen nur 50\% $\mathrm{S} 100$ positiver unreifer Schwannzellen (Brennan et al. 2000). Dieser Effekt auf die Reifung der Schwannzellvorläuferzellen zu unreifen Schwannzellen wurde auch in vivo an ETB-Rezeptordefizienten „spotting lethal“ (sl/sl) Ratten beobachtet. Die Analyse der Ischiasnerven mutanter Ratten bei E16 zeigte mehr S100 positive unreife Schwannzellen als bei wildtypischen Kontrolltieren (Brennan et al. 2000). Daher ist zu folgern, dass das ETB-Rezeptor/ET-3Signalsystem die Schwannzelldifferenzierung verlangsamt und antagonistisch auf den „Reifungseffekt“" von NRG-1 wirkt.

\subsubsection{Signale, die das Überleben der Schwannzellen beeinflussen}

Das Überleben von Schwannzellvorläuferzellen ist abhängig von parakrinen Signalen der Neurone. Zu diesen Signalen zählt unter anderem NRG-1 (Jessen und Mirsky 2005). Schwannzellen in Nerven adulter Tiere sind hingegen in der Lage, einige Monate ohne Axone zu überleben (Jessen und Mirsky 2002). Dies ist eine notwendige Eigenschaft für die Regeneration von Nerven, da Schwannzellen für das Wachstum von Axonen nach Verletzungen benötigt werden (Mirsky et al. 2002). Reife Schwannzellen besitzen autokrine Mechanismen (,survival loops“), durch die sie ihr eigenes Überleben sichern können (Meier et al. 1999). Daran beteiligte Faktoren sind unter anderem IGF (,insulin like growth factor" $=$ Insulin-ähnlicher Wachstumsfaktor), NT-3 (Neurotrophin-3) und PDGF (,platelet-derived growth factor"). Ein solcher autokriner Mechanismus konnte in Schwannzellvorläuferzellen und unreifen Schwannzellen nicht identifiziert werden (Jessen und Mirsky 2005). Beide Arten von reifen Schwannzellen, sowohl myelinisierende wie auch nicht-myelinisierende, können nach einer Verletzung zu unreifen Schwannzellen differenzieren. Sobald wieder axonaler 
Kontakt besteht, differenzieren sie abhängig von axonalen Signalen, zu myelinisierenden oder nicht-myelinisierenden Schwannzellen (Bhatheja und Field 2006).

\subsubsection{Das Myelin}

Das Myelin (myelos; griech. Mark) ist im Nervensystem höherer Vertebraten die physikalische Grundlage schneller saltatorischer Erregungsleitung. Markscheiden gewährleisten die elektrische Isolierung von Axonsegmenten und beschränken Aktionspotentiale auf die Ranvierschen Schnürringe (Raine, 1984). Die Reizleitungsgeschwindigkeit myelinisierter Axone ist daher bis zu 100-mal höher als die nackter Fasern gleichen Durchmessers (Lemke und Axel 1985). Gleichzeitig reduzieren Myelinscheiden axonale Leckströme und stabilisieren das extrazelluläre Milieu von schnellfeuernden Axonen. Myelin kann als lipidreiches, extrazelluläres Organell der Gliazelle angesehen werden, welches metabolisch mit dem Gliazellkörper verbunden bleibt. Im zentralen Nervensystem wird Myelin von Oligodendrozyten produziert, die der Subventrikularzone entstammen. Abkömmlinge der Neuralleiste, die Schwannzellen, übernehmen diese Aufgabe im PNS. Eine Schwannzelle myelinisiert nur ein Axonsegment, ein Oligodendrozyt hingegen gleichzeitig bis zu 50 Axonsegmente, indem sich Bereiche seiner Plasmamembran bis zu 160-mal konzentrisch um ein Axon winden (Pannese et al. 1994;Abbildung 8, S. 15). Trotz dieser ontogenetischen und morphologischen Unterschiede ähneln sich peripheres und zentrales Myelin in ihrer Ultrastruktur, da sie auf einem äquivalenten, spiraligen Umwickeln eines Axonabschnittes durch die flächig ausgebreitete Gliamembran beruht. Durch die Reduktion von Membranzwischenräumen (Kompaktierung) entstehen elektronendichte Bereiche. Hierbei werden kondensierte extrazelluläre Seiten gegenüberliegender Membranen als ,intraperiod line“ (IPL) bzw. intrazelluläre als „major dense line“ (MDL) bezeichnet (Lees et al. 1984; Abbildung 7, S. 13).

Die Funktion dieser Proteine für die Architektur von kompaktem Myelin ist intensiv mit Hilfe von natürlich vorkommenden und künstlich generierten Tiermodellen studiert worden (Nave 1995). 


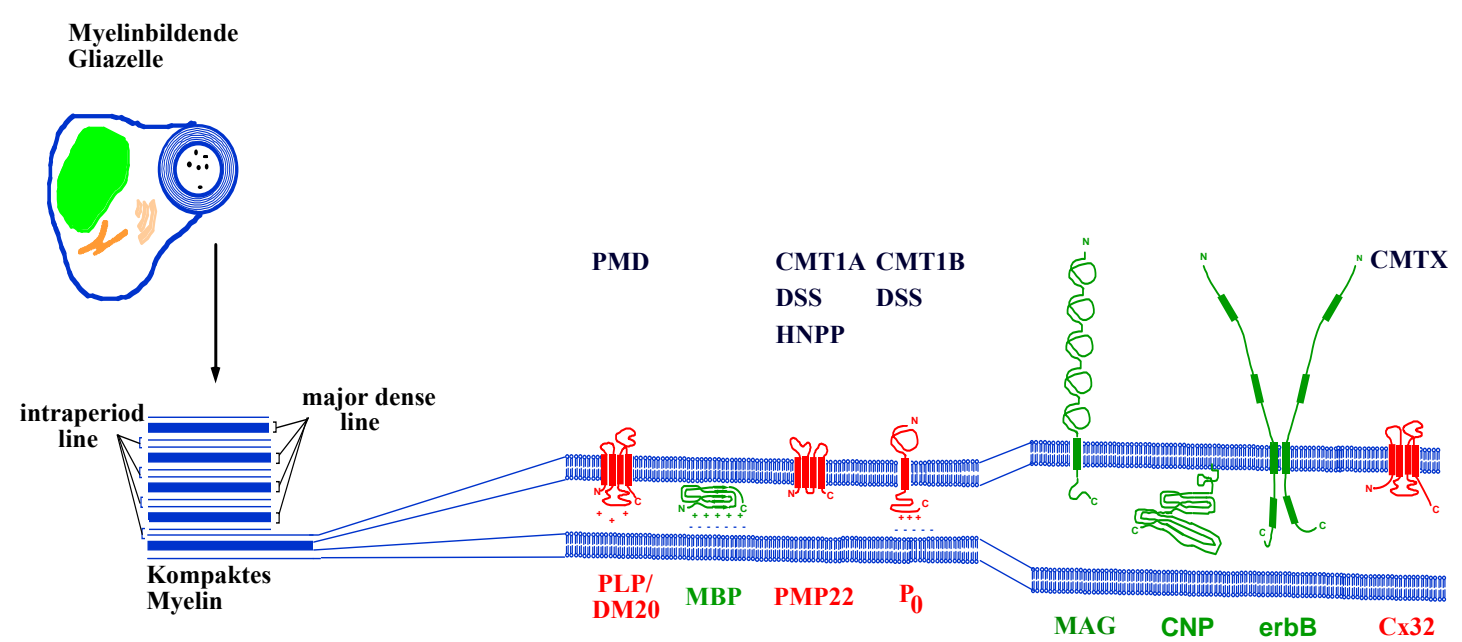

Abbildung 7: Myelin Organisation im zentralen und peripheren Nervensystem

Schematisch dargestellt sind eine Myelin-bildende Gliazelle, die Ultrastruktur von kompaktem Myelin und wichtige Strukturproteine. Die „major dense line” und „intraperiod line“ werden jeweils durch anliegende intrazelluläre und extrazelluläre Membranoberflächen gebildet. Die angenommenen topologischen Modelle der wichtigsten Myelinproteine des ZNS und PNS umfassen: PLP=Proteolipidprotein; $\mathrm{MBP}=$ Myelin basisches Protein; $\mathrm{MAG}=\mathrm{Myelin}$-assoziiertes Glykoprotein; Cx32=Connexin 32; CNP=2',3'-zyklische Nukleotid 3'-Phosphodiesterase; ErbB ist eine Rezeptor-Tyrosin-Kinase (Adaptiert von Werner et al. 1998, S.772).

\subsubsection{Die Myelinisierung im peripheren Nervensystem}

Bei der Ratte wandern am Embryonaltag 9-10 (E9-10) die Schwannzellvorläufer vom Neuralrohr lateral und ventral in ihre Zielgebiete und entwickeln sich u. a. zu Melanozyten, glatten Muskelzellen, PNS-Neuronen und glialen Zelltypen (Anderson 1993; Henion und Weston 1997).

Für die Entwicklung von Schwannzellen ist eine Reihe von verschiedenen Faktoren zur Differenzierung in die unterschiedlichen Entwicklungsstufen notwendig. Die Entwicklung des Ischiasnerven der Ratte hat sich zur Untersuchung des peripheren Nervensystems als gutes Modellsystem herausgestellt (Mirsky und Jessen 1999; Lobsiger et al. 2002). Die ersten Axone des $N$. ischiadicus projizieren in den Bereich der Hinterbeine zwischen E13 und E14. Diese Axone sind mit Vorläuferzellen der Schwannzellen assoziiert, die die Axone in Gruppen formieren (,radial sorting“). In Zellkultur, getrennt von ihren Axonen, sterben diese frühen Schwannzellvorläufer. Daher wurde vermutet, dass Ihr Überleben von axonalen Faktoren abhängig ist. Später wurde gezeigt, dass es sich bei diesen Faktoren vor allem um BNeureguline handelt, die an erbB3- oder erbB4-Rezeptoren auf den Schwannzellvorläufern binden können (Dong et al. 1995; Shah et al. 1994; Shah et al. 1996). Sie bewirken nicht nur das Überleben der Vorläuferzellen, sondern verhindern auch, dass diese in eine neuronale Entwicklung eintreten. Mausmutanten, die entweder Neuregulin- oder erbB3-defizient sind, 
zeigen kaum Schwannzellvorläufer (Riethmacher et al. 1997; Meyer und Birchmeier 1994). Interessanterweise wurde auch umgekehrt eine Abhängigkeit der Neurone von glialen Faktoren nachgewiesen. Während Neuregulin-defiziente-Mutanten bereits am Tag E11.5 aufgrund von Herzdefekten starben, überlebten die erbB3-Mutanten bis zur Geburt und besaßen Axone, die ihre Zielgebiete innervieren konnten (Garratt et al. 2000). Allerdings starben rund 80\% aller Spinalganglien und Motoneurone bis zum Tag E18 ab (Henderson et al. 1998). Schwannzellen scheinen daher nicht für die Elongation oder das Auswachsen der Axone verantwortlich zu sein, aber für das Überleben der Neurone. In diesem Zusammenhang wurden Mitglieder der GDNF- Familie (glial-derived neurotrophic factor) diskutiert, die von den Schwannzellen exprimiert und sezerniert werden (Kotzbauer et al. 1996; Milbrandt et al. 1998; Arce et al. 1998).

Ab dem Tag E16 finden sich im PNS der Ratte zwei Typen von Schwannzellen (Lobsiger et al. 2002). Die myelinisierenden Schwannzellen, die mit größeren Axonen assoziiert sind und die Myelingene P0 und MBP (myelin basic protein, Basisches Myelin Protein) verstärkt exprimieren, sowie die nicht- myelinisierenden Schwannzellen, die mit kleineren Axonen in Kontakt treten und nur geringe Mengen an P0 und MBP exprimieren. Die Differenzierung zu myelinisierenden Zellen ist reversibel, damit werden zum Beispiel nach Nervenverletzungen geeignete Wachstumsbedingungen für wieder auswachsende Neurone geschaffen (Mirsky und Jessen 1996). Es kommt zum Abbau des Myelins, zur Einwanderung von Makrophagen und zur Schwannzellproliferation (Salzer und Bunge 1980).

Für die Prozesse während der Myelinisierung sind in der Entwicklung wie auch nach einer Nervenläsion eine Reihe von Transkriptionsfaktoren von großem Interesse (Küry et al. 2001; Mirsky und Jessen 1999). Vor allem für das Zink-Finger Protein Krox-20 und das POUDomänen Protein Oct-6 konnte gezeigt werden, dass sie für die Myelinisierung und Kompaktierung des Myelins im PNS essentiell sind. Krox-20-defiziente Mausmutanten zeigen zwar eine 1:1 Kontaktaufnahme von Schwannzellen mit Axonen, aber keine Ausbildung der Myelinscheide. Auch Oct-6-defiziente Mausmutanten bilden kein Myelin oder nur zeitlich verzögert. 

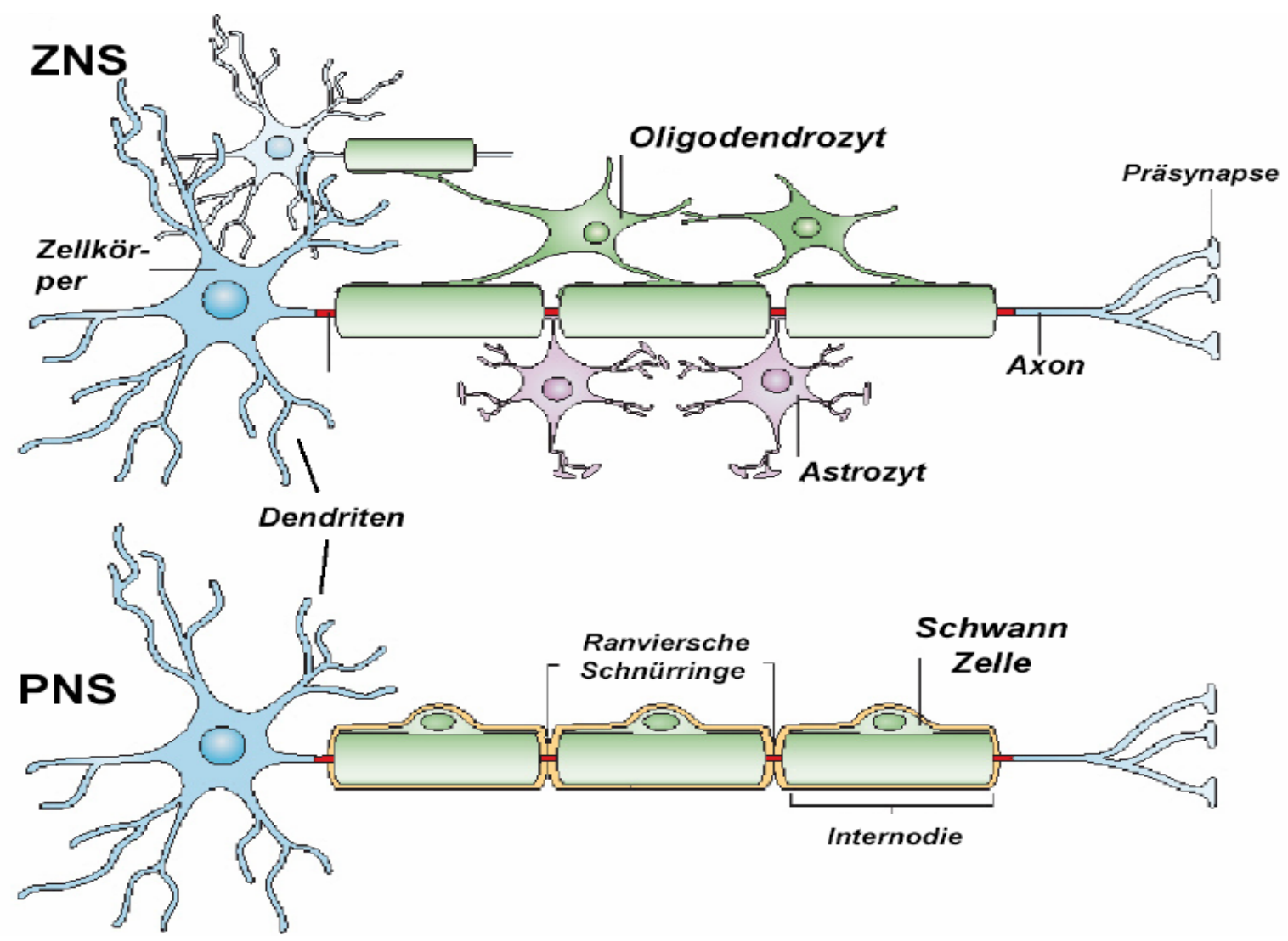

\section{Abbildung 8: Schematische Darstellung von myelinisierten Axonen im PNS und ZNS}

Oligodendrozyten können mehrere Axonabschnitte auch unterschiedlicher Axone myelinisieren, während Schwannzellen immer nur ein Segment eines Axons myelinisieren (Modifiziert nach Poliak und Peles 2003, S. 969).

Die Mutationen einiger Myelingene ähneln zum Teil stark den Phänotypen der Oct-6- bzw. Krox-20-Mutanten (zur Übersicht der Myelingene siehe Nave 1994; Martini und Schachner 1997). Das wichtigste Myelinprotein im PNS ist P0 (mehr als 50\% aller Myelinproteine). Es wird neben anderen Proteinen aufgrund seiner homophilen Interaktionsfähigkeit für die Kompaktierung der extrazellulären Seite verantwortlich gemacht (D’Urso et al. 1990). Darüber hinaus scheint P0 durch Interaktion mit der Membran und dem Zytoskelett Desmosomen zu bilden, wodurch die Kompaktierung des Zytoplasmas ermöglicht wird (Doyle et al. 1995). Wie Oct-6-defiziente Mäuse bilden auch Mausmutanten ohne P0-Gen einen 1:1-Kontakt zwischen Axonen und Schwannzellen auf, jedoch keine Myelinscheide (Martini et al. 1995). Heterozygote P0-Mäuse weisen zunächst morphologisch unauffällige Myelinscheiden aus, entwickeln aber im Alter von vier Monaten eine Myelindegeneration mit so genannter Zwiebelschalenstruktur und vermehrter Schwannzellproliferation (Martini und Schachner 1997). P0 scheint daher an der Aufrechterhaltung der Myelinscheiden beteiligt zu sein. 
Ähnliche gendosisabhängige Effekte konnten im Falle des Peripheren Myelin Proteins PMP22 gefunden werden (Suter und Snipes 1995; Sereda et al. 1996; Müller 2000, Young und Suter 2003, Meyer zu Hörste et al. 2006, Sereda und Nave 2006). Eine Duplikation des Gens führt zu der erblichen humanen Neuropathie Charcot-Marie-Tooth Typ 1A (Timmerman et al. 1990; Matsunami et al. 1992; Sereda et al. 1996), während der Verlust einer Kopie von PMP22 verursacht hingegen die erbliche Neuropathie mit Neigung zu Druckparesen (HNPP) (Chance et al. 1994). PMP22-defiziente Tiere zeigen eine verspätete Myelinisierung, fokale Hypomyelinisierung, vermehrt proliferierende Schwannzellen und Demyelinsierung des peripheren Nervensystems (Adlkofer et al. 1995). Die richtige Protein-Stöchiometrie und quantitative Zusammensetzung der Zellmembran scheint demnach für die Bildung und den Erhalt der Markscheiden wichtig zu sein (Anzini et al. 1997; Garbern et al. 1997).

\subsubsection{Die Rolle der Endotheline im Nervensystem}

Durch eine Reihe von Expressionsanalysen konnte gezeigt werden, dass die Funktion des ET $_{\mathrm{B}}$-Rezeptors eine ausschlaggebende Rolle in der Entwicklung des Nervensystems von Säugern spielt.

Es besteht außerdem eine Assoziation mit der Induktion von $\mathrm{ET}_{\mathrm{B}}$-Rezeptor mRNA und der Differenzierung von embryonalen Zelllinien zu neuralen Zelllinien (Monge et al. 1995). Zur genauen Darstellung der physiologischen Rolle der Endotheline und ihrer Rezeptoren in der Entwicklung des Nervensystems wurde die Expression des $\mathrm{ET}_{\mathrm{B}}$-Rezeptors in verschiedenen Entwicklungsstadien des Nervensystems durch in-situ-Hybridisierungsexperimente dargestellt. Dabei konnte gezeigt werden, dass im ZNS der $\mathrm{ET}_{\mathrm{B}}$-Rezeptor pränatal in der ventrikulären und subventrikulären Zone, sowie in der subependymalen Zone der Seitenventrikel stark exprimiert wird (Meei-Ling et al. 1997). Diese Areale enthalten neurale Stammzellen, die entscheidend für die Formation des Nervensystems während der Embryogenese (Reynolds und Weiss 1996) und der Neuroregeneration im Erwachsenenalter sind (Gritti et al. 1996). Diese neuralen Stammzellen spielen eine wichtige Rolle bei Patienten mit neurodegenerativen Erkrankungen, wie Morbus Parkinson oder Morbus Alzheimer. Im ZNS war die ET $_{\mathrm{B}}$-Rezeptor-mRNA hauptsächlich in den Gliazellen und neuralen Stammzellen lokalisiert (Hori et al. 1992). Dies impliziert die Wichtigkeit des $\mathrm{ET}_{\mathrm{B}}$-Rezeptors für die Differenzierung und Proliferation von glialen Zellen aus neuralen Stammzellen, sowie die Initiierung von Gliosen bei Gehirnverletzungen (Hama et al. 1997).

Es konnte gezeigt werden, dass die Aktivierung des $\mathrm{ET}_{\mathrm{B}}$-Rezeptors verstärkend auf die Funktion von EGF bei der Wundheilung wirkt (Tao et al. 1995). Es ist somit möglich, dass 
der $\mathrm{ET}_{\mathrm{B}}$-Rezeptor zusätzlich zu der Funktion der Proliferation und Differenzierung eine Rolle bei der Aktivierung von Gliazellen zum Steuern der neuronalen Migration spielt. Ein Beispiel dafür im ZNS sind die Bergmann-Gliazellen, die ebenfalls $\mathrm{ET}_{\mathrm{B}}$-Rezeptor-mRNA exprimieren. Während der zerebellären Entwicklung steuern Bergmann-Gliazellen die Migration der Körnerzellen mittels ihrer langen Fortsätze zu ihrer korrekten Lage. Danach retrahieren sie die Fortsätze und werden zu Satellitenzellen, um Purkinjezellen zu schützen (Parent et al. 1996). Die Neuralleiste ist eine sensible, transiente aber multipotente embryonale Struktur (Etchevers et al. 1999). Es wurde bereits mehrfach gezeigt, dass über ein Endothelin-vermitteltesSignalsystem die Migration, Entwicklung und Differenzierung von bestimmten Neuralleistenzellen wesentlich beeinflusst wird (Nataf et al. 1996; Brand et al. 1998; Wu et al. 1999). Diverse andere Studien haben die Rolle des $\mathrm{ET}_{B}$-Rezeptors und seines Liganden ET-3 hinsichtlich der Rolle in der Entwicklung der Melanozyten und enterischen Neurone untersucht (Nataf et al. 1996; Brand et al. 1998; Wu et al. 1999). Schwannzellen sind ebenfalls Derivate der Neuralleistenzellen, die in einem zeitlich sehr festen Plan entstehen. Ihre Entwicklung ist durch axonale Signale reguliert, insbesondere durch die $\beta$-Neureguline. Es konnte in einer in-vitro-Studie von Brennan et al. aus dem Jahre 2000 zum ersten Mal gezeigt werden, dass die Endotheline auch eine wichtige Rolle in der Entwicklung der Schwannzellen (Brennan et al. 2000) spielen. Die Endotheline agieren in diesem Fall als negative Regulatoren von Schwannzellgenerationen. 


\subsection{Zielsetzung der Arbeit}

Das Endothelin/Endothelin-Rezeptor-Signalsystem reguliert eine Reihe von physiologischen Prozessen von der Schwannzelldifferenzierung bis zur Regulierung des systolischen Blutdrucks. Drei verschiedene Endotheline (ET-1, 2, 3), die über 2 Rezeptoren (A, B) agieren, sind bekannt. Es wurde in jüngerer Zeit nachgewiesen, dass der $\mathrm{ET}_{\mathrm{B}}$-Rezeptor eine wichtige Rolle in der Entwicklung der Neuralleiste spielt. Daraus entwickeln sich Melanozyten, Neurone des enterischen Nervensystems, spinale Nervenwurzeln und die myelinbildenden Schwannzellen des peripheren Nervensystems. Eine funktionelle Nullmutation im $\mathrm{ET}_{\mathrm{B}^{-}}$ Rezeptorgen führt zu einer kongenitalen Aganglionose des Dickdarms, die zum Morbus Hirschsprung führt.

Ziel der vorliegenden Arbeit war es, anhand eines Tiermodells mit einer funktionellen Nullmutation des $\mathrm{ET}_{\mathrm{B}}$-Rezeptors dessen Funktion in der postnatalen Entwicklung der Myelinisierung des peripheren Nervensystems $\mathrm{zu}$ erarbeiten. Es sollte in drei frühen Altersstadien P1, P6 und P18 auf immunhistologischer und elektronenmikroskopischer Ebene morphologisch untersucht werden, inwieweit der $\mathrm{ET}_{\mathrm{B}}$-Rezeptor die Funktion der Schwannzellen, also die Myelinisierung peripherer Nerven, beeinflusst und ob ein Mangel dieses Rezeptors zu Fehlentwicklungen führen kann.

Die Möglichkeit, über das ET-Signalsystem die Regulation der Myelinisierung und der Schwannzellen zu beeinflussen, würde die biologische Signifikanz dieser Signalkaskade im PNS untermauern und möglicherweise neue thematische Optionen hinsichtlich demyelinisierender Erkrankungen des peripheren Nervensystems eröffnen. Ein Erkenntnisgewinn über den $\mathrm{ET}_{\mathrm{B}}$-Rezeptor und die Entwicklung der Schwannzellen war zu erwarten. 


\section{Material und Methoden}

\subsection{Material}

\subsubsection{Chemikalien und Bioreagenzien}

Agarose

Ammoniumazetat $\left(\mathrm{NH}_{4} \mathrm{Azetat}\right)$

Azur-II-Farbstoff

Bromphenolblau

Chloroform

DAPI (4,6-diamidino-2-phenylindol)

DDSA (2-Duodecenyl-succinicacidanhydrid)

DEPC (Diethylpyrocarbonat)

DMP30 (2,4,6-tris-dimethylaminomethyl-Phenol)

DTT

Eosin Farbstoff

Essigsäure

Ethanol

Ethidiumbromid

Ficoll (Typ 400)

Glutaraldehyd

Glycidether

Haematoxylin

HBSS (Hanks Balanced Salts Solution)

Isopropanol

$\mathrm{KCl}$

Ketanest ${ }^{\circledR}$ (Wirkstoff: Ketamin)

$\mathrm{KH}_{2} \mathrm{PO}_{4}$

Methylenblau

Methyl nadicanhydrid (MNA)

$\mathrm{Na}_{2} \mathrm{HPO}_{4}$

$\mathrm{Na}_{2} \mathrm{HPO}_{4} * 2 \mathrm{H}_{2} \mathrm{O}$

Na-Cacodylat-Trihydrat

$\mathrm{NaCl}$

$\mathrm{NaH}_{2} \mathrm{PO}_{4} * \mathrm{H}_{2} \mathrm{O}$

Osmiumtetroxid

Paraformaldehyd
Bio-Rad, Hercules, CA, USA

Merck, Darmstadt

Merck, Darmstadt

International Biotechnology Inc.

Merck, Darmstadt

Boehringer Mannheim

Serva, Heidelberg

Sigma-Aldrich, Schnelldorf

Serva, Heidelberg

GibcoBRL, Karlruhe

Merck, Darmstadt

Merck, Darmstadt

Merck, Darmstadt

Sigma-Aldrich, Schnelldorf

Sigma-Aldrich, Schnelldorf

Merck, Darmstadt

Serva, Heidelberg

Merck, Darmstadt

GibcoBRL, Karlsruhe

Merck, Darmstadt

Merck, Darmstadt

Parke-Davis, Berlin

Merck, Darmstadt

Merck, Darmstadt

Serva, Heidelberg

Merck, Darmstadt

Merck, Darmstadt

Roth, Karlsruhe

Merck, Darmstadt

Merck, Darmstadt

Serva, Heidelberg

Serva, Heidelberg 
Propylenoxid

Sodium-Dodecyl-Sulfat (SDS)

Taq-Polymerase Puffer

Tris-HCl Base

Xylencyanol

Xylol
Serva, Heidelberg

Sigma-Aldrich, Schnelldorf

Promega, Mannheim

Sigma-Aldrich, Schnelldorf

Merck, Darmstadt

Merck, Darmstadt

\subsubsection{Verbrauchsmaterial}

$\mathrm{CO}_{2}$-Gas

Einmalhandschuhe

Eppendorfgefäße

Falconröhrchen 15ml, $50 \mathrm{ml}$

Falconröhrchen Rundboden $6 \mathrm{ml}$

histologisches Einschlussmittel „Eukitt“

Injektionskanülen 17G, 20G, 23G

Objektträger

PCR-Mikrotiterplatten

PCR-Tape "Air Pore Sheet"

Pipettenspitzen

Präparationsbesteck

chirurgische Pinzette

gerade scharfe/stumpfe Schere

gebogene scharf/scharfe Schere

Rattenstandarddiät „Ssniff R/M-H V1535“

S-Monovette 2,6 ml

Spritzen NormInjekt

Transferpipetten

Trockeneis

Weichholzgranulateinstreu „Bedding S8/15“
Messer-Griesheim, Krefeld

Hartmann, Heidenheim

Eppendorf, Hamburg

Becton \& Dickinson,

Le Pont De Claix, Frankreich

Becton \& Dickinson,

Le Pont De Claix, Frankreich

Kindler, Freiburg

Becton \& Dickinson,

Le Pont De Claix, Frankreich

Menzel-Gläser, Braunschweig

ABgene, Surrey, UK

ABgene, Surrey, UK

Molecular Bioproducts,

San Diego, CA, USA

Fine Science Tools, Heidelberg

Fine Science Tools, Heidelberg

Fine Science Tools, Heidelberg

Ssniff Spezialdiäten, Soest

Sarstedt, Nümbrecht

Henke Saas Wolf, Tuttlingen

Bio-Rad, Hercules, CA, USA

Messer-Griesheim, Krefeld

Ssniff Spezialdiäten, Soest

\subsubsection{Geräte}


Agarose-Gelkamm

Agarose-Gelkammer

Agarosegeldokumentation „ImageMaster VDS“

Diamantmesser „Ultrathin Diamond Knife 45

Drucker Apple LaserWriter 16

Drucker Minolta-QMS magicolor 2

Feinwaage, digital

Fräse für Epon-Präparate

Gefrierschrank $-20^{\circ} \mathrm{C}$

Gefrierschrank $-80^{\circ} \mathrm{C}$

Gewebe-Einbettautomat "Lynx el"

Gewebeinfiltrationsautomat „Microm HMP 110“

Glaswaren

Magnetrührer RCT basic Ikamag

Mikroskop Leica DM RXA2

Paraffin-Ausgießstation „Microm AP 280“

PCR-Thermocycler „T3“

PCR-Versiegler „Combi Thermosealer“

Peristaltikpumpe

Pipetten

Quarzküvette

Reinstwasseranlage „SeralPur Pro 90 CN“

Rotationsmikrotom „Leica RM 2155“

Schlittenmikrotom „Microm HM 400“

Spannungsgeräte Elektrophorese

Spektralphotometer

Stangentesteinrichtung

Thermomixer

Tierkäfige Ratten
MPI Exp. Med. wiss. Werkstatt

MPI Exp. Med. wiss. Werkstatt

Amersham Pharmacia Biotech,

Freiburg

Diatome U.S.,

Fort Washington, PA, USA

Apple Macintosh,

Minolta, München

Heraeus Instruments,

Langenselbold

Reichert, Wien, Österreich

Liebherr, Ochsenhausen

New Brunswick Scientific,

Nürtingen

Vision BioSystems Inc,

Norwell, MA USA

Leica Microsystems, Wetzlar

Schott, Mainz

Omnilab, Bremen

Leica Microsystems, Wetzlar

Leica Microsystems, Wetzlar

Biometra, Göttingen

Advanced Biotechnologies,

Surrey, UK

Heraeus Instruments,

Langenselbold

Gilson, Villiers-le-Bel, Frankreich

Hellma, Müllheim / Baden

Seral, Ransbach

Leica Microsystems, Wetzlar

Leica Microsystems, Wetzlar

Amersham Pharmacia Biotech,

Freiburg

Amersham Pharmacia Biotech,

Freiburg

MPI Exp. Med. wiss. Werkstatt

Eppendorf, Hamburg

Tecniplast, Buguggiate, Italien 
Trocknungszentrifuge (Speed Vac)

Videomikroskopie-Kamera

Vortexer Probenmischung

Zentrifugen

„Laboratory Centrifuge 4K15“

„Heraeus Biofuge 13“
Eppendorf, Hamburg

Hamamatsu, Herrsching

Bender \& Hobein, München

Sigma Laborzentrifugen, Osterode am Harz

Heraeus Instruments, Langenselbold

\subsubsection{Lösungen und Puffer}

\subsubsection{Molekularbiologie}

$\mathrm{DEPC}-\mathrm{H}_{2} \mathrm{O}$

$\mathrm{H}_{2} \mathrm{O}$

$1000 \mathrm{ml}$

DEPC

$1 \mathrm{ml}$

über Nacht bei $37^{\circ} \mathrm{C}$ inkubieren und anschließend autoklavieren

DNA-Probenpuffer

Bromphenolblau

$0,25 \%$

Xylencyanol

$0,25 \%$

Ficoll (Typ 400)

$15 \%$ in $\mathrm{H}_{2} \mathrm{O}$

Erststrangpuffer (Teil des Superscript II RT-Kits)

GibcoBRL, Karlruhe

Zusammensetzung vom Hersteller nicht angegeben

PBS $(10 \times$ Stammlösung, $1000 \mathrm{ml})$

$\mathrm{NaCl}$

$100 \mathrm{~g}$

$\mathrm{KCl}$

$2,5 \mathrm{~g}$

$\mathrm{Na}_{2} \mathrm{HPO}_{4} * 2 \mathrm{H}_{2} \mathrm{O}$

$7,2 \mathrm{~g}$

$\mathrm{KH}_{2} \mathrm{PO}_{4}$

$2,5 \mathrm{~g}$

auf $900 \mathrm{ml}$ mit $\mathrm{H}_{2} \mathrm{O}$ auffüllen; pH 7,2 mit $10 \mathrm{~N} \mathrm{NaOH}$ einstellen; auf $1000 \mathrm{ml}$ mit $\mathrm{H}_{2} \mathrm{O}$ auffüllen; 1:10 verdünnen $(1 \times \mathrm{PBS})$ und autoklavieren

Puffer AE, AL/E, ATL, AW1, AW2

Qiagen, Hilden

(Teile des DNeasy 96 Kit)

Zusammensetzung vom Hersteller nicht angegeben

$\mathrm{SDS}-\mathrm{DEPC}-\mathrm{H}_{2} \mathrm{O}$ 
Sodium-Dodecyl-Sulfat

auf $1000 \mathrm{ml}$ mit DEPC- $\mathrm{H}_{2} \mathrm{O}$ auffüllen

$\operatorname{TAE}(50 \times, 1000 \mathrm{ml})$

Tris-HCl Base

$242 \mathrm{~g}$

Essigsäure 100\%

$57,1 \mathrm{ml}$

$\operatorname{EDTA}(0,5 \mathrm{M} \mathrm{pH} 8)$

$100 \mathrm{ml}$

auf $1000 \mathrm{ml}$ mit $\mathrm{H}_{2} \mathrm{O}$ auffüllen

\section{TE-Puffer}

Tris- $\mathrm{HCl}(\mathrm{pH} 7,4)$

$10 \mathrm{mM}$

$\operatorname{EDTA}(0,5 \mathrm{M})$

$1 \mathrm{mM}$

in $\mathrm{H}_{2} \mathrm{O}$; für DEPC-TE DEPC- $\mathrm{H}_{2} \mathrm{O}$ verwenden

$10 \mathrm{~g}$

$$
\text { ml }
$$

\subsubsection{Histologie}

Fixativ für die Elektronenmikroskopie (Karnovsky 1965)

Paraformaldehydlösung (8\%) $250 \mathrm{ml}$

Glutardialdehyd (25\%) $100 \mathrm{ml}$

$\mathrm{CaCl}_{2} * 2 \mathrm{H}_{2} \mathrm{O} \quad 0,33 \mathrm{~g}$

Na-Cacodylat-Puffer $(0,08 \mathrm{M}) \quad 150 \mathrm{ml}$

Fixativ für die Paraffineinbettung

Paraformaldehyd $\quad 40 \mathrm{~g}(4 \%)$

auf $500 \mathrm{ml} \mathrm{mit} \mathrm{H}_{2} \mathrm{O}$ auffüllen, auf $60^{\circ} \mathrm{C}$ erhitzen und tropfenweise $1 \mathrm{M} \mathrm{NaOH}$ zugeben bis die Lösung klar wird; $500 \mathrm{ml}$ 0,2 M Sörensenpuffer zugeben, sterilfiltrieren, $\mathrm{pH}$ 7,2 einstellen

Kunstharzmischung Epon (Luft 1961)

Lösung A

Glycidether

$67,5 \mathrm{~g}$

DDSA

$88,2 \mathrm{~g}$

eine Stunde mit Magnetrührer rühren

Lösung B

Glycidether

$82,3 \mathrm{~g}$

MNA

$73,3 \mathrm{~g}$ 
eine Stunde mit Magnetrührer rühren

Gebrauchslösung Epon

Mischung A + B

$1: 1$

$1,8 \%$ DMP30 zugeben

Methylen-Azur-II-Färbelösung (Richardson et al., 1960)

Methylenblau-Lösung: 1\% Methylenblau in 1\% wässriger Boraxlösung

Azur-II-Lösung: $1 \%$ Azur II in $\mathrm{H}_{2} \mathrm{O}$

in einem Verhältnis von 1: 1 mischen

Na-Kakodylat-Puffer (0,08 M) pH 7,2

Na-Kakodylat (8,56 g) auf $500 \mathrm{ml} \mathrm{mit} \mathrm{H}_{2} \mathrm{O}$ auffüllen, $\mathrm{pH}$ 7,2 einstellen, steril filtrieren

Paraformaldehydlösung (8\%)

Paraformaldehyd (40 g) auf $500 \mathrm{ml}$ mit $\mathrm{H}_{2} \mathrm{O}$ auf $60^{\circ} \mathrm{C}$ erhitzen, $1 \mathrm{M} \mathrm{NaOH}$ bis zum Aufklaren zusetzen, steril filtrieren, $\mathrm{pH}$ 7,2 mit $1 \mathrm{M} \mathrm{HCl}$ einstellen

\section{Sörensenpuffer}

Lösung A

$\mathrm{NaH}_{2} \mathrm{PO}_{4} * \mathrm{H}_{2} \mathrm{O}$

$6,9 \mathrm{~g}(0,2 \mathrm{M})$

in $250 \mathrm{ml} \mathrm{H} \mathrm{H}_{2} \mathrm{O}$

Lösung B

$\mathrm{Na}_{2} \mathrm{HPO}_{4}$

$28,4 \mathrm{~g}(0,2 \mathrm{M})$

in $1000 \mathrm{ml} \mathrm{H}_{2} \mathrm{O}$

Lösung A

$196 \mathrm{ml}$

Lösung B

$804 \mathrm{ml}$

mischen und $\mathrm{pH} 7,4$ einstellen

\section{DAB-Lösung}

$100 \mathrm{mg}$ DAB unter Lichtausschluss in $200 \mathrm{ml}$ Tris-Puffer lösen, dem 200 $\mu 1$ 30\%iges Wasserstoffperoxid zugesetzt wurden. 


\subsubsection{Enzyme und Reaktionskomplettsysteme}

\subsubsection{Enzyme}

Proteinase K (Lyophilisat; auf 10 mg/ml eingestellt)

Boehringer Mannheim

Taq-DNA-Polymerase (5 U/ $\mu$ l)

Boehringer Mannheim

\subsubsection{Reaktionskomplettsysteme}

DNeasy 96 Kit

Qiagen, Hilden

PCR-Komplettansatz

Promega, Mannheim

Terminal desoxynucleotidyl transferase-mediated

Desoxyuridine triphosphate nick-end-labelling

[TUNEL] Methode, TUNEL-Kit

Boehringer, Mannheim

\subsubsection{Nukleinsäuren und Nukleotide}

Desoxyribonukleosid-Triphosphate (dNTPs)

Boehringer Mannheim, Mannheim

DNA-Größenmarker Lambda/HindIII

Promega, Mannheim

DNA-Größenmarker PhiX174/HaeIII

Promega, Mannheim

zufällige Nonamerprimer

F. Benseler, MPI f. Exp. Med.

\subsubsection{Primer zur Genotypisierung mutanter Ratten}

sense ENDRB: 5'-AGC CGG TGC GGA CGC GCC TT-3'

antisense ENDRB: 3'-CAC GAC TTA GAA AGC TAC AC-3'

\subsubsection{Tiere}

Wildtyp-Ratten vom Stamm Wistar.

\subsubsection{Computersoftware}

Excel 2003

Illustrator 10.0
Microsoft Europe, Berlin

Adobe Systems Software, 
Openlab 3.0

Photoshop 7.0

PrimerExpress v1.65

Scion Image Beta 4.0.2

Statistica 6.0

Word 2003
Saggart, Irland

Improvision, Heidelberg

Adobe Systems Software,

Saggart, Irland

Applied Biosystems

Foster City, CA, USA

Scion Corporation U.S.,

Frederick, MD, USA

StatSoft Europe, Hamburg

Microsoft Europe, Berlin 


\subsection{Methoden}

\subsubsection{Zucht und Analyse von Ratten}

\subsubsection{Tiere}

$\mathrm{ET}_{\mathrm{B}}$-Rezeptor-defiziente Ratten; Linie: ,spotting lethal““ (sl/sl)

\subsubsection{Tierhaltung}

Die Tierhaltung erfolgte unter standardisierten Bedingungen im Tierhaus des MPI für experimentelle Medizin (Göttingen) betreut durch staatlich geprüfte Tierpfleger und entsprechend den Empfehlungen der Gesellschaft für Versuchstierkunde (GV-Solas). Die Ratten wurden in Gruppen von 2 bis zu 6 Tieren in Makrolonkäfigen Typ III (Typ III H: $1291 \mathrm{H}, 425 \times 266 \times 185 \mathrm{~mm}(\mathrm{~L} \times \mathrm{B} \times \mathrm{H})$, Grundfläche $\left.800 \mathrm{~cm}^{2}\right)$ oder IV (Typ IV: 1354G, $595 \times 380 \times 200 \mathrm{~mm}(\mathrm{~L} \times \mathrm{B} \times \mathrm{H})$, Grundfläche $\left.1820 \mathrm{~cm}^{2}\right)$ je nach Wurfgröße gehalten, die zweimal pro Woche gewechselt wurden. Die Haltung erfolgte auf staubfreiem Weichholzgranulateinstreu (Bedding S8/15, Ssniff Spezialdiäten GmbH). Die Ratten wurden mit einer pelletierten Standarddiät gefüttert (Ssniff R/M-H V1535, Ssniff Spezialdiäten $\mathrm{GmbH}$ ). Futter war zu jeder Zeit ad libitum für die Tiere verfügbar. Zur Wasserversorgung wurde Leitungswasser aus Tränkeflaschen ebenfalls ad libitum bereitgestellt. Die Raumtemperatur lag für alle Tiere bei $22 \pm 1{ }^{\circ} \mathrm{C}$, die relative Luftfeuchtigkeit bei $55 \pm 10 \%$. Die Luftwechselrate lag bei 15-fach pro Stunde. Die Beleuchtung erfolgte mit Kunstlicht von 4.30 bis 16.30 Uhr MEZ mit einer Lichtintensität von 300 Lux, gemessen in einer Höhe von einem Meter über dem Fußboden in der Raummitte.

\subsubsection{Identifikation der Tiere und Schwanzbiopsien}

Zunächst erfolgte die Genotypisierung der Tiere per Auge. Tiere mit einem komplett weißen Fell wurden als homozygot, Tiere mit einem kleinen schwarzen Fleck am Kopf als heterozygot und Tiere mit einem schwarz-weißen Fell als Wildtyp eingestuft (Abbildung 5, S. 9). Diese Methode wurde später durch die Schwanzbiopsie zur Genotypisierung ergänzt. Dies erfolgte nach der CO2-Narkose von Ratten zum Finalversuch. Bei den Biopsien wurde ein ca. 0,5 cm langes Stück der Schwanzspitze mit einer Schere entfernt. Die Schwanzbiopsie wurde danach bis zur weiteren Verarbeitung (s.u.) in einem Eppendorfgefäß bei $-20^{\circ} \mathrm{C}$ gelagert. Dieses wurde markiert mit der fortlaufenden Nummer des Tieres. In einem Zuchtprotokoll 
wurden für jeden Wurf die Nachkommenanzahl, das Geburtsdatum, das Geschlecht der Einzeltiere, die Identifikationsnummern der Elterntiere und eventuelle Auffälligkeiten notiert.

\subsubsection{Narkotisierung und Tötung der Tiere}

Für histologische Probengewinnung, die eine Perfusionsfixierung erforderte, erhielten die Ratten eine Injektionsnarkose durch intraperitoneale Injektion einer Kombination aus $5 \mathrm{mg} / \mathrm{kg}$ Körpergewicht Ketanest ${ }^{\circledR}$ (Wirkstoff: Ketamin) und $2 \mathrm{mg} / \mathrm{kg}$ Körpergewicht Rompun ${ }^{\circledR}$ (Wirkstoff: Xylazin). Für eine Probengewinnung, die keine Perfusion erforderte, wurden die Tiere durch Einleiten von $\mathrm{CO}_{2}$ in einen gasundurchlässigen Käfig getötet.

\subsubsection{Präparation von Ischiasnerven, spinalen Nervenwurzeln (DRG's) und}

\section{Rückenmarksabschnitten}

Um Veränderungen in der Entwicklung des peripheren Nervensystems zu beurteilen, wurde nach Tötung den Versuchstieren der Nervus ischiadicus als größter peripherer Nerv entnommen. Zur Präparation wurde die Haut der Tiere im Bereich der Hüfte und dorsalen Teil der unteren Extremität abpräpariert und die Muskulatur freigelegt. Durch Inzisur der Glutealmuskulatur wurde der Nervus ischiadicus freigelegt und proximal nach Austritt aus dem Foramen infrapiriforme sowie distal im Bereich der Aufteilung in Nervus tibialis und Nervus peronaeus durchtrennt. Die Präparation des Rückenmarks und der spinalen Nervenwurzeln erfolgte durch einen länglichen Hautschnitt im Lumbalbereich. Die Wirbelsäule wurde von der Muskulatur frei präpariert. Anschließend wurden die Laminae vertebralis der lumbalen Wirbelkörper entfernt. Es zeigte sich das Rückenmark mit den seitlich anliegenden DRG's. Zunächst wurden diese beidseits heraus geschnitten, anschließend erfolgt durch einen sauberen Schnitt im unteren und oberen Bereich der Intumescentia lumbalis die Resektion eines Rückenmarkzylinders in der Länge von etwa 4 mm. Die Präparation wurde mit einem Präparierbesteck (Fine Science Tools, Heidelberg) durchgeführt. Nach Resektion wurden die Präparate auf einer sauberen Unterlage mit einer Pinzette von Binde- und Fettgewebe befreit und je nach weiterer Verwendung weiterbehandelt. Nerven zur histologischen Analyse wurden nach Ganzkörperfixierung (s.u.) weiter in Fixativ nach Karnovsky auf $4^{\circ} \mathrm{C}$ gelagert. 


\subsubsection{Histologische Methoden}

\subsubsection{Ganzkörperfixation von Ratten durch Perfusion}

Tiere in den entsprechenden Altersstadien und Genotypen wurden perfusionsfixiert. Dazu wurde nach tiefer Anästhesie durch intraperitoneale Injektion von Ketamin ${ }^{\circledR} /$ Rompun ${ }^{\circledR}$ das Herz der Ratten frei präpariert und eine $23 \mathrm{G}$ „Venofix“-Kanüle (B.Braun) in den linken Ventrikel eingeführt. Die Vena cava inferior gerade distal des rechten Vorhofs wurde eröffnet. Über die Kanüle, verbunden mit einer Peristaltikpumpe (Heraeus SR70, Flussrate 2$5 \mathrm{ml} / \mathrm{min}$ ), wurde der Kreislauf des Tieres mit 50ml HBSS (GibcoBRL) perfundiert, gefolgt von 50ml Fixativ für Epon- oder Paraffineinbettung (Karnovsky 1965) und dadurch fixiert. Nach der Perfusionsfixation erfolgte eine Immersionsfixierung der entnommenen Präparate durch Lagerung im Fixativ für weitere 24 Stunden.

\subsubsection{Einbettung der Gewebeproben in Kunstharz}

Die fixierten Ischiasnerven, dorsalen spinalen Nervenwurzeln und Rückenmarksabschnitte wurden zur Herstellung von Semidünnschnitten in das Kunstharz Epon eingebettet nach der Methode von Luft (1961). Dazu wurden die Proben aus den perfundierten Ratten reseziert (s.o.). Ein 0,5 cm langes Stück wurde auf immer gleicher Höhe aus dem Nerven herausgeschnitten. Das Rückenmark wurde als ein ca. 0,4 cm langer Zylinder im Bereich der Intumescencia lumbalis heraus geschnitten. Die entsprechenden spinalen Nervenwurzeln ebenfalls präpariert. Diese Gewebestücke wurden in gleicher Ausrichtung in vorgefertigte Körbchen des Einbettautomaten „Lynx el“ gelegt und dann mit Epon infiltriert. Dabei wurden die Körbchen bei $4^{\circ} \mathrm{C}$ nach folgendem Schema in den entsprechenden Lösungen geschwenkt.

Lösung
Na-Kakodylatpuffer
$1 \% \mathrm{OsO}_{4} /$ Osmiumtetroxid
$\mathrm{Na-Kakodylatpuffer}$
$30 \%$ Ethanol
$50 \%$ Ethanol
$70 \%$ Ethanol
$80 \%$ Ethanol
$90 \%$ Ethanol
$100 \%$ Ethanol

Dauer

$2 \times 30$ Minuten

2 Stunden

$2 \times 15$ Minuten

15 Minuten

15 Minuten

15 Minuten

15 Minuten

15 Minuten

$2 \times 15$ Minuten 


$\begin{array}{ll}\text { Isopropanol } & 15 \text { Minuten } \\ \text { Propylenoxid } & 2 \times 15 \text { Minuten } \\ \text { Propylenoxid : Epon 2:1 Mischung } & 2 \text { Stunden } \\ \text { Propylenoxid : Epon 1:1 Mischung } & 2 \text { Stunden } \\ \text { Propylenoxid : Epon 1:2 Mischung } & 4 \text { Stunden } \\ \text { Epon } & 4 \text { Stunden }\end{array}$

Nach der Infiltration wurden die Proben in Epon eingebettet. Dazu wurden sie in Ausgießformen mit reinem Epon gegeben, welches durch Erhitzen auf $60^{\circ} \mathrm{C}$ für 24 Stunden polymerisierte, so dass feste Epon-Kunstharzblöcke entstanden.

\subsubsection{Semidünnschnitte von in Kunstharz eingebetteten Gewebeproben}

Die Eponblöcke wurden mit einer Fräse an der Spitze zu Pyramidenform angeschliffen. Von diesen Eponblöcken wurden an einem Rotationsmikrotom mit einem Diamantmesser 0,5 $\mu \mathrm{m}$ dicke Schnitte angefertigt. Diese Semidünnschnitte wurden auf Objektträger transferiert und eine Stunde lang getrocknet.

\subsubsection{Methylenblaufärbung von Semidünnschnitten}

Die Semidünnschnitte wurden gefärbt mit der Methylen-Azur-II-Färbung nach Richardson et al. (1960). Die Methylenblau-Lösung und Azur-II-Lösung wurden im Verhältnis 1:1 gemischt und filtriert. Die fertige Färbelösung wurde auf die Schnitte der Ischiasnerven, Rückenmarksabschnitte und spinalen Nervenwurzeln gegeben und nach einer Minute bei $60^{\circ} \mathrm{C}$ mit destilliertem Wasser abgewaschen. Die gefärbten Schnitte wurden für 15 Minuten bei Raumtemperatur getrocknet und dann mit Eukitt-Kleber eingedeckt.

\subsubsection{Ultradünnschnitte von in Kunstharz eingebetteten Nerven}

Von den Eponblöcken wurden mit Hilfe eines Ultramikrotoms Ultradünnschnitte $(50-70 \mathrm{~nm})$ angefertigt, auf Formavar befilmte Netze gezogen, $20 \mathrm{~min}$ auf einen Tropfen 1\%iger Uranylazetat kontrastiert und anschließend in $\mathrm{H}_{2} \mathrm{O}$ gespült. Eine zweite Kontrastierung erfolgte 7 min in Bleicitrat, das ebenfalls durch $\mathrm{H}_{2} \mathrm{O}$ abgespült wurde. Nachdem die Schnitte auf den Netzen gut getrocknet waren, erfolgte die mikroskopische Analyse mit Hilfe eines EM 10 bzw. eines EM 109 der Firma Zeiss. 


\subsubsection{Paraffinschnitte von den entnommenen Gewebeproben}

Nach Ganzkörperfixation von Ratten mit achtprozentiger Paraformaldehydlösung wurden wie bereits oben beschrieben der $N$. ischiadicus, ein Rückenmarkszylinder im Bereich der Intumescentia lumbalis und die entsprechenden spinalen Nervenwurzeln präpariert und reseziert. Der Nerv wurde mit Hilfe eines Gewebe-Infiltrationsautomaten (Leica Microsystems) paraffiniert und dann an einer Paraffin-Ausgießstation (Leica Microsystems) ausgegossen. Von den Paraffinblöcken wurden $3 \mu \mathrm{m}$ dicke Schnitte an einem Schlittenmikrotom (Leica Microsystems) angefertigt. Die Schnitte wurden auf Objektträger aufgezogen, mit Haematoxylin-Eosin und weiter auch immunhistochemisch gefärbt.

\section{Programm:}

\begin{tabular}{|l|l|}
\hline Reagenz & Dauer \\
\hline $50 \%$ Ethanol & $1 \mathrm{~h}$ \\
\hline $70 \%$ Ethanol & $2 \mathrm{~h}$ \\
\hline $70 \%$ Ethanol & $2 \mathrm{~h}$ \\
\hline $96 \%$ Ethanol & $1 \mathrm{~h}$ \\
\hline $96 \%$ Ethanol & $1 \mathrm{~h}$ \\
\hline $100 \%$ Ethanol & $1 \mathrm{~h}$ \\
\hline $100 \%$ Ethanol & $1 \mathrm{~h}$ \\
\hline Isopropanol & $1 \mathrm{~h}$ \\
\hline Xylol & $2 \mathrm{~h}$ \\
\hline Xylol & $2 \mathrm{~h}$ \\
\hline Paraffin & $2 \mathrm{~h}$ \\
\hline Paraffin & $2 \mathrm{~h}$ \\
\hline
\end{tabular}

\subsubsection{Immunhistochemie}

\subsubsection{Dako-LSAB2 System an Paraffinschnitten}

Es wurden $5 \mu \mathrm{m}$ dicke Schnitte von DRG's und Rückenmarksabschnitten (zuvor in Paraffin eingebettet) in entsprechenden Genotypen und Altersstufen angefertigt, auf beschichtete Objektträger (Histobond oder Apes) aufgezogen und über Nacht getrocknet. Die 
Entparaffinierung erfolgte über Xylol und eine absteigende Alkoholreihe. Die Schnitte wurden dann $5 \mathrm{~min}$ in Citratpuffer inkubiert, anschließend in kochendem Citratpuffer (Mikrowelle) gegeben, darin 2-3× 5 min gekocht und bei RT ca. 20 min abgekühlt. Dann wurden die Schnitte $5 \mathrm{~min}$ in Tris-Puffer mit 2\% Milchpulver gespült und mit einem PAP-Pen umrandet. Zur Inaktivierung der endogenen Peroxidase wurden die Schnitte für 5 min in 3\% $\mathrm{H}_{2} \mathrm{O}_{2}$ inkubiert. Das anschließende Spülen erfolgte in Tris-Puffer mit 2\% Milchpulver. Um die unspezifische Hintergrundfärbung möglichst gering zu halten, wurden die Schnitte bei RT in inaktiviertem Ziegenserum $(200 \mu \mathrm{l}+800 \mu \mathrm{l}$ PBS/BSA) inkubiert, das nach 10 min dekantiert wurde. Die Inkubation mit dem primären Antikörper (hier TUNEL System), verdünnt in $\mathrm{PBS} / \mathrm{BSA}$, erfolgte über Nacht $\left(4^{\circ} \mathrm{C}\right)$. Nach Spülung mit Tris-Puffer $(+2 \%$ Milchpuffer) wurde der Brückenantikörper $10 \mathrm{~min}$ bei Raumtemperatur auf die Schnitte gegeben (gelbe Flasche), mit Tris-Puffer (+2\% Milchpulver) abgewaschen und anschließend der „Horseradish-Peroxidase-Streptavidin-Komplex“ aufgetragen (rote Flasche). Diese Inkubation dauerte ebenfalls $10 \mathrm{~min}$. Nachdem die Schnitte wiederum in Tris-Puffer ohne Milchpulver gespült wurden, folgte die enzymhistochemische Reaktion. Dazu wurde eine DAB Gebrauchslösung hergestellt. Die Inkubationszeit der Schnitte in dieser Lösung betrug 7 min. Im Anschluss wurden die Schnitte zweimal in $\mathrm{H}_{2} \mathrm{O}$ gespült (je $5 \mathrm{~min}$ ), mit Hämalaun 30 s gefärbt und nochmals in $\mathrm{H}_{2} \mathrm{O}$ gespült. Das Bläuen erfolgte alternativ in Tris-Puffer oder Leitungswasser (10 min, 3x wechseln), es fügte sich eine aufsteigende Alkoholreihe an, und die Schnitte wurden zuletzt in Eukitt eingedeckt. Die Analyse der Schnitte erfolgte mit Hilfe eines Axiophots (Zeiss).

\subsubsection{Histologische Analyse von Ischiasnerven}

Verschiedene histologische Charakteristika im peripheren Nerven wurden untersucht, um den Entwicklungsstand des Nerven festzustellen. Dazu gehören die Myelinisierung, die Anzahl von Schwannzellen und die Gesamtanzahl von Axonen. Um eventuelle Veränderungen dieser histologischen Merkmale bei den $\mathrm{ET}_{\mathrm{B}}$-Rezeptor-defizienten Ratten untersuchen zu können, wurden von den Semidünnschnitten der Ischiasnerven mikroskopische Bilder angefertigt. Die Aufnahmen wurden an einem Lichtmikroskop (Leica DM RXA2) mit einer Videomikroskopie-Kamera (Hamamatsu) und dem Programm Openlab 2.0 angefertigt. Die Weiterbearbeitung erfolgte mit den Programmen Photoshop 6.0 (Adobe) und ScionImage (Scion Corporation). 
Die Gesamtzahl aller Axone der Ischiasnerven auf einer definierten Höhe wurde gezählt. Dazu wurde der Gesamtnerv der Wildtyptiere und der $\mathrm{ET}_{\mathrm{B}}$-Rezeptor-defizienten Ratten unterteilt in analysierbare Abschnitte. Nach Blindung wurden solche Axone gezählt, die der Größe nach physiologischerweise eine Myelinisierung erwarten ließen. Also Axone, die eine 1:1 Schwannzell zu Axon Assoziierung aufwiesen (Abbildung 16a). Die Gesamtsumme aller in Ischiasnerven vorhandenen Axone diente als Zeichen der Ausprägung der Myelinisierung. Außerdem wurde die Gesamtzahl aller Zellkerne auf den Querschnitten der Ischiasnerven gezählt, um ermitteln zu können, ob es möglicherweise einen Defekt in der Migration der Schwannzellen gibt oder gar einen programmierten vorzeitigen Zelltod. Dabei wurde technisch genau so vorgegangen wie bei den Axonanzahlzählungen.

a)

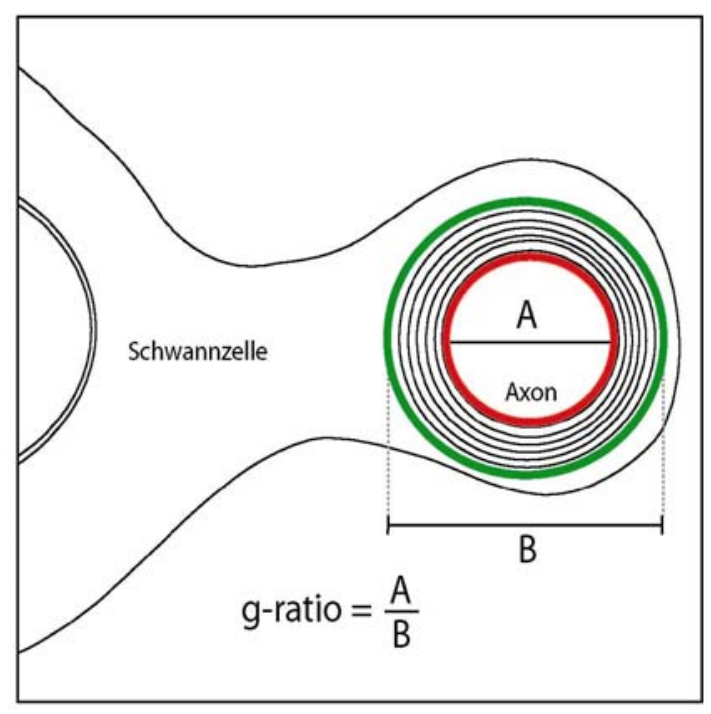

b)

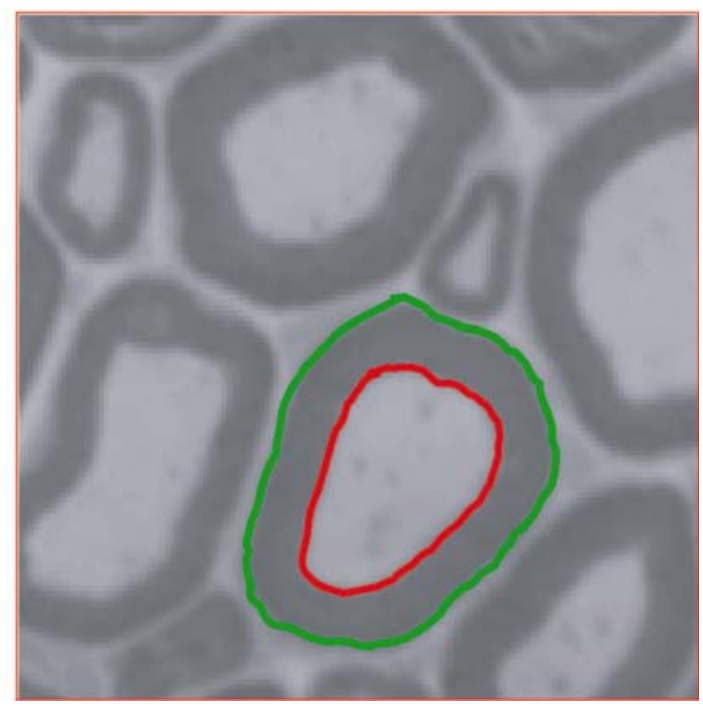

$$
\begin{aligned}
\text { g-ratio }= & \frac{D_{\text {Axon }}}{D_{\text {Myelin }}}=\frac{U_{\text {Axon }}}{U_{\text {Myelin }}} \\
& \begin{aligned}
D=\text { Durchmesser } \\
U=\text { Umfang }
\end{aligned}
\end{aligned}
$$

\section{Abbildung 9: Das ,g-ratio“ als Maß für die Myelindicke}

a) Schematische Darstellung der theoretischen Bestimmung des ,g-ratios“. Der Quotient aus Innerem (A) und äußerem (B) Durchmesser der Myelinscheide dient als so genanntes „g-ratio“ als Maß für die Dicke des Myelins. Bei nicht vollständig kreisrunden Myelinscheiden kann der Quotient aus innerem (roter Kreis) und äußerem (grüner Kreis) Umfang als ausreichendes Maß für das Verhältnis der Durchmesser gelten. b) Beispielhafte Bestimmung des „g-ratios“ in einem histologischen Schnitt des Ischiasnerven. Der äußere und innere Umfang der Myelinscheide wird am Computer mit der Maus umfahren und ihre Länge gemessen. Das Verhältnis aus beiden wird errechnet. 
Als viertes histologisches Kriterium der Myelinentwicklung wurde die Dicke des Myelins bestimmt. Dazu wurde im histologischen Bild der innere und der äußere Umfang der Myelinscheide von zufällig ausgewählten Axonen gemessen (Abbildung 9a, S. 33). Der Quotient aus innerem und äußerem Umfang wurde gebildet: das so genannte ,g-ratio“. Ein ,g-ratio“ von 1,0 entspricht dabei keinem Myelin und ein kleiner werdendes ,g-ratio“ einem dickerem Myelin. Als Standardwert für die Dicke des Myelins in normalen Ratten kann ein "g-ratio" von ca. 0,68 gelten (Fahrenkamp und Friede 1987), wobei das "g-ratio" als Quotient aus zwei Längenangaben dimensionslos ist (Abbildung 9, S. 33).

\subsubsection{Histologische Analyse des Rückenmarks}

Zur Feststellung eines möglichen Zelltodes auf Rückenmarksebene führten wir bei den Semidünnschnitten eine Quantifizierung von den großen $\alpha$-Motoneuronen durch. Dabei wurden per Auge auf Gesamtquerschnitten im oberen Bereich des Rückenmarks $\alpha$ Motoneurone markiert und statistisch mit Statistica 6.0 (StatSoft Europe, Hamburg) ausgewertet.

Außerdem erfolgte eine immunhistochemische Färbung der Rückenmarksabschnitte, die in Paraffin eingebettet wurden. Hierzu wurde ein Apoptose TUNEL Kit (Boehringer Ingelheim) angewandt, anschließend wurde es mit DAB gegen gefärbt.

\subsubsection{Histologische Analyse der dorsalen spinalen Nervenwurzeln}

Hier wurde ähnlich wie bei den Rückenmarksproben verfahren. Zunächst erfolgte per Auge die Zählung der Gesamtzahl aller in der Nervenwurzel enthaltenen Zellleiber. Da es jedoch schwierig war, die Nervenwurzel aufgrund ihrer minimalen Größe jedes Mal in der Mitte zu treffen, wurde anschließend die Fläche des Querschnitts mittels Photoshop 6.0 (Adobe) berechnet und aus beiden Daten ein Verhältnis zueinander errechnet und anschließend statistisch für alle Altersgruppen ausgewertet.

\subsubsection{Molekularbiologische Methoden}

\subsubsection{Präparation von DNA und Genotypisierung}

Zur Genotypisierung der gezüchteten Ratten in Wildtyptiere oder sl/sl-Tiere war es nötig, aus dem durch Biopsie der Schwanzspitze gewonnenen Gewebe genomische DNA zu extrahieren. Dies erfolgte mit Hilfe des „DNeasy 96 Kits“ (Qiagen) nach dem Protokoll des Herstellers 
(DNeasy 96 Kit Handbuch). Dazu wurden die bei $-20^{\circ} \mathrm{C}$ gelagerten Gewebebiopsien aufgetaut

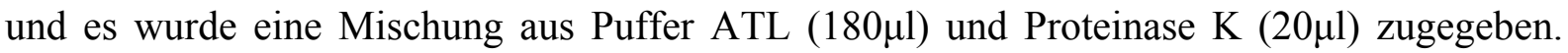
Nach intensivem Mischen und einer kurzen Zentrifugation bei 3000 rpm in einer „Laboratory Centrifuge 4K15“ (Sigma) erfolgte durch Inkubation über Nacht bei $55^{\circ} \mathrm{C}$ die Lyse des

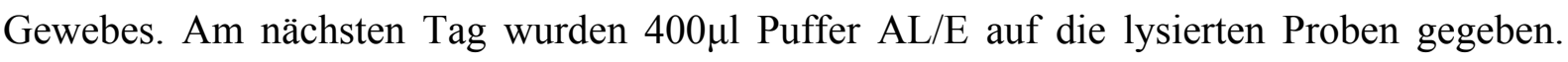
Nach Mischen und kurzer Zentrifugation bei 3000 rpm wurde der Überstand (maximal 900 $\mu$ ) auf die Silicamembran der DNeasy Säulchen pipettiert. Die DNeasy Platte wurde mit einem „Air Pore Tape Sheet" verschlossen und 10 min bei $6000 \mathrm{rpm}$ zentrifugiert. Danach wurden je $500 \mu \mathrm{l}$ Puffer AW1 auf die Säulchen gegeben und wieder 5 min bei $6000 \mathrm{rpm}$ zentrifugiert. Nach Zugabe von $500 \mu$ Puffer AW2 wurde wieder 5 min bei 6000 rpm zentrifugiert und die DNeasy Platte 15 min bei $70^{\circ} \mathrm{C}$ inkubiert. Zur Elution der DNA, die nun an die Silicamembran der Säulchen gebunden war, wurden $200 \mu 1$ vorgewärmter Puffer AE auf die Säulchen gegeben, $5 \mathrm{~min}$ bei $60^{\circ} \mathrm{C}$ inkubiert und $2 \mathrm{~min}$ bei $6000 \mathrm{rpm}$ zentrifugiert. Der gleiche Vorgang wurde mit weiteren $100 \mu \mathrm{l}$ Puffer AE wiederholt. Die so eluierte genomische DNA wurde bei $4^{\circ} \mathrm{C}$ gelagert.

\subsubsection{Die Polymerasekettenreaktion (PCR)}

Das Prinzip der Reaktion beruht auf zwei spezifischen Oligonukleotiden, die als Primer bezeichnet werden, und an komplementäre Bereiche denaturierter DNA binden. Durch die hitzestabile DNA-Polymerase aus dem Bakterium Thermus aquaticus (Taq-Polymerase) wird anschließend die molare Menge der eingesetzten Matrizen-DNA in jedem Zyklus verdoppelt (Holland et al. 1991). Der Standardansatz für die Genotypisierung der sl/sl-Ratten wurde in einem Reaktionsvolumen von $20 \mu 1$ durchgeführt.

\section{Standardreaktion:}

Matrizen-DNA

5'-Primer (10 pmol/ $/ \mu \mathrm{l})$

3'-Primer $(10 \mathrm{pmol} / \mu \mathrm{l})$

dNTPs $(2,5 \mathrm{mM})$

$5 \times$ Reaktionspuffer

GoTaq-Polymerase

$\mathrm{H}_{2} \mathrm{O}$
$1 \mu 1$

$2 \mu 1$

$2 \mu 1$

$2 \mu 1$

$4 \mu 1$

$0,1 \mu 1$

$8,9 \mu 1$ 
Standard-Amplifikationsprotokoll (32 Zyklen):

\begin{tabular}{|ll|l|}
5 & $94^{\circ} \mathrm{C}$ (Denaturierung) \\
\hline $30^{\prime}$, & $60^{\circ} \mathrm{C}$ (Anlagerung der Primer) Zyklus & \\
30, & $72^{\circ} \mathrm{C}$ (Extension) Zyklus & $32 \mathrm{x}$ \\
$60^{\prime}$, & $94^{\circ} \mathrm{C}$ (Denaturierung) Zyklus & \\
\hline $10^{\prime}$ & $72^{\circ} \mathrm{C}$ (End- Extension) & \\
\end{tabular}

\subsubsection{Agarose-Gelelektrophorese von DNA}

Zur Auftrennung von DNA Fragmenten wurde ein 2\%iges Agarosegel verwendet. Die Agarose wurde in $350 \mathrm{ml}$ 1x TAE-Puffer durch Erhitzen gelöst. Nach kurzem Abkühlen wurde Ethidiumbromid $(1 \mu \mathrm{g} / \mu \mathrm{l})$ hinzu gegeben und die Agarose in einen Gelschlitten gegossen. Die Geltaschen wurden durch das Einsetzen verschiedener Kämme erhalten.

Für einen Gellauf wurde der Schlitten in eine Gelkammer gelegt und diese mit Laufpuffer (1x TAE) gefüllt Die angelegte Spannung betrug 90-130V. Das Ethidiumbromid in dem Gel interkaliert mit der aufgetragenen DNA und kann nach dem Lauf auf einem UV-Illuminator sichtbar gemacht werden. Als Größenmarker wurde ein 100 bp Marker verwendet.

\subsubsection{Statistische Methoden: Histologische Analysen}

Zur Auswertung der in den histologischen Analysen erhobenen Daten wurden diese mit Excel 2003 (Microsoft) weiterbearbeitet. Die statistische Auswertung erfolgte mit Statistica 6.0 (StatSoft). Zur Testung der Signifikanz wurde der Student's t-test für unabhängige Stichproben verwendet, wobei ein $\mathrm{p}<0,05$ als signifikant gewertet wurde. 


\section{Ergebnisse}

In der vorliegenden Arbeit wurde die Rolle des ETB-Rezeptors für die Myelinisierung m peripheren Nervensystem in „spotting lethal“"-Ratten (sl/sl) untersucht. Diese Ratten tragen eine homozygote Deletion im ETB-Rezeptorgen, äquivalent zum Morbus Hirschsprung beim Menschen. Im Folgenden werden die ETB-Rezeptorgen-defizienten-Ratten als mutante Tiere/Ratten oder mit s1/sl bzw. die Kontrolltiere mit wt bezeichnet. Es wurden 3 verschiedene Zeitpunkte während der Myelinisierung gewählt. Der erste experimentelle Zeitpunkt stellte einen Punkt zum Beginn der Myelinisierung dar - den Postnataltag 1 (P1). Als zweiter Untersuchungszeitpunkt wurde der Postnataltag 6 (P6) während der Myelinisierung gewählt. Den dritten und letzten Zeitpunkt stellte der Postnataltag 18 (P18) dar. Die Myelinisierung ist zu diesem Zeitpunkt fast abgeschlossen. Die Untersuchung der Myelinisierung adulter sl/sl-Ratten ist nicht möglich, da die Lebensdauer der mutanten Ratten aufgrund des toxischen Megacolons nur ca. 3 Wochen beträgt. Die Genotypisierung erfolgte zunächst per Auge, wobei Tiere mit einem komplett weißen Fell als homozygot und Tiere mit einem schwarz-weißen Fell als wildtyp eingeordnet wurden (Abbildung 5, S. 9). Pro Gruppe wurden je drei Kontrolltiere und sl/sl-Tiere analysiert. Die Myelinisierung wurde im Ischiasnerven analysiert. Die Präparation des Nerven erfolgte proximal an dem Austrittsort aus dem Becken und distal seiner Trifurkation. Die Analyse erfolgte immer in der Mitte von diesem Teil des Ischiasnerven. Es wurden Semi- und Ultradünnschnitte angefertigt. Semidünnschnitte haben eine Schnittdicke von 0,5 $\mu \mathrm{m}$. Bei lichtmikroskopischer Betrachtung sind Blutgefäße, Schwannzellen sowie myelinisierte und unmyelinisierte Axone deutlich zu erkennen. Es wurden zunächst die Anzahl der Schwannzellen, die Anzahl myelinisierter Axone und deren Myelindicke im Ischiasnerven von sl/sl-Ratten mit Wildtyptieren in allen drei Altersstufen untersucht und miteinander verglichen. Anschließend wurde eine histologische und morphologische Analyse des Rückenmarks und der dorsalen spinalen Nervenwurzeln (dorsal root ganglia; DRG's) durchgeführt. Hierbei sollten mögliche Effekte des ETB-Rezeptor auf neuronale motorische Zellen im Vorderhorn des Rückenmarks ( $\alpha$ Motoneurone) oder der sensiblen Neurone in den DRG's untersucht werden. 


\subsection{Morphologie des $N$. ischiadicus auf lichtmikroskopischer Ebene}

Um Unterschiede in der Morphologie des peripheren Nervensystems zwischen den s1/s1Ratten und den Wildtypratten zu eruieren wurde der N. ischiadicus, als der größte periphere Nerv, auf lichtmikroskopischer Ebene untersucht. Es wurden drei Altersstufen als Untersuchungszeitpunkte (P1, P6, P18) gewählt, um die Entwicklung der Myelinisierung zu erfassen (Abbildung 10).
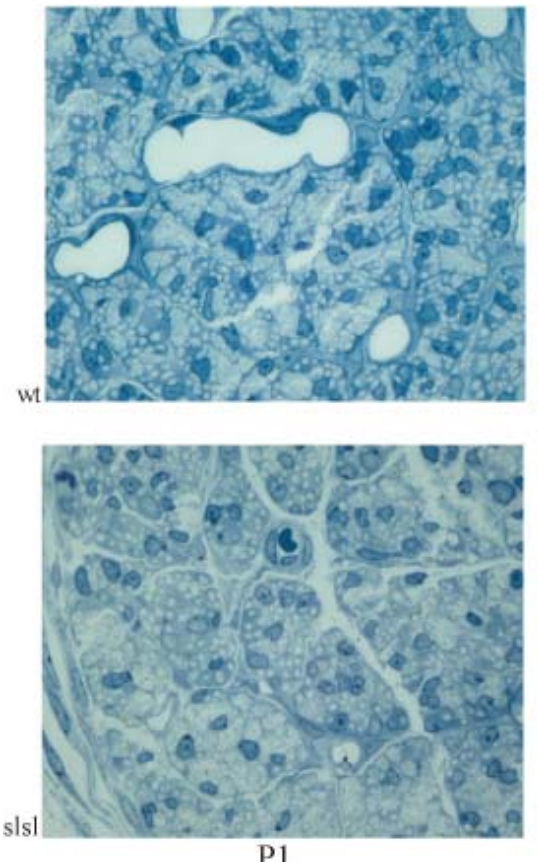

P1
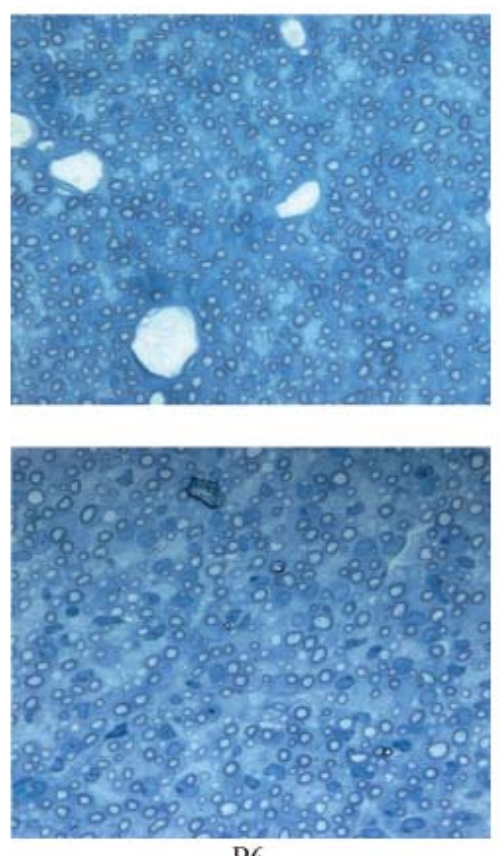

P6
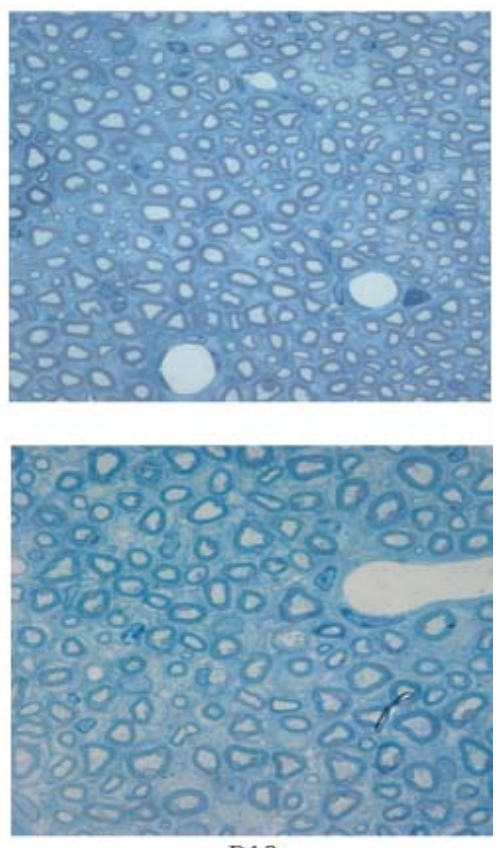

P18

Abbildung 10: Histologie des $N$. ischiadicus

Ausschnitte aus Querschnitten des N. ischiadicus als Semidünnschnitte von Wildtypen und s1/sl-Ratten in den Altersstufen P1, P6 und P18.

\subsubsection{Anzahl myelinisierter Axone im N. ischiadicus}

In den Altersstufen P6 und P18 wurden von 3 Tieren pro Genotyp die Anzahl myelinisierter Axone im N. ischiadicus auf Semidünnschnitten gezählt. Da es auf lichtmikroskopischer Ebene nicht möglich ist, myelinisierte Axone in der Altersstufe von P1 zu erkennen, wurde darauf bei dieser Untersuchung verzichtet. Die statistische Analyse der Ergebnisse wurde jetzt und nachfolgend mit dem Programm Statistika durchgeführt. Ein Unterschied ist signifikant, wenn der t-Test, in diesem Fall für unabhängige Variablen, einen p-Wert $<0,05$ ergibt. Es konnten signifikante ( $\mathrm{p}<0,05$; Student's t-test für unverbundene Stichproben) Unterschiede in der Anzahl myelinisierter Axone bei P6 und auch P18 festgestellt werden. Im Vergleich zur 
Kontrollgruppe $(n=3)$ wiesen die sl/sl-Tiere $(n=3)$ bei P6 $33 \%$ weniger myelinisierte Axone. Im Gesamtquerschnitt wurden in sl/sl-Tieren 2650 Axone und in den Kontrolltieren 3908 Axone festgestellt. Bei P18 zeigte sich ebenfalls ein Unterschied von $33 \%$. Bei den sl/slTieren in der Altersstufe P18 fanden sich 3311 Axone im Gesamtquerschnitt des $N$. ischiadicus, im Vergleich dazu bei den Wildtypratten 4956 Axone (Abbildung 11). Das Verhältnis von myelinisierten und nicht myelinisierten Axonen konnte auf lichtmikroskopischer Ebene nicht erstellt werden.

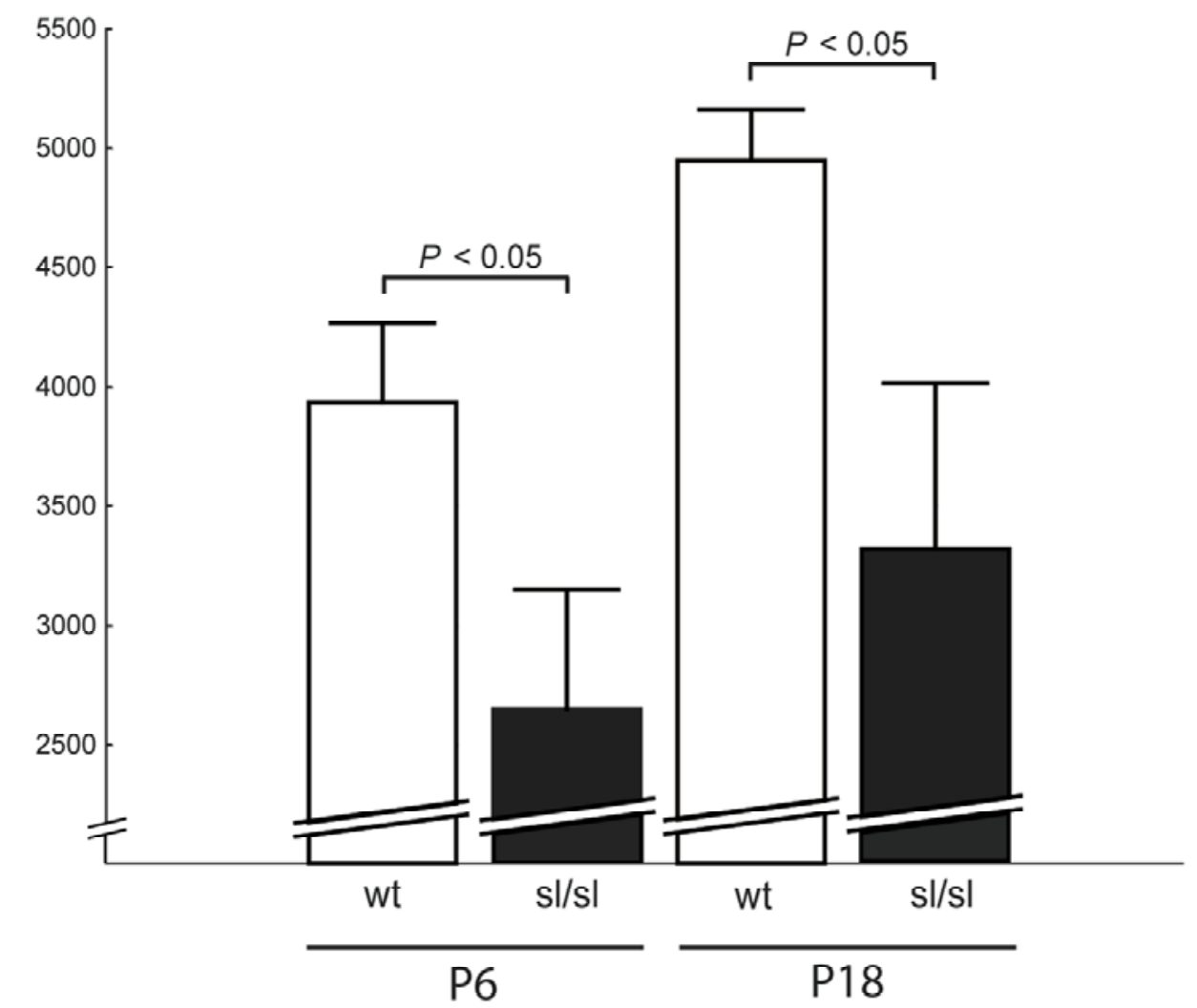

Abbildung 11: Gesamtanzahl myelinisierter Axone im Querschnitt des N. ischiadicus P6 und P18

Die Anzahl aller myelinisierter Axone in Querschnitten des N. ischiadicus bei P6 sowohl auch bei P18 ist in den sl/sl-Tieren im Vergleich zu den Wildtypkontrollen um ca. 33\% reduziert ( $\mathrm{n}=3$ pro Alter und Genotyp).

\subsubsection{Gesamtanzahl von Zellkernen im $N$. ischiadicus}

Neben der Gesamtanzahl von myelinisierten Axonen wurde auch die Gesamtanzahl von Zellkernen quantifiziert. Da es bei Semidünnschnitten auf lichtmikroskopischer Ebene nicht möglich ist hinreichend zwischen Schwannzellen und anderen Zellen im Nerven, wie z.B. einfache Fibroblasten, zu unterscheiden, wurden hier die Gesamtanzahl aller Zellkerne gezählt. Es ist davon auszugehen, dass es sich dabei um größtenteils Schwannzellen handelt und dass der Quantifizierungsfehler durch andere Zellen bei der Kontrollgruppe gleichermaßen gegeben ist. Es zeigt sich hier kein signifikanter (Student's t-test für 
unverbundene Stichproben) Unterschied in der Anzahl von Zellkernen bei P1 in den sl/slTieren $(n=3)$ verglichen zur Kontrollgruppe $(n=3)$. Bei den P1 sl/sl-Tieren konnten $440( \pm$ SD) Zellkerne im Gesamtquerschnitt des N. ischiadicus gezählt werden, im Vergleich dazu waren es bei den Wildtypen 460 ( \pm SD) Zellkerne. In der Altersstufe von P6 ist ein deutlicher Unterschied zu verzeichnen, jedoch ist dieser aufgrund der hohen Varianz nicht signifikant. In den sl/sl-Tieren $(n=3)$ konnten $600( \pm$ SD) und in den Kontrolltieren $(n=3) 700( \pm$ SD) Zellkerne gezählt werden. Somit haben die sl/sl-Tiere 15\% ( \pm SD) weniger Zellkerne als die Wildtyptiere in der Altersstufe P6 (Abbildung 12, S. 40). In der Altersstufe P18 stellt sich eine deutliche und signifikante Reduktion $(\mathrm{p}<0,03)$ der Zellkerne um 30\% $( \pm \mathrm{SD})$ in den sl/slTieren $(n=3)$ im Vergleich zu den Wildtyptieren $(n=3)$ dar. In den Wildtyptieren sind $750( \pm$ $\mathrm{SD})$ und in den sl/sl-Tieren 550 ( \pm SD) Zellkerne gezählt worden (Abbildung 12, s.u.).

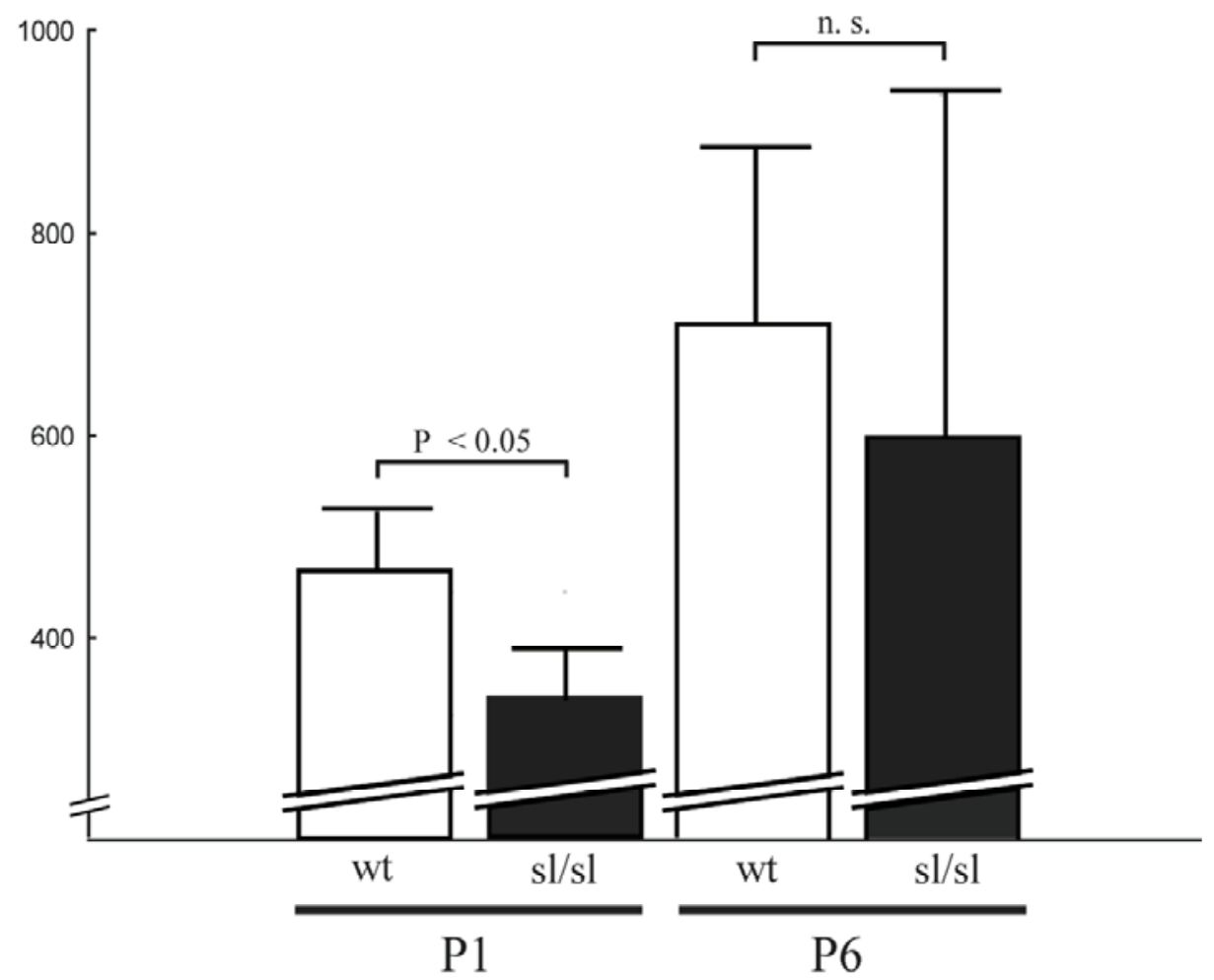

Abbildung 12: Gesamtanzahl von Zellkernen in Gesamtquerschnitten des N. ischiadicus bei P1, P6 und P18

Die Gesamtanzahl von Zellkernen in den Querschnitten der Nn. ischiadici bei sl/sl-Ratten ist im Vergleich zu den Wildtypkontrollen bei P1 unverändert. Bei P6 ist bei den sl/sl-Tieren ein nicht signifikanter Unterschied von ca. $15 \%$ weniger Zellkernen zu verzeichnen, jedoch nicht signifikant. In der Altersstufe P18 stellt sich jedoch ein signifikanter Unterschied dar, wobei bei den sl/sl-Ratten die Anzahl der Zellkerne um ca. 33\% reduziert ist ( $\mathrm{n}=3$ pro Alter und Genotyp). 


\subsubsection{Die Myelindicke, "g-ratio"}

Neben der Anzahl der myelinisierenden Axone ist die Myelindicke ein weiteres Merkmal der Myelinisierung. $\mathrm{Zu}$ dickes oder zu dünnes Myelin können Hinweise auf verschiedene Funktionsstörungen in Schwannzellen, in der Axon-Glia-Kommunikation aber auch im Axon sein. In histologischen Schnitten wurden der innere und der äußere Umfang der Myelinscheide von 100 zufällig ausgewählten Axonen gemessen. Der Quotient aus innerem und äußerem Umfang wurde gebildet: das so genannte ,g-ratio“. Ein „g-ratio“ von 1,0 entspricht dabei keinem Myelin und ein kleiner werdendes ,g-ratio“ einem dickerem Myelin (Abbildung 9, S. 33).

Hier wurden ebenfalls Tiere im Alter von P6 und P18 untersucht. Bei P6 zeigt sich ein signifikanter Unterschied ( $\mathrm{p}<0,05$; Student's t-test für unverbundene Stichproben), die s1/slTiere $(n=5)$ weisen ein dünneres Myelin im Vergleich zu den Wildtyptieren $(n=4)$ auf. Im Gegensatz dazu gibt es keinen Unterschied zu verzeichnen bei beiden Gruppen im Alter von P18 (je n=3). Auch war die Schwankungsbreite innerhalb der P18 Gruppen deutlich geringer als bei P6 (Abbildung 13).

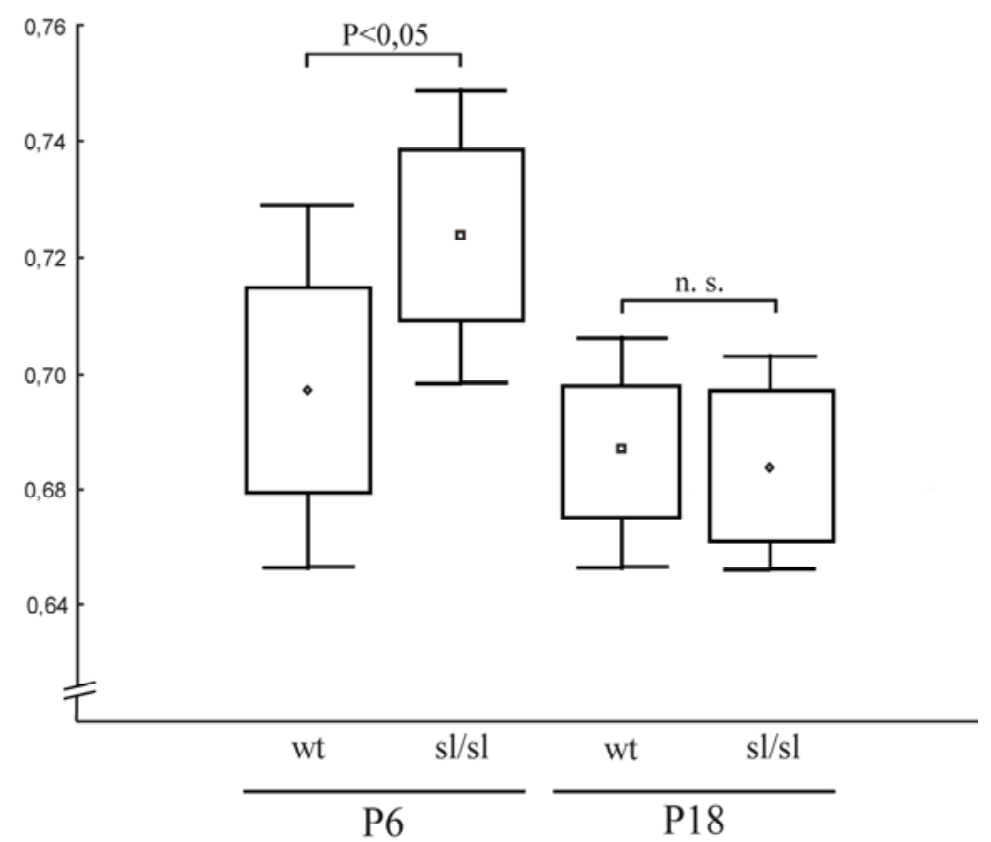

\section{Abbildung 13:"g-ratio" bei P6- und P18-Tieren}

Das " $g$-ratio" ist im Alter von P6 bei den sl/sl-Tieren ( $\mathrm{n}=5$ ) signifikant höher als bei den Wildtyptieren ( $\mathrm{n}=4)$, d.h. deren Myelin ist dünner als normales Myelin. Im Alter von P18 ist kein Unterschied mehr zu verzeichnen ( $\mathrm{n}=3$ pro Gruppe).

Im Rahmen dieser Messungen wurden die einzelnen Axondurchmesser bestimmt und eine Verteilung nach Größe der Axone und deren Myelindicke/“"g-ratio“" aufgestellt, sowohl bei P6 
als auch bei P18. Bei P6 fällt eine Hypomyelinisierung der kleinen Axone bei den sl/sl-Tieren auf. In den Wildtypen zeigt sich eine breitere Verteilung, wobei bei den sl/sl-Tieren die meisten Axone zwischen 2-4 $\mu \mathrm{m}$ im Durchmesser liegen (Abbildung 14, S. 42). In den P18Tieren ist dieser Trend nicht zu verzeichnen. Es zeigt sich eine gleichmäßigere Verteilung der großen und kleinen Axone (Abbildung 15, s.u.).

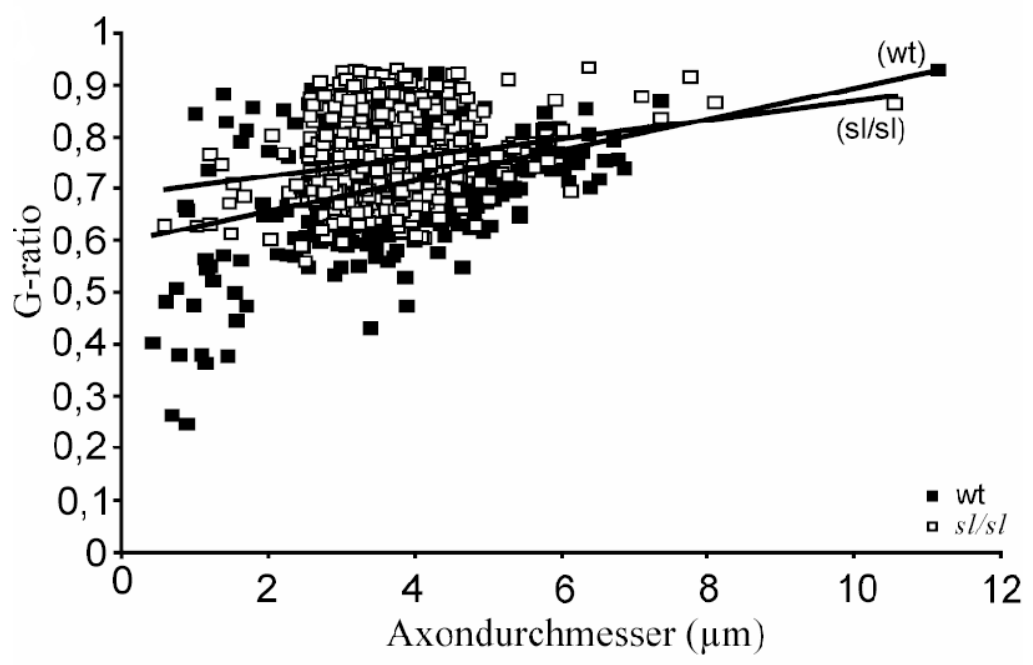

\section{Abbildung 14: Axongrößenverteilung bei P6}

Scatter Plot für mutante Tiere (sl/sl) und Kontrolltiere (wt): der Axondurchmesser (Abzisse) wird gegen den " $g$-ratio" Wert (Ordinate) aufgetragen. Auffällig ist eine Hypomyelinisierung bei kleinen Axonen der sl/sl-Ratten, wobei die Wildtyptiere insgesamt eine breitere Verteilung aufweisen.

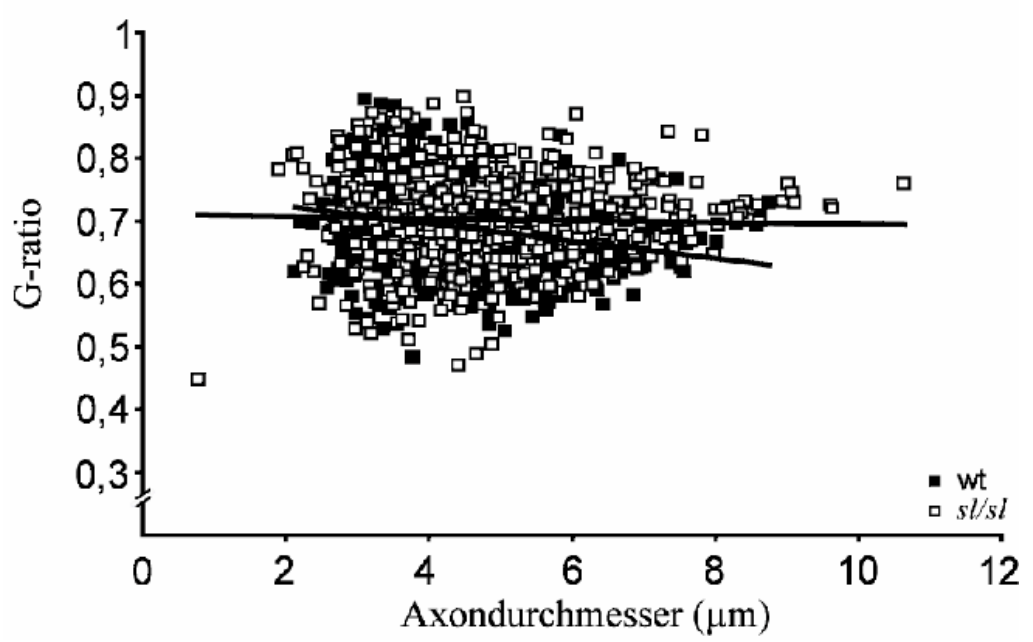

\section{Abbildung 15: Axongrößenverteilung bei P18}

Scatter Plot für mutante Tiere (sl/sl) und Kontrolltiere (wt): der Axondurchmesser (Abzisse) wird gegen den "g-ratio" Wert (Ordinate) aufgetragen. Es zeigt sich eine gleichmäßigere Verteilung der Axone, ein Trend zeigt sich nicht. 


\subsection{Elektronenmikroskopische Untersuchung des $\boldsymbol{N}$. ischiadicus bei P1}

\subsubsection{Anzahl myelinisierter Axone}

Da es in der Altersstufe P1 auf lichtmikroskopischer Ebene eine ausreichende morphologische Analyse aufgrund fehlender Myelinisierung und der kleinen Größe der Axone nicht möglich ist, wurden die Analysen auf elektronenmikroskopischer Ebene durchgeführt.

Die Abbildung 16 zeigt elektronenmikroskopische Aufnahmen von Ischiasquerschnitten der Wildtypen und sl/sl-Tiere. Die Bilder zeigen Schwannzellen (SZ), unmyelinisierte (U) und bereits myelinisierte Axone (rote Pfeilspitzen). Um eine Aussagen über den Grad der Myelinisierung treffen zu können, wurde bei P1 die Anzahl myelinisierter Axonen pro Nerv elektronenmikroskopisch bei $\mathrm{n}=3$ Tieren pro Genotyp quantifiziert. Am Postnataltag 1 bedingen zeitliche Unterschiede der Ratten von nur einigen Stunden deutliche Veränderungen im Grad der Myelinisierung. Um die Untersuchungsbedingungen möglichst gleich zu halten, wurden die zu untersuchenden Tiere bei P1 komplett einem Wurf entnommen $(\mathrm{n}=3$ pro Genotyp; s.u.).

Die Auswertung ergab eine signifikant erhöhte Anzahl myelinisierter Axone in den sl/slRatten im Vergleich zu den Kontrolltieren. Der p-Wert für die Anzahl an myelinisierten Axonen ergab ein $p<0,004$ und ist signifikant (Abbildung 16B, S. 44).
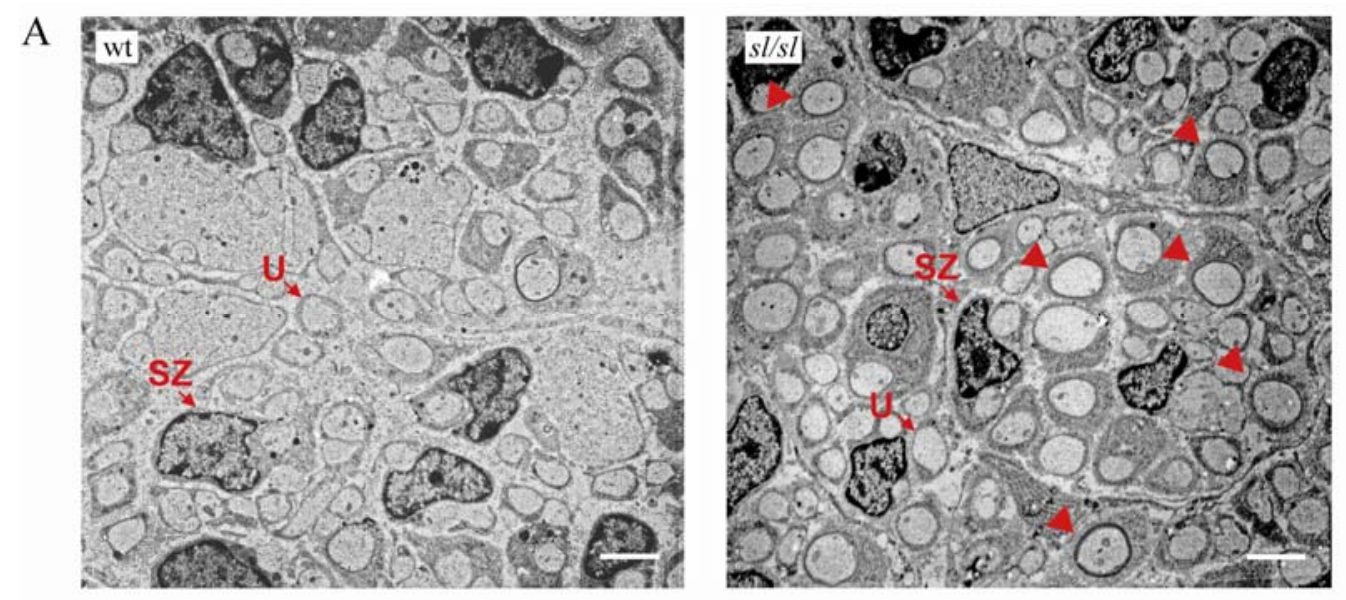


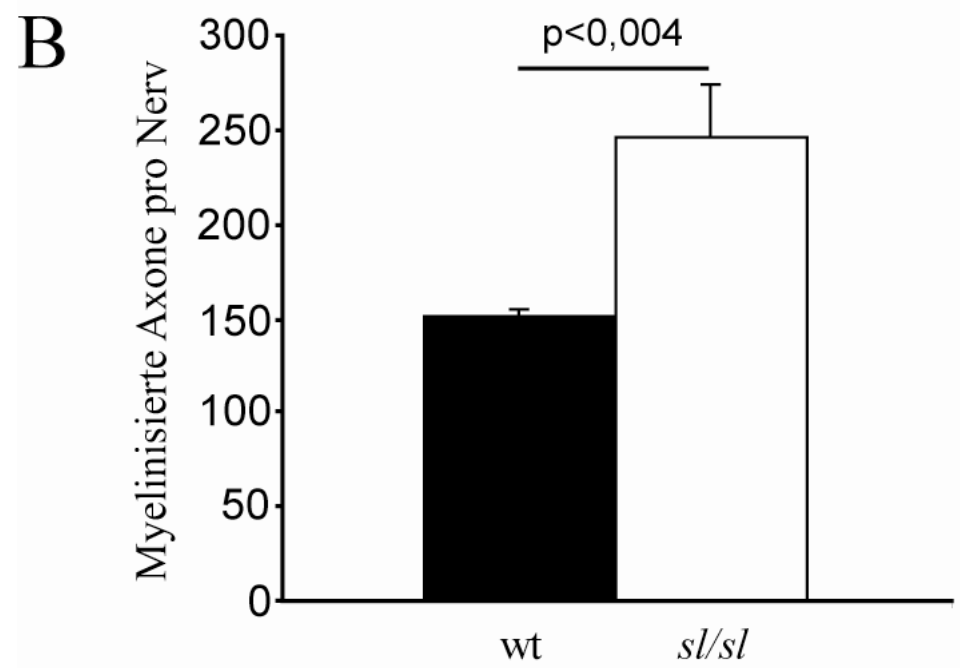

\section{Abbildung 16: Histologische Analyse der Myelinisierung bei P1}

A) Elektronenmikroskopische Aufnahmen vom Querschnitt des Ischiasnerven (P1). Es sind myelinisierte Axone (rote Pfeilspitzen), unmyelinisierte Axone (U) und Schwannzellen (SZ) zu erkennen. In den sl/sl-Ratten sind mehr myelinisierte Axone zu erkennen als in den Wildtyptieren (wt). B) Graphische Auswertung der quantifizierten P1 Daten. Die Auswertung der myelinisierten Axone pro Nerv ergab in den sl/sl-Ratten mehr myelinisierte Axone $(p<0,004)$ im Vergleich zu den Kontrolltieren (je $\mathrm{n}=3$ pro Genotyp). Maßstabsbalken: 2,5 $\mu \mathrm{m}$ (In Zusammenarbeit mit A. Matz, Max-Planck-Institut für Experimentelle Medizin Göttingen).

\subsubsection{Axonale Dichte im N. ischiadicus bei P1}

Es wurden zufällig 10 Ausschnitte in einer 3000 fachen Vergrößerung aus einem Querschnitt des $N$. ischiadicus von P1-Tieren von einem geblindeten Untersucher ausgewählt. Eine definierte Gesamtfläche von $0,0813 \mathrm{~mm}^{2}$ pro Nerv wurde untersucht. Für beide Tiergruppen, den sl/sl-Tieren sowie den Wildtyptieren, wurde die Anzahl der Axone gezählt und die Dichte pro Nerv bestimmt. Dabei konnte kein Unterschied zwischen den $\mathrm{sl} / \mathrm{sl}$-Tieren $(\mathrm{n}=3)$ und den Wildtyptieren ( $\mathrm{n}=3$ ) festgestellt werden (Abbildung 17, S. 45).

Es ist somit bei P1 ein signifikanter Unterschied in der Anzahl myelinisierter Axone nachweisbar, jedoch nicht in der axonalen Dichte. Dies lässt Rückschlüsse auf die Funktion des $\mathrm{ET}_{\mathrm{B}}$-Rezeptors als möglicher direkter oder indirekter Regulator bei der Initiierung der Myelinisierung zu. 


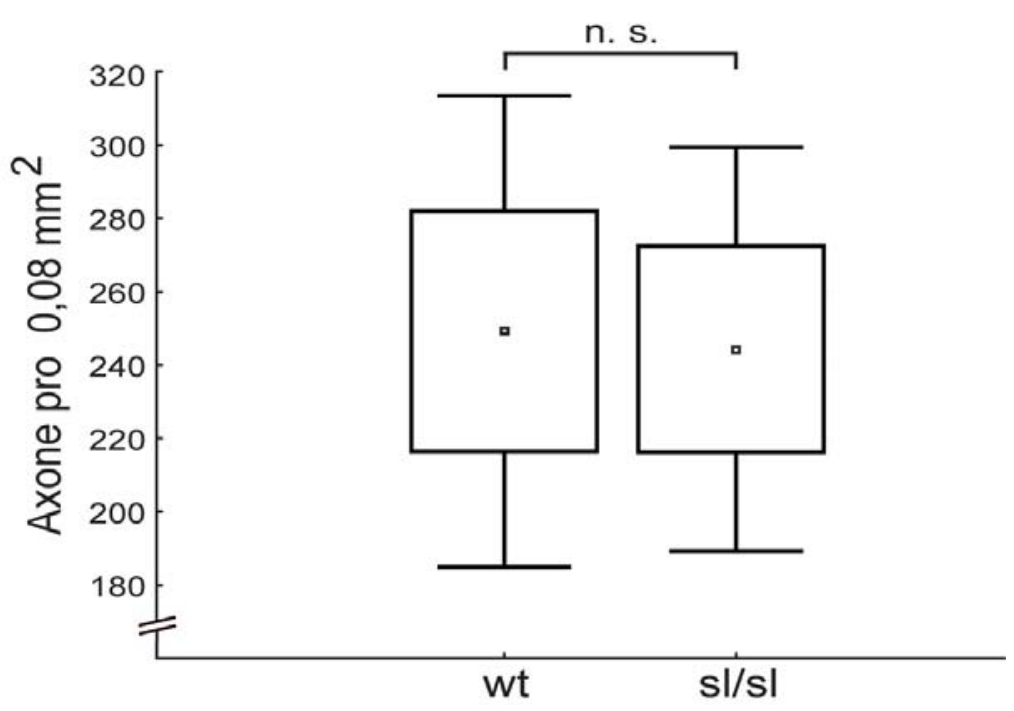

Abbildung 17: Axonale Dichte bei P1

Die Dichte der Axone auf einer definiert gemessenen Fläche unterscheidet sich zwischen den sl/sl-Tieren ( $\mathrm{n}=3$ ) und den Wildtyptieren $(\mathrm{n}=3)$ nicht.

\subsection{Histologische Analyse des Rückenmarks und der DRG's}

In den Querschnitten des N. ischiadicus zeigten sich eine Reihe von interessanten Beobachtungen, wovon eine die erhöhte Anzahl von myelinisierten Axonen in den Wildtyptieren im Vergleich zu den sl/sl-Tieren bei P1 war. Hier stellte sich die Frage, wie es dazu kommt, dass der Mangel des $\mathrm{ET}_{\mathrm{B}}$-Rezeptors eine erhöhte Anzahl von myelinisierten Axonen hervorruft. Die Differenzierung der Schwannzellen wird durch das Fehlen des $\mathrm{ET}_{\mathrm{B}}$ Rezeptors beschleunigt (Brennan et al. 2000). In dieser Arbeit konnte gezeigt werden, dass Axone im Altersstadium P6 hypomyelinisiert sind, wobei dies in P18 nicht mehr nachweisbar war (Abbildung 13, S. 41). Außerdem konnte eine reduzierte Gesamtanzahl von Zellkernen in P6 und P18 festgestellt werden (Abbildung 12, S. 40). Die beschleunigte Reifung von Schwannzellvorläufern bei $\mathrm{ET}_{\mathrm{B}}$-Rezeptor-defizienten Ratten kommt es möglicherweise $\mathrm{zu}$ einer früheren Myelinisierung bei P1, wobei am Postnataltag 6 eine Hypomyeliniserung festzustellen war. Folglich wäre es möglich, dass die $E_{\mathrm{B}}$-Rezeptor-Defizienz zu Entwicklungsstörungen von Schwannzellen führt. Zellsomata oder versorgende Schwannzellen von hypomyelinisierten Axonen können aufgrund der insuffizienten Myelinisierung und infolge mangelnder axonaler Unterstützung absterben. Um dies zu ergründen, wurden Apoptosefärbungen auf Querschnitten vom Rückenmark und den dorsalen spinalen Nervenwurzeln, den so genannten ,dorsal root ganglia“ (DRG's) durchgeführt. 
Außerdem erfolgte eine Quantifizierung auf lichtmikroskopischer Ebene von AlphaMotoneuronen ( $\alpha$-Motoneuronen) auf Rückenmarksquerschnitten sowie von DRGQuerschnitten. Im Vorderhorn des Rückenmarks befinden sich die $\alpha$-Motoneurone, deren efferente motorische Axone die Peripherie innervieren. In den DRG's hingegen findet man die Zellsomata von den afferenten sensorischen Axonen.

\subsubsection{TUNEL Färbungen DRG's und Rückenmark}

Um die entsprechenden Zellsomata von Axonen im N. ischiadicus zu treffen, wurde der Bereich der Intumescentia lumbalis gewählt, woraus bekanntermaßen der Plexus lumbalis und somit der N. ischiadicus, als größter peripherer Nerv seinen Ursprung nimmt. Dazu wurde von Tieren in allen 3 Altersstufen, jeweils von einem pro Genotyp und Altersstufe (P1, P6 und P18), auf der Höhe der Intumescentia lumbalis ca. ein $4 \mathrm{~mm}$ großer Zylinder Rückenmarsgewebe entnommen. Bei der Präparation wurden ebenfalls die lumbalen DRG's entnommen. Beide Präparatgruppen wurden in Paraffin eingebettet. Die angefertigten Präparate von Rückenmarksgewebe und DRG's wurden immunhistochemisch mit dem TUNEL-Kit Reaktionssystem (Boehringer Ingelheim) gefärbt. Dabei wurden auf den gleichen Objektträgern von einem Alters- und Genotyp-entsprechenden Tier beide Gewebeproben gefärbt. Es zeigte sich bei den Rückenmarksschnitten bei P1 kein Unterschied in der Anzahl der apoptotischen Zellen, wobei dies als normaler Entwicklungsvorgang anzusehen ist. Bei P6 und P18 konnten keine apoptotischen Zellen dargestellt werden. (Abbildung 18B, S. 47). Die DRG's zeigten auch in allen drei Altersstufen keine TUNEL positiven Zellen (Abbildung 18A, S. 47). Eine Positivkontrolle wurde nicht durchgeführt, womit ein negatives Ergebnis nicht verifizierbar ist. 
A TUNEL Färbung DRG's
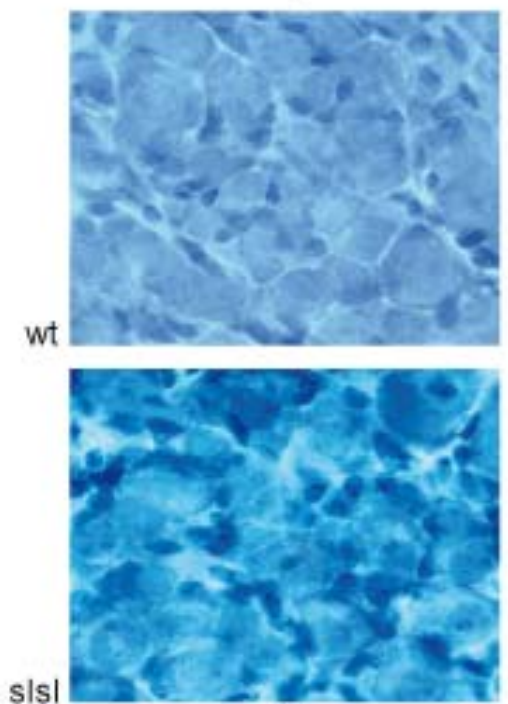

P1

B TUNEL Färbung Rūckenmark
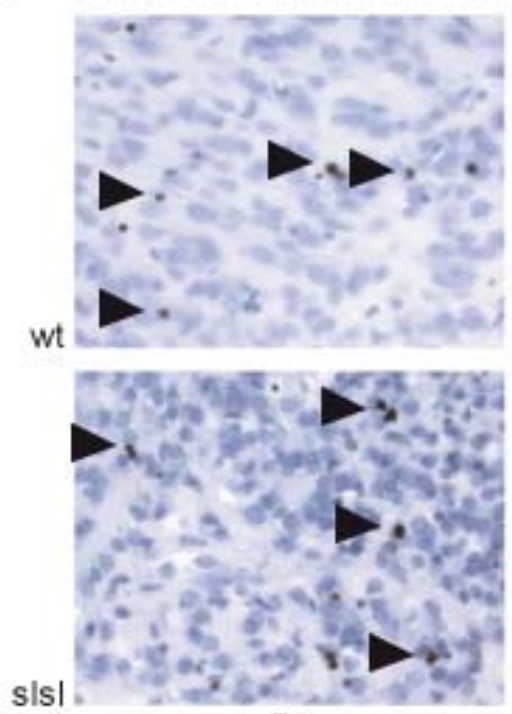

P1
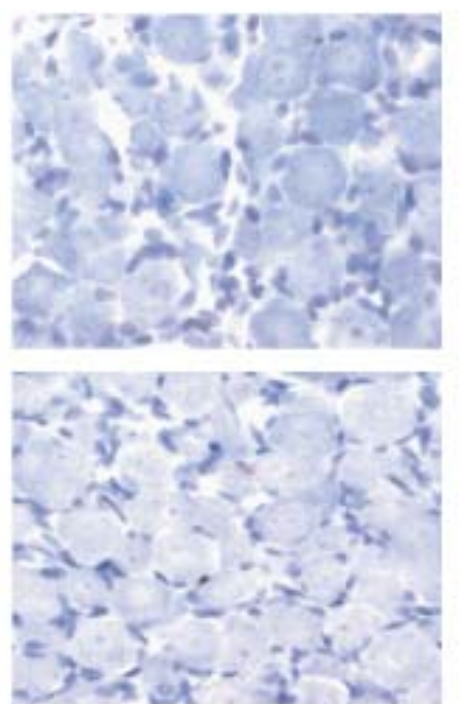

P6
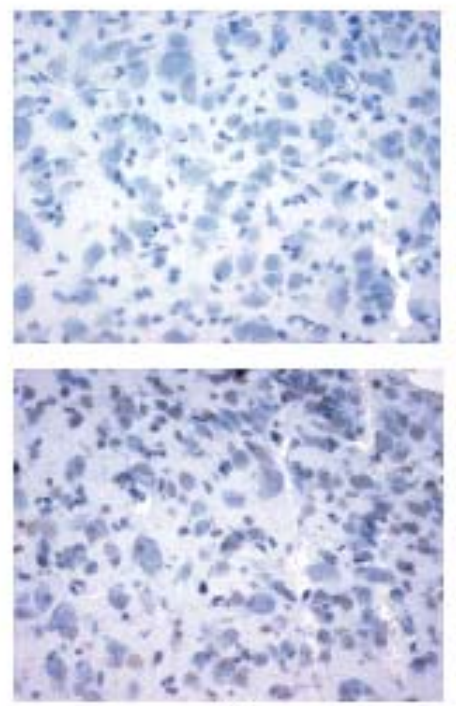

P6
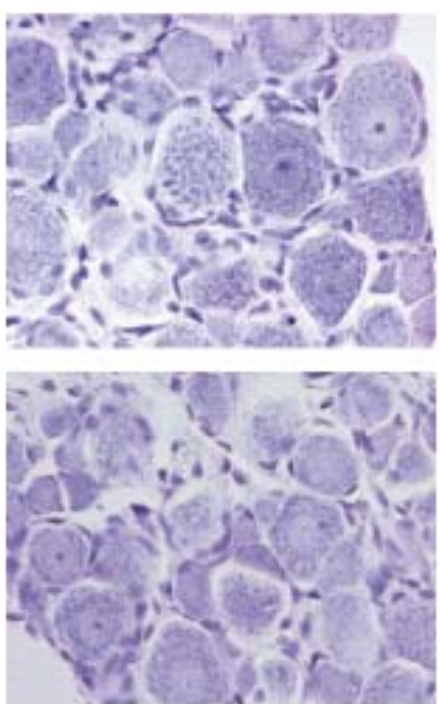

P18
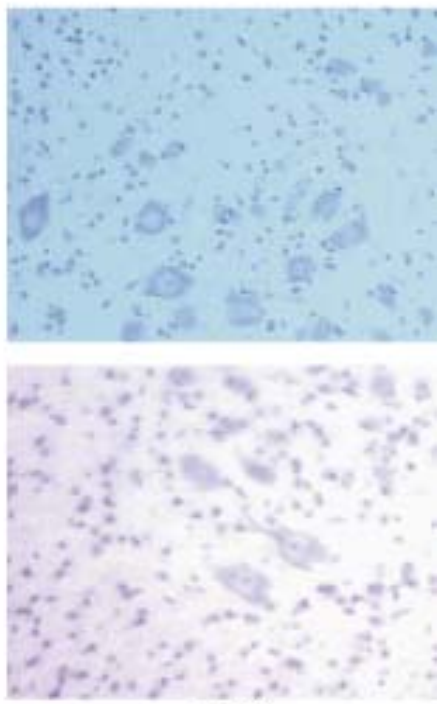

P18

\section{Abbildung 18: TUNEL Färbung DRG und Rückenmark}

A) Die obere Reihe zeigt jeweils Ausschnitte aus einem Querschnitt eines DRG's in 3 Altersstufen eines Wildtyptiers ( $\mathrm{n}=1)$, die untere Reihe die entsprechenden sl/sl-Tiere $(n=1)$. Es sind normale sensorische Neurone und keine TUNEL-positiven (braune Zellkerne) Zellen zu sehen. B) TUNEL Färbungen der Rückenmarksproben in 3 Altersstufen und in der oberen Reihe die Wildtypen und in der unteren Reihe die sl/sl-Tiere. Bei P1 sind in beiden Tiergruppen apoptotische/ TUNELpositive Zellen zu sehen (schwarze Pfeilköpfe). Bei P6 und P18 stellen sich keine TUNEL-positiven Zellen dar.

\subsubsection{Dichte der DRG-Neuronen}

Zur Differenzierung einer Affektion von motorischen oder sensorischen Axonen und deren entsprechende Zellsomata erfolgte die Bestimmung der Dichte der Neuronen in den einzelnen 
DRG's. Es wurden in jeweils 2 DRG's pro Tier, wobei hier erneut jeweils 3 Tiere pro Alter und Genotyp analysiert wurden, die Anzahl der Neuronen ausgezählt und im Verhältnis zur Gesamtfläche des einzelnen DRG's gesetzt. Dazu wurden DRG aus Paraformaldehyd und Glutaraldehyd fixierten Tieren entnommen und in Epon eingebettet. Daraus wurden Semidünnschnitte angefertigt, mit Methylenblau gefärbt und anschließend lichtmikroskopisch untersucht. Dabei fiel zunächst eine große Varianz bei den einzelnen Messungen auf. Insgesamt zeigten die sl/sl-Tiere $(n=3)$ im Vergleich zu den Wildtyptieren $(n=3)$ im Alter von P1 eine deutlich höhere neuronale Dichte in den DRG's, jedoch nicht signifikant. Bei P6 konnte eine unveränderte neuronale Dichte in den sl/sl-Tieren $(n=3)$ im Vergleich zu den alters entsprechenden Wildtypkontrollen $(n=3)$ dargestellt werden. Lediglich im Alter von P18 konnte eine deutlich höhere neuronale Dichte in den Wildtyptieren $(n=3)$ als in den s1/slTieren ( $n=3$ ) festgestellt werden. Die Ergebnisse bei P6 und P18 waren ebenfalls aufgrund der hohen Varianz statistisch nicht signifikant. Es fällt auf, dass bei den sl/sl-Tieren die neuronale Dichte der Zellsomata von sensorischen Axonen von P1 zu P18 kontinuierlich abnimmt. Im Vergleich dazu zeigen die Neurone der DRG's der Wildtyptiere bei P1 und P18 die gleichen Dichtewerte (Abbildung 19, S. 48).

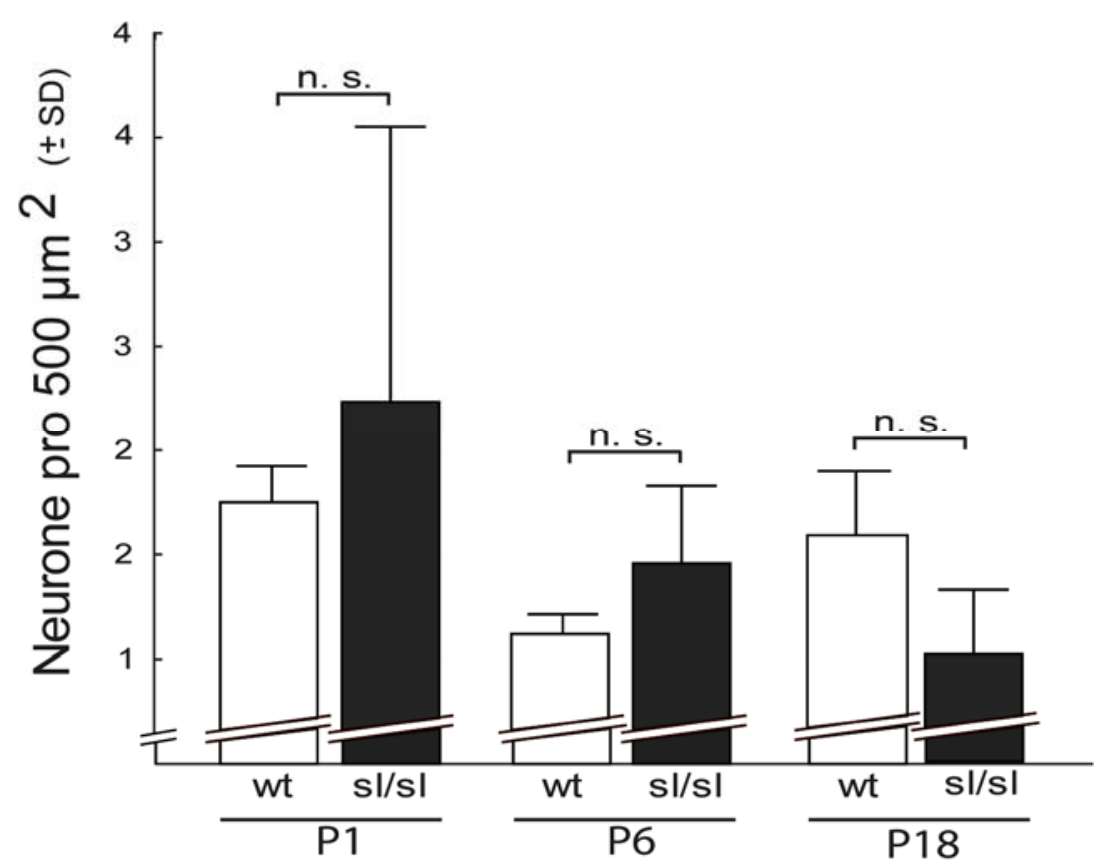

\section{Abbildung 19: Neuronale Dichte lumbaler DRG's}

Bei P1 und P6 zeigt sich eine etwas höhere neuronale Dichte bei den sl/sl-Tieren $(n=3)$ im Vergleich zu den Wildtyptieren $(n=3)$, jedoch nicht signifikant. Bei P18 sieht man eine höhere Dichte bei den Wildtyptieren $(n=3)$ als in den sl/sl-Tieren $(n=3)$. Es stellt sich eine kontinuierliche Dichteabnahme der sensorischen Neurone im Verlauf von P1 bis P18 in den sl/slTieren dar. 


\subsubsection{Anzahl von $\alpha$-Motoneuronen im Vorderhorn des Rückenmarks}

Nach der Quantifizierung der sensorischen Neurone in den DRG's wurde eine Quantifizierung der $\alpha$-Motoneurone im Vorderhorn des Rückmarks durchgeführt. Dazu wurden erneut 3 Tiere pro Genotyp und Altersstufe geopfert und mit PFA und Glutaraldehyd perfundiert und somit fixiert. Das Rückenmark wurde ab der Intumescentia lumbalis in einem ca. $4 \mathrm{~mm}$ großen Stück herausgetrennt und anschließend in Epon eingebettet. Danach wurden Semidünnschnitte angefertigt, mit Methylenblau angefärbt und lichtmikroskopisch untersucht. Die untersuchte Fläche betrug die Gesamtfläche oberhalb einer durch die Mitte des Zentralkanals gezogenen waagerechten Linie. Dabei wurden einzelne deutlich als $\alpha$ Motoneuron zu erkennende Zellen quantifiziert (Abbildung 20, S. 50). Die Auswertung ergab keine signifikanten Unterschiede.

A
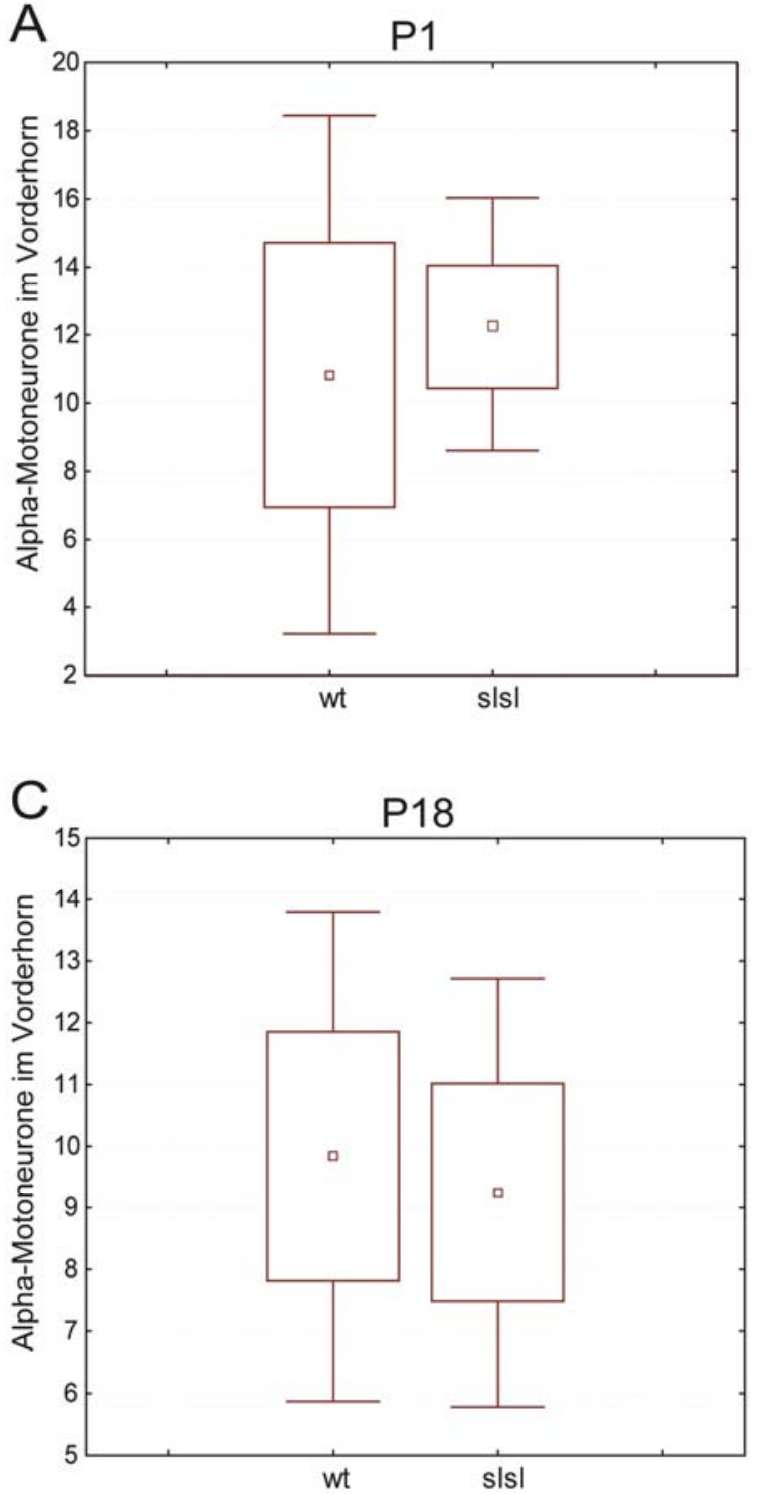

B

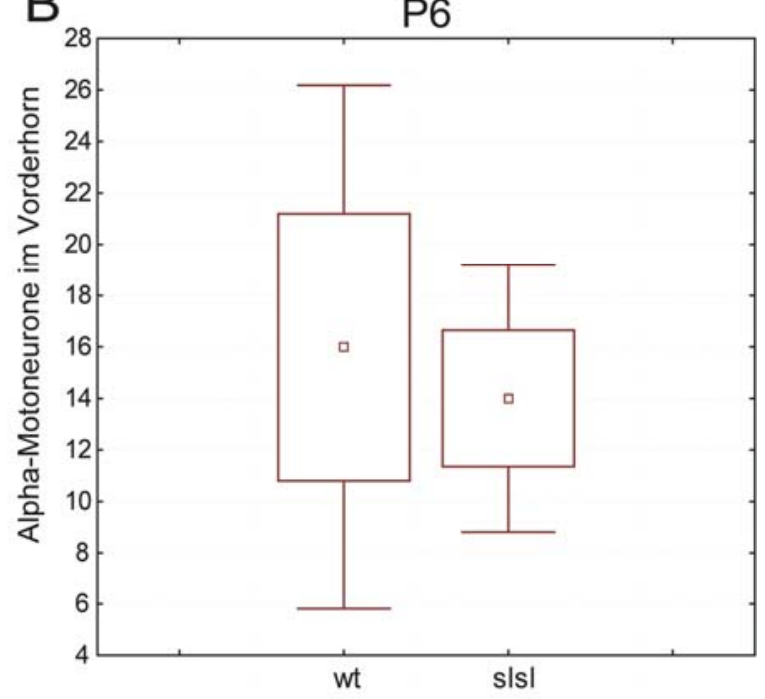




\section{Abbildung 20: Anzahl der $\alpha$-Motoneurone im Vorderhorn des Rückenmarks}

A) Die sl/sl-Tiere ( $n=3)$ weisen im Vergleich zu den Wildtypkontrollen ( $n=3)$ im Altersstadium P1 keinen signifikanten Unterschied in der Anzahl von $\alpha$-Motoneuronen auf. B) Hier verhält es sich bis auf eine diskret geringere Anzahl der $\alpha$ Motoneurone bei den sl/sl-Tieren ( $n=3)$ im Vergleich zu den Wildtyptieren ( $n=3)$ ähnlich wie bei P1. C) Auch hier zeigt sich zwischen beiden Gruppen (je $n=3$ ) kein signifikanter Unterschied. Trends sind in allen 3 Altersstadien nicht zu verzeichnen. 


\subsection{Zusammenfassung der Ergebnisse}

In der vorliegenden Arbeit wurde die Myelinisierung des peripheren Nervensystems bei $\mathrm{ET}_{\mathrm{B}^{-}}$ Rezeptor-defizienten Ratten in vivo untersucht. Vermutlich kommt es in Folge des Fehlens eines intakten $\mathrm{ET}_{\mathrm{B}}$-Rezeptors während der embryonalen und postnatalen Entwicklung des peripheren Nervensystems zunächst zu einer früheren Reifung von Schwannzellen aus deren Vorläuferzellen und somit $\mathrm{zu}$ vermehrt auftretenden myelinisierten Axonen bei P1. Möglicherweise kommt es dann durch eine frühere Reifung der Schwannzellen zu einem Verlust der Migrationsfähigkeit.

Die Analyse der Myelinisierung im weiteren Verlauf ergab eine Hypomyelinisierung bei sl/slTieren im Vergleich zu den Wildtyptieren in der Altersstufe P6, jedoch eine normale Myelindicke bei beiden P18 Gruppen. Weiterhin zeigte sich eine reduzierte Anzahl myelinisierter Axone in den sl/sl-Tieren verglichen mit den altersentsprechenden Wildtyptieren bei P6 und P18. Auffällig war bei der P6-Analyse, dass insbesondere kleine Axone unter 2-4 $4 \mathrm{~m}$ vermehrt von der Hypomyelinisierung betroffen waren. Diese kleinen Axone entsprechen im PNS den sensorischen Axonen. Entsprechend dazu konnte zwar immunhistochemisch keine Apoptose in den dorsalen spinalen Nervenwurzeln der sl/sl-Tiere gezeigt werden, jedoch war ein abnehmender Trend in der Dichte von sensorischen Neuronen der sl/sl-Ratten von P1 bis P18 zu verzeichnen. Veränderungen im Bereich der $\alpha$ Motoneurone zeigten sich nicht. Insgesamt sprechen diese Ergebnisse für eine Affektion der sensorischen Axone und möglicherweise auch deren Zellsomata in den dorsalen spinalen Nervenwurzeln durch den $\mathrm{ET}_{\mathrm{B}}$-Rezeptor-Mangel. 


\section{Diskussion}

In jüngerer Zeit wurde mehrfach nachgewiesen, dass das ET $_{\mathrm{B}}$-Rezeptor/ET-Signalsystem eine wichtige Rolle in der Entwicklung der Neuralleiste und deren Zellabkömmlingen spielt. Die wichtigsten Zelllinien, die daraus entstehen und folglich eine Notwendigkeit eines intakten $\mathrm{ET}_{\mathrm{B}}$-Rezeptor/ET-Signalsystems zeigen sind Melanozyten, enterischen Ganglienzellen sowie Schwannzellen (Baynash et al. 1994; Hosoda et al. 1994; Brennan et al. 2002). Defekte im $\mathrm{ET}_{\mathrm{B}}$-Rezeptor/ET-Signalsystem und der gesamte Verlust dieses Signalweges führen, wie bereits oben erwähnt, zu Entwicklungsdefekten in den enterischen Ganglien und Melanozyten (Baynash et al. 1994; Hosoda et al. 1994). Es kommt bei diesen Tieren zu einem weißen Fell, was auf den Mangel an Melanozyten zurückzuführen ist (McCabe et al. 1990; Gariepy et al. 1996). Außerdem entwickeln diese Ratten mangels intrinsischer Ganglienzellen im distalen gastrointestinalen Trakt ein toxisches Megacolon, das nach etwa 3 Wochen durch eine Ileussymptomatik zur Letalität führt. Der intestinale Defekt in den sl/sl-Ratten dient als ein Tiermodell für den menschlichen Morbus Hirschsprung (Ceccherini et al. 1995).

Während der embryonalen Entwicklung wirken Endotheline (ET) über den $\mathrm{ET}_{\mathrm{B}}$-Rezeptor auf den Entwicklungsschritt einer Schwannzellvorläuferzelle zu einer unreifen Schwannzelle. Das $\mathrm{ET}_{\mathrm{B}}$-Rezeptor/ET-Signalsystem verlangsamt die Schwannzelldifferenzierung und wirkt zu diesem embryonalen Zeitpunkt antagonistisch $\mathrm{zu}$ Neuregulin-1 (NRG-1) auf den Reifungseffekt (Brennan et al. 2000). Der Einfluss des ET $_{\mathrm{B}}$-Rezeptor/ET-Signalsystems auf die postnatale Entwicklung hinsichtlich des peripheren Nervensystems hingegen ist nicht bekannt. Im Rahmen der vorliegenden Arbeit sollten anhand eines Tiermodells mögliche Effekte des ET $_{\mathrm{B}}$-Rezeptor/ET-Signalsystems auf die postnatale Myelinisierung im PNS untersucht werden. Die Analyse erfolgte mit Hilfe der natürlich vorkommenden $\mathrm{ET}_{\mathrm{B}^{-}}$ Rezeptor-defizienten, so genannten ,spotting lethal“-Ratten (sl/sl). Die Myelinisierung wurde zur Erfassung einer Entwicklung an drei verschiedenen Zeitpunkten (Postnataltag 1, 6 und 18) analysiert. Diese 3 Zeitpunkte stellen einen frühen, mittleren und einen Endzeitpunkt der Myelinisierung in Ratten dar. Die Myelinisierung ET $_{\mathrm{B}}$-Rezeptor-defizienter Ratten im PNS sollte im Vergleich zu Wildtyptieren auf histologischer und morphologischer Ebene näher untersucht werden. 


\subsection{Effekte des $\mathbf{E T}_{B}$-Rezeptor/ET-Signalsystems auf die Myelinisierung im peripheren Nervensystem (PNS)}

Die Myelinisierung von Axonen im peripheren Nervensystem beginnt mit der Geburt. Die morphologischen Veränderungen in einem Nerven sind von der genauen transkriptionellen Kontrolle bestimmter Gene abhängig. Veränderungen der zeitlichen Abfolge verschiedener Signale oder verringerte Expression eines einzelnen Gens können starke Veränderungen der Myelinisierung hervorrufen. Ein essentieller Faktor für die Myelindicke im PNS ist Neuregulin-1 (NRG-1) Typ III (Michailov et al. 2004). Auch die Initiierung der Myelinisierung ist abhängig von dieser Isoform (Taveggia et al. 2005). Die Menge von axonal präsentierten NRG-1 Typ III entscheidet, ob ein Axon myelinisiert wird oder unmyelinisiert in einem Remakbündel verbleibt (Taveggia et al. 2005). Die fehlende ET $_{B}$-Rezeptor/ETSignaltransduktion bewirkt eine verfrühte Entwicklung der Schwannzellvorläuferzellen zu unreifen Schwannzellen in peripheren Nerven von sl/sl-Ratten bei E16, so dass davon auszugehen ist, dass dieses System einen wesentlichen Einfluss auf die Terminierung der Schwannzelldifferenzierung hat (Brennan et al. 2000).

\subsubsection{Erhöhte Anzahl myelinisierter Axone im Ischiasnerven der sl/sl- Ratten bei P1}

Elektronenmikroskopische Analysen im Ischiasnerven von sl/sl-Ratten bei P1 zeigten eine signifikant erhöhte Anzahl myelinisierter Axone im Vergleich zu Kontrolltieren (Abbildung 11, S. 39). Erste Analysen an P1 Ratten aus unterschiedlichen Würfen wiesen eine hohe Varianz der Anzahl myelinisierter Axone auch innerhalb einer Gruppe auf (zwischen 50 und 300 myelinisierte Axone). Um die Versuchsbedingungen möglichst gleich zu halten wurden die Analysen daher zu diesem Zeitpunkt an Ratten des gleichen Wurfs durchgeführt. Trotz dessen können zeitliche Unterschiede in einem Wurf vom erst bis zum letzt geborenen Tier Auswirkungen auf den Myelinisierungsgrad haben. Die Bestimmung der axonalen Dichte bei P1, wobei auf einer definierten Fläche des Ischiasnerven alle Axone ausgezählt worden, zeigte keinen Unterschied zwischen den sl/sl-Ratten und Wildtyptieren. $\mathrm{Zu}$ Beginn der Myelinisierung wird möglicherweise zur Kompensation der ET $_{\mathrm{B}}$-Rezeptor-Defizienz der Ligand ET-3 hoch reguliert. Ein axonaler Verlust kann somit evtl. noch verhindert werden. Aufgrund der embryonal beschleunigten Entwicklung der Schwannzellvorläuferzellen in Vorläufer myelinbildender Schwannzellen im PNS von sl/sl-Ratten, ist davon auszugehen, dass auch der Beginn der Myelinisierung zeitlich verschoben ist. Ein Pilotexperiment zur 
Untersuchung des Myelinisierungsbeginns bei E20,5 und P0 zeigte allerdings keine Unterschiede zwischen $\mathrm{ET}_{\mathrm{B}}$-Rezeptor defizienten und Wildtyptieren im untersuchten Bereich der Ischiasnerven (Brinkmann und Sereda et al. unpublizierte Daten, Max-Planck-Institut für Experimentelle Medizin Göttingen 2009). Somit scheint zwar nicht die Anzahl unreifer Schwannzellen, jedoch das frühere Vorhandensein im peripheren Nerven der bestimmende Faktor für den Beginn der Myelinisierung zu sein.

Die erhöhte Anzahl myelinisierter Axone im PNS der sl/sl-Ratten könnte somit auf die bei Myelinisierungsbeginn fehlende $\mathrm{ET}_{\mathrm{B}}$-Rezeptor/ET-Signaltransduktion in sl/sl-Ratten zurückzuführen sein. Das Zahlenverhältnis von bereits unreifen Schwannzellen zu Schwannzellvorläuferzellen kann im Vergleich zu Kontrolltieren verschoben sein. Solch ein ungleiches Verhältnis der verschiedenen Schwannzellstadien ist in sl/sl-Ratten während der Embryonalentwicklung (E16) bereits beschrieben worden (Brennan et al. 2000). Wie bereits oben erläutert, ist das NRG-1 Typ III für die Dicke des Myelins und die Initiierung der Myelinisierung verantwortlich (Michailov et al. 2004; Taveggia et al. 2005). Zu Beginn der Myelinisierung bei P1 könnte somit eine mögliche erhöhte Zahl unreifer Schwannzellen bereits für das NRG-1-Typ-III-Signal empfänglich sein und mit der Myelinisierung beginnen. Dies würde die höhere Zahl myelinisierter Axone in mutanten Tieren bei P1 erklären. Eine Veränderung der axonalen Dichte wäre demnach bei fehlender $E_{\mathrm{B}}$-Rezeptor/ETSignaltransduktion nicht $\mathrm{zu}$ erwarten und ist auch nicht beobachtet worden. Weitere Experimente zur Bestätigung dieser Theorie könnten immunhistochemische Färbungen bei P0 und E20,5 darstellen, die das Zahlenverhältnis von Schwannzellvorläuferzellen zu unreifen Schwannzellen durch spezifische Markerproteine näher beschreiben.

\subsubsection{Verminderte Anzahl von myelinisierten Axonen und Schwannzellen in sl/sl-Ratten bei P6 und P18}

Im Gegensatz zu den Beobachtungen in der Altersstufe P1 konnte bei den P6- und P18-Tieren eine signifikant verminderte Gesamtanzahl von myelinisierten Axonen im Gesamtquerschnitt von Ischiasnerven in den sl/sl-Ratten festgestellt werden (Abbildung 11, S. 39).

Es wird hypothetisiert, dass durch die verfrühte Reifung von Schwannzellen im Ischiasnerven der sl/sl-Ratten es zu einer früheren Myelinisierung bei P1 kommt. Möglicherweise kommt es jedoch auch zu einer früheren Beendigung der Myelinisierung bei den sl/sl-Ratten, da die Myelinisierung einem festgelegten Zeitplan folgt.

Eine Quantifizierung aller Zellkerne im Gesamtquerschnitt eines Ischiasnerven bei P1 und P6 auf lichtmikroskopischer Ebene zeigte keinen Unterschied in der Altersstufe P1, jedoch einen 
deutlichen Unterschied in der Altersstufe P6 (Abbildung 12, S. 40). Da es bei Semidünnschnitten auf lichtmikroskopischer Ebene nicht möglich ist, suffizient zwischen Schwannzellen und anderen Zellen im Nerven, wie z.B. einfache Fibroblasten zu unterscheiden, wurden hier die Gesamtanzahl aller Zellkerne gezählt. Es ist davon auszugehen, dass es sich dabei um größtenteils Schwannzellen handelt und dass der Quantifizierungsfehler durch andere Zellen bei der Kontrollgruppe gleichermaßen gegeben ist. In den Ischiasnerven der sl/sl-Ratten bei P6 und konnte eine deutliche, jedoch aufgrund einer hohen Varianz nicht signifikante Reduktion von Gesamtzellen festgestellt werden (Abbildung 12, S. 40). In 18 Tage alten sl/sl-Ratten wurde eine signifikante Reduktion der Schwannzellen im Vergleich $\mathrm{zu}$ Kontrolltieren nachgewiesen (Abbildung 12, S. 40). Zusammen genommen zeigte sich eine vermehrte Anzahl von myelinisierten Axonen in sl/slTieren bei P1, die sich in den späteren Stadien P6 und P18 vermindert darstellte. Auch die Anzahl der Gesamtzellen zeigte sich bei P6 und P18 in den s1/sl-Tieren deutlich reduziert im Vergleich zu den Wildtyptieren.

Die Frage, warum eine verfrühte und möglicherweise insuffiziente Myelinisierung später zu einem Mangel an myelinisierten Axonen, Schwannzellen und auch Hypomyelinisierung (s.u.) führt, ist am ehesten auf die Unfähigkeit von $\mathrm{ET}_{\mathrm{B}}$-Rezeptor-defizienten Schwannzellen das neuronale trophische Endothelin-Signal zu verarbeiten, zurückzuführen. Möglicherweise kann die fehlende $\mathrm{ET}_{\mathrm{B}}$-Rezeptor/ET-Signaltransduktion durch eine Hochregulation der EndothelinExpression temporär kompensiert werden, so dass der Hauptanteil der Axone initial adäquat myelinisiert werden. Jene Axone, die hypomyelinisiert sind, haben eine gestörte Axon-GliaKommunikation. Die versorgende Schwannzelle von hypomyelinisierten Axonen kann durch den permanenten Verlust des $\mathrm{ET}_{\mathrm{B}}$-Rezeptor/ET-Signalsystem und somit auch einer gestörten Axon-Glia-Kommunikation apoptotisch werden. In folge dessen können dann auch die entsprechenden Axone absterben.

\subsubsection{Hypomyelinisierung kleiner Axone in sl/sl-Ratten bei P6}

Die postnatale Entwicklung myelinisierender und nicht-myelinisierender Schwannzellen verläuft über einen Zeitraum von einigen Wochen (Mirsky et al. 2002). Axone mit einem Durchmesser $>1 \mu \mathrm{m}$ werden aus Remakbündeln aussortiert und myelinisiert. Die kleinkalibrigen Axone $(<1 \mu \mathrm{m})$ verbleiben in Remakbündel, die mit einer nichtmyelinisierenden Schwannzelle assoziiert sind. Die Analyse der Ischiasnerven am Postnataltag 6 (P6) stellt einen mittleren Zeitpunkt während des Myelinsierungsprozesses dar. Die Untersuchung der Myelindicke wurde über das "g-ratio" (Verhältnis des 
Axondurchmessers zum Gesamtdurchmesser der myelinisierten Faser) ermittelt. In adulten Ratten liegt das "g-ratio" bei 0,66-0,68. Die Erhöhung von diesem Wert zeigt eine Hypo-, die Verringerung eine Hypermyelinisierung an. Bei jüngeren Tieren fällt das "g-ratio" höher aus, da die Myelinisierung noch nicht abgeschlossen und die endgültige Myelindicke also noch nicht erreicht ist. Die Analyse des "g-ratio" bei P6 ergab eine Hypomyelinisierung, insbesondere kleinkalibriger Axone in sl/sl-Tieren $(\mathrm{p}<0,05)$ im Vergleich zu Kontrolltieren (Abbildung 13 und Abbildung 14, S. 41 und S. 42). Interessanterweise konnte zwischen den sl/sl-Ratten und den Wildtyptieren bei P18 kein Unterschied in der Myelindicke festgestellt werden (Abbildung 13 und Abbildung 15, S. 41 und S.42).

Die Myelindicke von myelinisierten Axonen im PNS wird direkt von axonal präsentiertem Neuregulin-1 Typ III (NRG-1) reguliert. Während in Tieren, die heterozygot für NRG-1 Typ III sind, eine Hypomyelinisierung im PNS gezeigt wurde, waren Axone von transgenen Tieren mit erhöhter NRG-1-Typ-III-Expression hypermyelinisiert (Michailov et al. 2004). Diesbezüglich haben Expressionsanalysen von NRG-1 Typ III in den DRG's und den Ischiasnerven keine Veränderungen zwischen den Wildtyptieren und den sl/sl-Ratten gezeigt (Brinkmann und Sereda et al. unpublizierte Daten, Max-Planck-Institut für Experimentelle Medizin Göttingen 2009). Dies führt $\mathrm{zu}$ der Erkenntnis, dass in den sl/sl-Tieren die Hypomyelinisierung bei P6 nicht durch ein vermindertes Vorhandensein von NRG-1 Typ III bedingt wird.

Die Analyse der Myelinisierung im PNS ergab in sl/sl-Ratten bei P6 eine selektive Hypomyelinisierung kleinkalibriger Axone (Abbildung 14, S. 42). Zusätzlich war die Anzahl myelinisierter Axone bei P6 und P18 verringert in mutanten Tieren (Abbildung 11, S. 39). Eine mögliche Erklärung dieser Ergebnisse ergibt sich aus einer wahrscheinlichen Interaktion des ET $_{\mathrm{B}}$-Rezeptor/ET-Signalsystems und des Neurotrophin-3 (NT-3) Regulationssystems. NT-3 stellt einen wichtigen Faktor selektiv für das Überleben von sensorischen Neuronen dar. Diese Rolle von NT-3 konnte in Knockout Mäusen für NT-3 gezeigt werden (Ernfors et al. 1994). Die Reduktion der Expression von diesem Faktor aufgrund von NT-3 Heterozygotie führt zu einer Hypomyelinisierung der Axone in peripheren Nerven (Woolley et al. 2008). In eigenen Expressionsanalysen zeigte sich hinsichtlich dieser Theorie eine verminderte NT-3 Expression in sl/sl-Ratten (Brinkmann und Sereda et al. unpublizierte Daten, Max-PlanckInstitut für Experimentelle Medizin Göttingen 2009). Folgend wird hypothetisiert, dass in ET $_{\mathrm{B}}$-Rezeptor-defizienten Ratten auch die Interaktion mit dem NT-3 gestört ist und somit zu einer selektiven Hypomyelinisierung myelinisierter sensorischer Axone bei P6 führt. In sl/slRatten wurde gezeigt, dass die Hypomyelinisierung bei P6 hauptsächlich Axone $<4 \mu \mathrm{m}$ 
betrifft. Analysen an wildtypischen sensorischen Nerven zeigen einen maximalen Axondurchmesser von 4,5 $\mu \mathrm{m}$ für sensorische myelinisierte Axone (Zwick et al. 2002). Daraus kann geschlossen werden, dass eine reduzierte NT-3 Expression in sl/sl-Ratten zu einer Hypomyelinisierung von sensorischen Axonen führt. Damit einhergehend ist der beobachtete Verlust von sensorischen unmyelinisierten Axonen bei P18 zu sehen (Brinkmann und Sereda et al. unpublizierte Daten, Max-Planck-Institut für Experimentelle Medizin Göttingen 2009). Weiterhin wird vermutet, dass die Reduktion myelinisierter Axone der sl/slRatten bei P18 im Ischiasnerven einen Verlust von sensorischen myelinisierten Axonen aufgrund der verringerten NT-3-mRNA-Expression darstellt. Die bereits hypomyelinisierten Axone bei P6 könnten durch Absterben die Reduktion der myelinisierten Axone im Ischiasnerven bei P18 bedingen. Weiterhin sprechen die Ergebnisse aus DHB- $\mathrm{ET}_{\mathrm{B}}$-Rezeptor sl/sl-Ratten für einen solchen Verlust von sensorischen Axonen. Diese transgenen sl/sl-Ratten exprimieren den $\mathrm{ET}_{\mathrm{B}}$-Rezeptor unter der Kontrolle eines menschlichen Dopamin- $\beta$ Hydroxylase Promotors (Gariepy et al. 1998). Die sl/sl-Ratten stellen einen Knockout für den $\mathrm{ET}_{\mathrm{B}}$-Rezeptor in allen Zellen des Organismus dar. Zur Verhinderung des toxischen Megacolons wurde durch ein transgenes Expressionskonstrukt die Expression des $\mathrm{ET}_{\mathrm{B}^{-}}$ Rezeptors in enterischen Ganglienzellen versucht wiederherzustellen. Aufgrund von Expressionsanalysen, die nur eine $\sim 30-35 \%$ ige Reduktion der ET $_{\mathrm{B}}$-Rezeptor-mRNAExpression im Ischiasnerven zeigen, ist anzunehmen, dass der Rezeptor auch auf Schwannzellen unter der Kontrolle des DHB-Promotors wieder exprimiert wird. Die Tiere zeigen allerdings bei einem Alter von 5 Monaten eine mechanische Hyperalgesie und eine taktile Allodynie (Berti-Matterra et al. 2006). Diese veränderte Schmerzempfindlichkeit könnte durch den Verlust von sensorischen Axonen hervorgerufen werden und würde die Ergebnisse aus den sl/sl-Ratten bestärken. Es wurde allerdings keine histologische Analyse in diesen DHB- $\mathrm{ET}_{\mathrm{B}}$-Rezeptor sl/sl-Ratten durchgeführt.

Hingegen scheinen Axonen mit einem größeren Axondurchmesser nicht durch die fehlende $\mathrm{ET}_{\mathrm{B}}$-Rezeptor/ET-Signaltransduktion auf Schwannzellen beeinflusst zu werden. Die Analyse der "g-ratio" Werte ergab keinen Unterschied der Myelindicke bei P18 zwischen sl/sl-Ratten und Wildtyptieren. Der analysierte Ischiasnerv enthält sowohl sensorische wie motorische Axone und stellt somit einen gemischten Nerv dar. Das legt die Vermutung nahe, dass die in die Analyse eingeflossenen normal myelinisierten Axone zu der Population von motorischen Axonen zählen. Motorische Axone werden durch verringerte NT-3-Expression nicht beeinflusst, da NT-3 selektiv für das Überleben sensorischer Axone wichtig ist (Ernfors et al. 1994). 
Zusammenfassend zeigen die Daten aus den sl/sl-Ratten und der bekannten Literatur in Verbindung mit den in-vitro-Analysen von primären Schwannzellen (Brinkmann und Sereda et al. unpublizierte Daten, Max-Planck-Institut für Experimentelle Medizin Göttingen 2009) eine mögliche Interaktion des $\mathrm{ET}_{\mathrm{B}}$-Rezeptor/ET-Signalsystems mit dem NT-3 als potentielle Ursache der Hypomyelinisierung von kleinen Axonen. Die verringerte Anzahl von myelinisierten Axonen in sl/sl-Ratten ist vermutlich auf das Absterben der versorgenden Schwannzellen oder Neurone zurückzuführen.

Um die Funktion des ET $_{\mathrm{B}}$-Rezeptor/ET-Signalsystems im PNS in Verbindung mit der NT-3mRNA-Expression näher zu charakterisieren, sollte in sl/sl-Ratten ein möglicher Verlust von sensiblen Neuronen bei P6 und P18 untersucht werden. Das Absterben von Schwannzellen oder von Neuronen muss ebenfalls genauer durch immunhistochemische Färbungen gezeigt werden.

\subsection{Wirkung des $\mathbf{E T}_{\mathrm{B}}$-Rezeptors auf Neurone von peripheren Axonen}

Die immunhistochemischen sowie auch die morphologischen Untersuchungen des Rückenmarks haben keine Veränderungen hinsichtlich der Anzahl der $\alpha$-Motoneurone zwischen den sl/sl-Ratten und Wildtyptieren gezeigt. Die Apoptosefärbungen konnten keinerlei erhöhte Apoptose Aktivität im Bereich der Vorderhörner des Rückenmarks zeigen (Abbildung 18B, S. 47). Auch die Quantifizierung durch Auszählung des gesamten Querschnittes eines Rückenmarkabschnittes konnte in allen 3 Altersstufen keine Veränderungen in der Anzahl der $\alpha$-Motoneurone aufweisen (Abbildung 20, S. 50). Diese sowie auch die Tatsache, dass in den sl/sl-Ratten bei P6 kleine Axone vorwiegend hypomyelinisiert waren, spricht wie bereits erläutert für die Notwendigkeit des ETBRezeptor/ET-Signalsystems für die Myelinisierung von sensorischen Axonen.

Ähnlich den Ergebnissen der Apoptosefärbungen auf Rückenmarksquerschnitten zeigte sich in den Apoptosefärbungen der DRG-Querschnitte keinerlei Apoptoseaktivität in allen Altersstufen und Genotypen (Abbildung 18, S. 47). In den Quantifizierungsversuchen zeigte sich zwar keine signifikante, jedoch eine stetige Abnahme der Dichte von DRG-Neuronen in den sl/sl-Tieren im Verlauf der 3 Altersstufen. In P1 war die Dichte der DRG-Neurone im Vergleich zu den Wildtyptieren in etwa gleich, wobei sie bei P6 und schließlich auch bei P18 deutlich vermindert (Abbildung 19, S. 48). In den Wildtyptieren hingegen war dies nicht zu 
beobachten. Auch diese Ergebnisse deuten daraufhin, dass das ETB-Rezeptor/ETSignalsystems für die Myelinisierung von sensorischen Axonen und möglicherweise auch für das Überleben von entsprechenden sensorischen Neuronen in den DRG's wichtig ist. 


\section{Zusammenfassung}

Pluripotente Stammzellen der Neuralleiste (neural crest stem cells) differenzieren sich in der embryonalen Entwicklung zu Melanozyten, enterischen Ganglien, kraniofaszialen Knochenund Knorpelzellen sowie Zellen des peripheren Nervensystems (Ayer-Le Lievre und Le Douarin 1982). Der Endothelin-B-Rezeptor ( $\mathrm{ET}_{\mathrm{B}}$-Rezeptor) stellt einen wichtigen Faktor für die Entwicklung der Neuralleistenzellen dar. Bei Ratten führt ein Defekt des $\mathrm{ET}_{\mathrm{B}^{-}}$ Rezeptorgens zu einem Entwicklungsdefekt von Neuralleistenzellen. Folglich kommt es zu einem Melanozytendefekt, einhergehend mit einem weißen Fell und zur kongenitalen Aganglionose des kaudalen Darmabschnitts, dem so genannten toxischen Megacolon. Diese natürlich vorkommenden $\mathrm{ET}_{\mathrm{B}}$-Rezeptor-defizienten mutanten Tiere werden als „spotting lethal"-Ratten ( $\mathrm{sl} / \mathrm{sl}$ ) bezeichnet und dienen als Modellsystem für den menschlichen Morbus Hirschsprung.

Da Schwannzellen ebenfalls Abkömmlinge der Neuralleiste sind, wurde im Rahmen dieser Arbeit anhand der sl/sl-Ratten eine mögliche Wirkung des ET $_{\mathrm{B}}$-Rezeptor/ET-Signalsystems auf die postnatale Myelinisierung des PNS in vivo untersucht.

Am Postnataltag 1 (P1) wurde eine erhöhte Anzahl von myelinisierten Axonen in sl/sl-Ratten im Vergleich zu Wildtyptieren festgestellt. Dies ist am ehesten auf eine verfrühte Myelinisierung durch eine beschleunigte Schwannzelldifferenzierung zurückzuführen. Weiterhin konnte eine Hypomyelinisierung von Axonen, insbesondere von kleinkalibrigen (Axondurchmesser $<4 \mu \mathrm{m}$ ), im Ischiasnerven der sl/sl-Ratten in der Altersstufe P6 festgestellt werden. Sowohl in der Altersstufe P6 als auch in P18 zeigte sich eine verringerte Anzahl von myelinisierten Axonen. Zusätzlich war die Anzahl von Schwannzellen bei P6 und P18 in sl/slRatten reduziert. Eine Apoptose konnte weder im Bereich der $\alpha$-Motoneurone noch in den dorsalen spinalen Nervenwurzeln (dorsal root ganglia; DRG's) festgestellt werden. Auffällig war eine im Verlauf der 3 Altersstufen abnehmende Dichte von sensorischen Neuronen in den DRG's.

Zusammengefasst konnte gezeigt werden, dass sensorische Axone und deren Zellsomata im PNS in ihrer Entwicklung auf das Vorhandensein des ET $_{\mathrm{B}}$-Rezeptor/ET-Signalsystems angewiesen sind. Es wird hypothetisiert, dass die Endotheline dabei über den $\mathrm{ET}_{\mathrm{B}}$-Rezeptor eine wichtige Rolle für die Axon-Glia-Interaktion spielen. 


\section{Literaturverzeichnis}

Adachi M, Yang YY, Furuichi Y, Miyamoto C (1991): Cloning and characterization of cDNA encoding human A-type endothelin receptor. Biochem Biophys Res Commun 180: $1265-72$.

Adlkofer K, Martini R, Aguzzi A, Zielasek J, Toyka KV, Suter U (1995): Hypermyelination and demyelinating peripheral neuropathy in Pmp22-deficient mice. Nat Genet 11: 274-80.

Anderson DJ (1993): Cell and molecular biology of neural crest cell lineage diversification. Curr Opin Neurobiol 3: 8-13.

Anzini P, Neuberg DH, Schachner M, Nelles E, Willecke K, Zielasek J, Toyka KV, Suter U, Martini R (1997): Structural abnormalities and deficient maintenance of peripheral nerve myelin in mice lacking the gap junction protein connexin 32.J Neurosci 17: 4545-51.

Arai H, Hori S, Aramori I, Ohkubo H, Nakanishi S (1990): Cloning and expression of a cDNA encoding an endothelin receptor. Nature $\underline{348}$ : 730-2.

Arce V, Pollock RA, Philippe JM, Pennica D, Henderson CE, deLapeyrière O (1998): Synergistic effects of schwann- and muscle-derived factors on motoneuron survival involve GDNF and cardiotrophin-1 (CT-1). J Neurosci 18: 1440-8.

Ayer-Le Lievre CS, Le Douarin NM (1982): The early development of cranial sensory ganglia and the potentialities of their component cells studied in quail-chick chimeras. Dev Biol 94: 291-310.

Battistini B, D'Orléans-Juste P, Sirois P (1993): Endothelins: circulating plasma levels and presence in other biologic fluids. Lab Invest 68: 600-28.

Baynash AG, Hosoda K, Giaid A, Richardson JA, Emoto N, Hammer RE, Yanagisawa M (1994): Interaction of endothelin-3 with endothelin-B receptor is essential for 
development of epidermal melanocytes and enteric neurons. Cell 79: 1277-85.

Berti-Mattera LN, Gariepy CE, Burke RM, Hall AK (2006): Reduced expression of endothelin $\mathrm{B}$ receptors and mechanical hyperalgesia in experimental chronic diabetes. Exp Neurol 201: 399-406. Epub 2006 Jun 27.

Bhatheja K, Field J (2006): Schwann cells: origins and role in axonal maintenance and regeneration. Int J Biochem Cell Biol 38: 1995-9. Epub 2006 May 27.

Brand M, Le Moullec JM, Corvol P, Gasc JM (1998): Ontogeny of endothelins-1 and -3, their receptors, and endothelin converting enzyme-1 in the early human embryo. J Clin Invest 101: 549-59.

Brennan A, Dean CH, Zhang AL, Cass DT, Mirsky R, Jessen KR (2000): Endothelins control the timing of schwann cells in vitro and in vivo. Dev. Biol 227: 545-57.

Brinkmann BG und Sereda MW: Max-Planck-Institut Experimentelle Medizin Göttingen: persönliche Mitteilung (2009).

Britsch S, Goerich DE, Riethmacher D, Peirano RI, Rossner M, Nave KA, Birchmeier C, Wegner M (2001): The transcription factor Sox10 is a key regulator of peripheral glial development. Genes Dev 15: 66-78.

Ceccherini I, Zhang AL, Matera I, Yang G, Devoto M, Romeo G, Cass DT (1995): Interstitial deletion of the endothelin-B receptor gene in the spotting lethal (sl) rat. Hum Mol Genet $\underline{4}:$ 2089-96.

Chance PF, Lensch MW, Lipe H, Brown RH Sr, Brown RH Jr, Bird TD (1994): Hereditary neuralgic amyotrophy and hereditary neuropathy with liability to pressure palsies: two distinct genetic disorders. Neurology 44: 2253-7.

Couly GF, Le Douarin NM (1987): Mapping of the early neural primordium in quail-chick chimeras. II. The prosencephalic neural plate and neural folds: implications for the genesis of cephalic human congenital abnormalities. Dev Biol 120: 198-214. 
Daub H, Weiss FU, Wallasch C, Ullrich A (1996): Role of transactivation of the EGF receptor in signalling by G-protein-coupled receptors. Nature $\underline{379}$ : 557-60.

Dong Z, Brennan A, Liu N, Yarden Y, Lefkowitz G, Mirsky R, Jessen KR (1995): Neu differentiation factor is a neuron-glia signal and regulates survival, proliferation, and maturation of rat Schwann cell precursors. Neuron 15: 585-96.

Doyle JP, Stempak JG, Cowin P, Colman DR, D'Urso D (1995): Protein zero, a nervous system adhesion molecule, triggers epithelial reversion in host carcinoma cells. J Cell Biol 131: 465-82.

D'Urso D, Brophy PJ, Staugaitis SM, Gillespie CS, Frey AB, Stempak JG, Colman DR (1990): Protein zero of peripheral nerve myelin: biosynthesis, membrane insertion, and evidence for homotypic interaction. Neuron $\underline{4}$ : 449-60.

Elshourbagy NA, Adamou JE, Gagnon AW, Wu HL, Pullen M, Nambi P (1996): Molecular characterization of a novel human endothelin receptor splice variant. J Biol Chem 271: $25300-7$.

Ernfors P, Lee KF, Jaenisch R (1994): Target derived and putative local actions of neurotrophins in the peripheral nervous system. Prog Brain Res 103: 43-54.

Etchevers HC, Couly G, Vincent C, Le Douarin NM (1999): Anterior cephalic neural crest is required for forebrain viability. Development 126: 3533-43.

Fahrenkamp I, Friede RL (1987): Characteristic variations of relative myelin sheath thickness in 11 nerves of the rat. Anat Embryol (Berl) 177: 115-21.

Garbern JY, Cambi F, Tang XM, Sima AA, Vallat JM, Bosch EP, Lewis R, Shy M, Sohi J, Kraft G, Chen KL, Joshi I, Leonard DG, Johnson W, Raskind W, Dlouhy SR, Pratt V, Hodes ME, Bird T, Kamholz J (1997): Proteolipid protein is necessary in peripheral as well as central myelin. Neuron 19: 205-18. 
Gariepy CE, Cass DT, Yanagisawa M (1996): Null mutation of endothelin receptor type B gene in spotting lethal rats causes aganglionic megacolon and white coat color. Proc Natl Acad Sci USA 93: 867-72.

Gariepy CE, Williams SC, Richardson JA, Hammer RE, Yanagisawa M (1998): Transgenic expression of the endothelin-B receptor prevents congenital intestinal aganglionosis in a rat model of Hirschsprung disease. J Clin Invest 102: 1092-101.

Garratt AN, Voiculescu O, Topilko P, Charnay P, Birchmeier C (2000): A dual role of erbB2 in myelination and in expansion of the schwann cell precursor pool. J Cell Biol 148: 1035-46.

Gritti A, Parati EA, Cova L, Frolichsthal P, Galli R, Wanke E, Faravelli L, Morassutti DJ, Roisen F, Nickel DD, Vescovi AL (1996): Multipotential stem cells from the adult mouse brain proliferate and self-renew in response to basic fibroblast growth factor. $\mathrm{J}$ Neurosci $\underline{6}$ : 1091-100.

Hama H, Kasuya Y, Sakurai T, Yamada G, Suzuki N, Masaki T, Goto K (1997): Role of endothelin-1 in astrocyte responses after acute brain damage. J Neurosci Res $\underline{47}$ : 590-602.

Harrison DG, Venema RC, Arnal JF, Inoue N, Ohara Y, Sayegh H, Murphy TJ (1995): The endothelial cell nitric oxide synthase: is it really constitutively expressed? Agents Actions Suppl 45: 107-17.

Hawes BE, van Biesen T, Koch WJ, Luttrell LM, Lefkowitz RJ (1995): Distinct pathways of Gi- and Gq-mediated mitogen-activated protein kinase activation. J Biol Chem $\underline{270}$ : 17148-53.

Haynes WG, Webb DJ (1994): Contribution of endogenous generation of endothelin-1 to basal vascular tone. Lancet 344: 852-4.

Henderson CE, Yamamoto Y, Livet J, Arce V, Garces A, deLapeyrière O (1998): Role of neurotrophic factors in motoneuron development. J Physiol Paris 92: 279-81. 
Henion PD, Weston JA (1997): Timing and pattern of cell fate restrictions in the neural crest lineage. Development 124: 4351-9.

Holland PM, Abramson RD, Watson R, Gelfand DH (1991): Detection of specific polymerase chain reaction product by utilizing the 5'----3' exonuclease activity of Thermus aquaticus DNA polymerase. Proc Natl Acad Sci USA $\underline{88}$ : 7276-80.

Hori S, Komatsu Y, Shigemoto R, Mizuno N, Nakanishi S (1992): Distinct tissue distribution and cellular localization of two messenger ribonucleic acids encoding different subtypes of rat endothelin receptors. Endocrinology. 130: 1885-95.

Hosoda K, Nakao K, Tamura N, Arai H, Ogawa Y, Suga S, Nakanishi S, Imura H (1992): Organization, structure, chromosomal assignment, and expression of the gene encoding the human endothelin-A receptor. J Biol Chem 267:18797-804.

Hosoda K, Hammer RE, Richardson JA, Baynash AG, Cheung JC, Giaid A, Yanagisawa M (1994): Targeted and natural (piebald-lethal) mutations of endothelin-B receptor gene produce megacolon associated with spotted coat color in mice. Cell 79: 126776.

Huggins JP, Pelton JT, Miller RC (1993): The structure and specificity of endothelin receptors: their importance in physiology and medicine. Pharmacol Ther 59: 55-123.

Jessen KR, Mirsky R (2002): Signals that determine Schwann cell identity. J Anat 200: 36776.

Jessen KR, Mirsky R (2005): The origin and development of glial cells in peripheral nerves. Nat Rev Neurosci 6: 671-82.

Karne S, Jayawickreme CK, Lerner MR (1993): Cloning and characterization of an endothelin-3 specific receptor (ETC receptor) from Xenopus laevis dermal melanophores. J Biol 268: 19126-33. 
Karnovsky, MJ (1965): A formaldehyd-glutaraldehyd fixative of high osmolarity for use in electron microscopy. J Cell Biol 27: 137A.

Kotzbauer PT, Lampe PA, Heuckeroth RO, Golden JP, Creedon DJ, Johnson EM Jr, Milbrandt J (1996): Neurturin, a relative of glial-cell-line-derived neurotrophic factor. Nature 384: 467-70.

Kunieda T, Kumagai T, Tsuji T, Ozaki T, Karaki H, Ikadai H (1996): A mutation in endothelin-B receptor gene causes myenteric aganglionosis and coat color spotting in rats. DNA Res $\underline{3}: 101-5$.

Küry P, Bosse F, Müller HW (2001): Transcription factors in nerve regeneration. Prog Brain Res 132: 569-85.

LaBonne C, Bronner-Fraser M (1999): Molecular mechanisms of neural crest formation. Annu Rev Cell Dev Biol 5: 81-112.

Le Douarin NM, Dupin E (2003): Multipotentiality of the neural crest. Curr Opin Genet Dev 13: 529-36.

Lees MB, Samiullah M, Laursen RA (1984): Structural analogies between myelin basic protein and proteolipid. Prog Clin Biol Res 146: 257-64.

Lemke G and Axel R (1985): Isolation and sequence of a cDNA encoding the major structural protein of peripheral myelin. Cell $\underline{40}: 501-8$

Lobsiger CS, Taylor V, Suter U (2002): The early life of a Schwann cell. Biol Chem $\underline{383}$ : 245-53.

Luft JH (1961): Improvements in epoxy resin embedding methods. J Biophys Biochem Cytol 9: 409-414.

Maemura K, Kurihara H, Kurihara Y, Kuwaki T, Kumada M, Yazaki Y (1995): Gene expression of endothelin isoforms and receptors in endothelin-1 knockout mice. $\mathrm{J}$ 
Cardiovasc Pharmacol 26 Suppl 3: 17-21.

Martini R, Schachner M (1997): Molecular bases of myelin formation as revealed by investigations on mice deficient in glial cell surface molecules. Glia 9: 298-310.

Martini R, Zielasek J, Toyka KV, Giese KP, Schachner M (1995): Protein zero (P0)-deficient mice show myelin degeneration in peripheral nerves characteristic of inherited human neuropathies. Nat Genet 11: 281-6.

Matsunami N, Smith B, Ballard L, Lensch MW, Robertson M, Albertsen H, Hanemann CO, Müller HW, Bird TD, White R, et al. (1992): Peripheral myelin protein-22 gene maps in the duplication in chromosome 17p11.2 associated with Charcot-MarieTooth 1A. Nat Genet 1: 176-9.

McCabe L, Griffin LD, Kinzer A, Chandler M, Beckwith JB, McCabe ER (1990): Overo lethal white foal syndrome: equine model of aganglionic megacolon (Hirschsprung disease). Am J Med Genet 36: 336-40.

Meei-Ling Tsaura, Yi-Chiou Wana, Fang-Pin Laia, Hwei-Fang Chengb (1997): Expression of B-type endothelin receptor gene during neural development, FEBS Letters 417: 208212 .

Meier C, Parmantier E, Brennan A, Mirsky R, Jessen KR (1999): Developing Schwann cells acquire the ability to survive without axons by establishing an autocrine circuit involving insulin-like growth factor, neurotrophin-3, and platelet-derived growth factor-BB. J Neurosci 19: 3847-59.

Metallinos DL, Bowling AT, Rine J (1998): A missense mutation in the endothelin-B receptor gene is associated with Lethal White Foal Syndrome: an equine version of Hirschsprung disease. Mamm Genome 9: 426-31.

Meyer D, Birchmeier C (1994): Distinct isoforms of neuregulin are expressed in mesenchymal and neuronal cells during mouse development. Proc Natl Acad Sci USA 91: 1064-8. 
Meyer zu Hörste G, Prukop T, Nave KA, Sereda MW (2006): Myelin disorders: causes and perspectives of Charcot-Marie-Tooth neuropathy. J Mol Neurosci 28: 77-88.

Michailov GV, Sereda MW, Brinkmann BG, Fischer TM, Haug B, Birchmeier C, Role L, Lai C, Schwab MH, Nave KA (2004): Axonal neuregulin-1 regulates myelin sheath thickness. Science 304: 700-3. Epub 2004 Mar 25.

Milbrandt J, de Sauvage FJ, Fahrner TJ, Baloh RH, Leitner ML, Tansey MG, Lampe PA, Heuckeroth RO, Kotzbauer PT, Simburger KS et al. (1998): Persephin, a novel neurotrophic factor related to GDNF and neurturin. Neuron 20: 245-53.

Milligan G (1999): Exploring the dynamics of regulation of $G$ protein-coupled receptors using green fluorescent protein. Br J Pharmacol 128: 501-10.

Mirsky R, Jessen KR (1996): Schwann cell development, differentiation and myelination. Curr Opin Neurobiol ㅁ: 89-96.

Mirsky R, Jessen KR (1999): The neurobiology of Schwann cells. Brain Pathol 9: 293-311.

Mirsky R, Jessen KR, Brennan A, Parkinson D, Dong Z, Meier C, Parmantier E, Lawson D (2002): Schwann cells as regulators of nerve development. J Physiol Paris $\underline{96}$ : 17-24.

Monge JC, Stewart DJ, Cernacek P (1995): Differentiation of embryonal carcinoma cells to a neural or cardiomyocyte lineage is associated with selective expression of endothelin receptors. J Biol Chem 270: 15385-90.

Müller HW (2000): Tetraspan myelin protein PMP22 and demyelinating peripheral neuropathies: new facts and hypotheses. Glia $\underline{29}$ : 182-5.

Nataf V, Lecoin L, Eichmann A, Le Douarin NM (1996): Endothelin-B receptor is expressed by neural crest cells in the avian embryo. Proc Natl Acad Sci USA 93: 9645-50.

Nave KA (1994): Neurological mouse mutants and the genes of myelin. J Neurosci Res $\underline{38}$ : 
$607-12$

Nave KA (1995): Myelin genetics: new insight into old diseases. Brain Pathol 5: 231-2.

Nayler WG (1990): Endothelin: isoforms, binding sites and possible implications in pathology. Trends Pharmacol Sci 11: 96-9

Nishizuka Y (1992): Intracellular signaling by hydrolysis of phospholipids and activation of protein kinase C. Science 258: 607-14.

Ohuchi T, Kuwaki T, Ling GY, Dewit D, Ju KH, Onodera M, Cao WH, Yanagisawa M, Kumada M (1999): Elevation of blood pressure by genetic and pharmacological disruption of the ETB receptor in mice. Am J Physiol 276: 1071-7.

Pannese E, Rigamonti L, Ledda M, Arcidiacono G (1994): Perikaryal projections of spinal ganglion neurons: quantitative differences between membrane domains in contact with different microenvironments. J Anat 185: 497-502.

Parent A, Asselin MC, Côté PY (1996): Dopaminergic regulation of peptide gene expression in the striatum of normal and parkinsonian monkeys. Adv Neurol 69: 73-7.

Poliak S, Peles E (2003): The local differentiation of myelinated axons at nodes of Ranvier. Nat Rev Neurosci 4: 968-80.

Raine CS (1984): On the association between perinodal astrocytic processes and the node of Ranvier in the C.N.S. J Neurocytol 13: 21-7.

Reynolds BA, Weiss S (1996): Clonal and population analyses demonstrate that an EGFresponsive mammalian embryonic CNS precursor is a stem cell. Dev Biol 175: 1-13.

Richardson KC, Jarettand L, Finke EH (1960): Embedding in epoxy resins for ultrathin sectioning in electron microscopy. Stain Techn $\underline{35}$ : 313-323.

Riethmacher D, Sonnenberg-Riethmacher E, Brinkmann V, Yamaai T, Lewin GR, Birchmeier 
C (1997): Severe neuropathies in mice with targeted mutations in the ErbB3 receptor. Nature 389: 725-30.

Sakamoto A, Yanagisawa M, Sakurai T, Takuwa Y, Yanagisawa H, Masaki T (1991): Cloning and functional expression of human cDNA for the ETB endothelin receptor. Biochem Biophys Res Commun 178: 656-63.

Sakurai T, Yanagisawa M, Takuwa Y, Miyazaki H, Kimura S, Goto K, Masaki T (1990): Cloning of a cDNA encoding a non-isopeptide-selective subtype of the endothelin receptor. Nature $\underline{348}$ (6303): 732-5.

Salzer JL, Bunge RP (1980): Studies of Schwann cell proliferation. I. An analysis in tissue culture of proliferation during development, Wallerian degeneration, and direct injury. J Cell Biol 84: 739-52.

Schramek H, Wang Y, Konieczkowski M, Rose PM, Sedor JR, Dunn MJ (1994): Endothelin1 stimulates cytosolic phospholipase A2 in Chinese hamster ovary cells stably expressing the human ETA or ETB receptor subtype. Biochem Biophys Res Commun 199: 992-7.

Sereda MW, Griffiths I, Pühlhofer A, Stewart H, Rossner MJ, Zimmerman F, Magyar JP, Schneider A, Hund E, Meinck HM et al. (1996): A transgenic rat model of CharcotMarie-Tooth disease. Neuron 16: 1049-60

Sereda MW, Nave KA (2006): Animal models of Charcot-Marie-Tooth disease type 1A. Neuromolecular Med $\underline{8}:$ 205-16.

Shah NM, Marchionni MA, Isaacs I, Stroobant P, Anderson DJ (1994): Glial growth factor restricts mammalian neural crest stem cells to a glial fate. Cell 77: 349-60.

Shah NM, Groves AK, Anderson DJ (1996): Alternative neural crest cell fates are instructively promoted by TGFbeta superfamily members. Cell 포 : 331-43.

Shyamala V, Moulthrop TH, Stratton-Thomas J, Tekamp-Olson P (1994): Two distinct 
human endothelin B receptors generated by alternative splicing from a single gene. Cell Mol Biol Res 40: 285-96.

Sokolovsky M (1995): Endothelin receptor heterogeneity, G-proteins, and signaling via cAMP and cGMP cascades. Cell Mol Neurobiol 15: 561-71.

Suter U, Snipes GJ (1995): Peripheral myelin protein 22: facts and hypotheses. J Neurosci Res 40: $145-51$.

Takasaki C, Tamiya N, Bdolah A, Wollberg Z, Kochva E (1988): Sarafotoxins S6: several isotoxins from Atractaspis engaddensis (burrowing asp) venom that affect the heart. Toxicon 26: 543-8.

Takuwa Y, Kasuya Y, Takuwa N, Kudo M, Yanagisawa M, Goto K, Masaki T, Yamashita K (1990): Endothelin receptor is coupled to phospholipase C via a pertussis toxininsensitive guanine nucleotide-binding regulatory protein in vascular smooth muscle cells. J Clin Invest $\underline{85}$ : 653-8.

Tao W, Liou GI, Wu X, Abney TO, Reinach PS (1995): ETB and epidermal growth factor receptor stimulation of wound closure in bovine corneal epithelial cells. Invest Ophthalmol Vis Sci 36: 2614-22. Erratum in: Invest Ophthalmol Vis Sci 37 (10): 1937.

Taveggia C, Zanazzi G, Petrylak A, Yano H, Rosenbluth J, Einheber S, Xu X, Esper RM, Loeb JA, Shrager P et al. (2005): Neuregulin-1 type III determines the ensheathment fate of axons. Neuron 47: 681-94.

Timmerman V, Raeymaekers P, De Jonghe P, De Winter G, Swerts L, Jacobs K, Gheuens J, Martin JJ, Vandenberghe A, Van Broeckhoven C (1990): Assignment of the CharcotMarie-Tooth neuropathy type 1 (CMT 1a) gene to 17p11.2-p12. Am J Hum Genet. 47: $680-5$.

Vane JR und Botting RM (1994): Regulatory mechanisms of the vascular endothelium: an update. Pol J Pharmacol 46: 499-521 
Vanhoutte PM, Houston DS (1985): Platelets, endothelium, and vasospasm. Circulation $\underline{72}$ : 728-34.

Werner H, Jung M, Klugmann M, Sereda M, Griffiths IR, Nave KA (1998): Mouse models of myelin diseases. Brain Pathol 8: 771-93.

Woolley AG, Tait KJ, Hurren BJ, Fisher L, Sheard PW, Duxson MJ (2008): Developmental loss of NT-3 in vivo results in reduced levels of myelin-specific proteins, a reduced extent of myelination and increased apoptosis of Schwann cells. Glia 56: 306-17.

Wu JJ, Chen JX, Rothman TP, Gershon MD (1999): Inhibition of in vitro enteric neuronal development by endothelin-3: mediation by endothelin B receptors. Development 126: 1161-73.

Yanagisawa M, Inoue A, Ishikawa T, Kasuya Y, Kimura S, Kumagaye S, Nakajima K, Watanabe TX, Sakakibara S, Goto K, et al. (1988): Primary structure, synthesis, and biological activity of rat endothelin, an endothelium-derived vasoconstrictor peptide. Proc Natl Acad Sci USA 모: 6964-7.

Yang GC, Croaker D, Zhang AL, Manglick P, Cartmill T, Cass D (1998): A dinucleotide mutation in the endothelin-B receptor gene is associated with lethal white foal syndrome (LWFS); a horse variant of Hirschsprung disease. Hum Mol Genet $\underline{7}$ : 1047-52.

Young P, Suter U (2003): The causes of Charcot-Marie-Tooth disease. Cell Mol Life Sci $\underline{60}$ : 2547-60.

Zwick M, Davis BM, Woodbury CJ, Burkett JN, Koerber HR, Simpson JF, Albers KM (2002): Glial cell line-derived neurotrophic factor is a survival factor for isolectin B4-positive, but not vanilloid receptor 1-positive, neurons in the mouse. J Neurosci 22: 4057-65. 


\section{Abkürzungsverzeichnis}

\begin{tabular}{|c|c|}
\hline APS & Ammoniumperoxodisulfat \\
\hline BDNF & aus dem Gehirn stammender neurotrophischer Faktor \\
\hline bp & Basenpaare \\
\hline BSA & Bovines Serumalbumin \\
\hline cDNA & komplementäre DNA \\
\hline $\mathrm{d}$ & delta \\
\hline DAPI & 4,6-diamidino-2-phenylindol \\
\hline DDSA & 2-Duodecenyl-succinicacidanhydrid \\
\hline DMP-30 & 2,4,6-Tris(dimethyl-amino-methyl)phenol \\
\hline dNTP & Desoxynukleosidtriphosphat \\
\hline DRG & dorsal root ganglia; dorsale spinale Nervenwurzel \\
\hline $\mathrm{E}$ & Embryonaltag \\
\hline EDNRB & Endothelin-Rezeptor-B \\
\hline EGTA & Ethylen-Glycol-bis(2-aminoethylether)-N,N,N','N-tetra-Essigsäure \\
\hline $\mathrm{EM}$ & Elektronenmikroskop \\
\hline ET-1 & Endothelin-1 \\
\hline ET-2 & Endothelin-2 \\
\hline ET-3 & Endothelin-3 \\
\hline $\mathrm{ET}_{\mathrm{A}}$-Rezeptor & Endothelin-Rezeptor-A \\
\hline $\mathrm{ET}_{\mathrm{B}}$-Rezeptor & Endothelin-Rezeptor-B \\
\hline GAPDH & Glycerinaldehydphosphat-Dehydrogenase \\
\hline GPCR & G-protein coupled receptor; G-Protein-gekoppelter Rezeptor \\
\hline $\mathrm{h}$ & Stunde \\
\hline HBSS & Hank's gepufferte Salzlösung \\
\hline HRP & horse radish peroxidase; Meerrettichperoxidase \\
\hline $\mathrm{kDa}$ & kiloDalton \\
\hline MNA & Methylensäure-Anhydrid \\
\hline mRNA & messenger ribonucleic acid; Boten-Ribonukleinsäure \\
\hline n.s. & nicht signifikant \\
\hline NGF & nerve growth factor; Nervenwachstumsfaktor \\
\hline NRG-1 & Neuregulin-1 \\
\hline NT-3 & Neurotrophin-3 \\
\hline $\mathrm{P}$ & Postnataltag \\
\hline $\mathrm{P} 0$ & Myelin Protein Null \\
\hline PCR & polymerase chain reaction; Polymerasekettenreaktion \\
\hline PFA & Paraformaldehyd \\
\hline $\mathrm{q}$ & Quantitative \\
\hline RNA & ribonucleic acid; Ribonukleinsäure \\
\hline $\mathrm{rpm}$ & rounds per minute; Umdrehungen pro Minute \\
\hline RT & Raumtemperatur \\
\hline
\end{tabular}




$\begin{array}{ll}\text { RT } & \text { Reverse Transkriptase } \\ \text { SD } & \text { Standardabweichung } \\ \text { SZ } & \text { Schwannzelle } \\ \text { TEMED } & \text { N,N,N',N'-Tetramethylethylendiamin } \\ \text { Tris } & \text { Tris(hydroxymethyl)-aminomethan } \\ \text { TrkC } & \text { Tyrosin-Kinase-Rezeptor C } \\ \text { V } & \text { Volumen }\end{array}$




\section{Abbildungsverzeichnis}

Abbildung 1: Struktur der Endotheline und des Sarafotoxin-S6b

Abbildung 2: Enzymatische Prozessierung von Endothelin-1

Abbildung 3: Struktur des humanen ETB-Rezeptors

Abbildung 4: Effektorsysteme der humanen Endothelin-Rezeptoren

Abbildung 5: Äußerlicher Phänotyp und Morphologie des Darms bei sl/sl-Ratten und Wildtypratten 9

Abbildung 6: Die Schwannzell-Entwicklungslinie 10

Abbildung 7: Myelin Organisation im zentralen und peripheren Nervensystem 13

Abbildung 8: Schematische Darstellung von myelinisierten Axonen im PNS und ZNS 15

Abbildung 9: Das ,g-ratio“ als Maß für die Myelindicke 33

Abbildung 10: Histologie des N. ischiadicus

Abbildung 11: Gesamtanzahl myelinisierter Axone im Querschnitt des N. ischiadicus P6 und P18 39

Abbildung 12: Gesamtanzahl von Zellkernen in Gesamtquerschnitten des N. ischiadicus bei P1, P6 und P18 40

Abbildung 13:"g-ratio" bei P6- und P18-Tieren 41

Abbildung 14: Axongrößenverteilung bei P6 42

Abbildung 15: Axongrößenverteilung bei P18 42

Abbildung 16: Histologische Analyse der Myelinisierung bei P1 44

Abbildung 17: Axonale Dichte bei P1 45

Abbildung 18: TUNEL Färbung DRG und Rückenmark 47

Abbildung 19: Neuronale Dichte lumbaler DRG's 48

Abbildung 20: Anzahl der $\alpha$-Motoneurone im Vorderhorn des Rückenmarks 50 


\section{Danksagung}

Ich danke allen, die mich bei der Verwirklichung dieser Arbeit unterstützt haben.

Ich möchte mich an erster Stelle außerordentlich bei Prof. Dr. Klaus Armin Nave bedanken, der mir dieses interessante Thema zur Verfügung stellte.

Weiterhin möchte ich mich bei PD Dr. Michael W. Sereda bedanken, der meine Arbeit betreute und jederzeit für Diskussionen und konstruktive Kritik zur Verfügung stand.

Allen Mitarbeitern der Abteilung Neurogenetik und insbesondere meiner PNS-Group danke ich für ihre Unterstützung und die schöne Zeit. 


\section{Lebenslauf}

Am 02.02.1979 wurde ich als zweites Kind von Amtul Hye und Jahangir Ahmad in Rabwah (Pakistan) geboren.

In Pakistan besuchte ich von 1985 bis 1987 die Primary school of Rabwah. Im September 1987 zog ich mit meiner Familie nach Deutschland. Hier wurde ich im Januar 1988 in die Grundschule in Bad Karlshafen eingeschult. Aufgrund eines Umzuges ging ich ab August 1989 in die Gesamtschule in Zierenberg bis zur 7. Klasse, anschließend vervollständigte ich die mittlere Reife in der Gymnasialstufe der Gesamtschule Immenhausen. Die allgemeine Hochschulreife (Abitur) erlangte ich nach weiteren drei Jahren an der Herderschule in Kassel 1998.

Nach Erhalt der allgemeinen Hochschulreife leistete ich vom Oktober 1998 bis März 1999 in der Neurologischen Abteilung des Klinikums Kassel ein freiwilliges halbes soziales Jahr ab.

Zum Sommersemester 1999 immatrikulierte ich mich an der Georg-August-Universität in Göttingen. Die Ärztliche Vorprüfung (Physikum) legte ich 2001, den ersten Abschnitt der Ärztlichen Prüfung (1. Staatsexamen) 2002 und den zweiten Abschnitt der Ärztlichen Prüfung (2. Staatsexamen) $2004 \mathrm{ab}$.

Von April 2002 bis März 2005 war ich als Wissenschaftliche Hilfskraft in der Abteilung für Neurogenetik unter der Leitung von Herrn Prof. Dr. rer. nat. K. A. Nave im Max Planck Institut für experimentelle Medizin in Göttingen angestellt. Im Rahmen dieser Tätigkeit entstand die vorliegende Arbeit unter der Supervision von PD Dr. med. M. Sereda.

Es folgte 2005 das Praktische Jahr, das ich am Universitätsspital in Zürich, Schweiz bei Herrn Prof. Dr. Y. Yonekawa, im Universitätsklinikum Göttingen bei Prof. Dr. M. Buchfelder und am Klinikum Wolfsburg bei Prof. Dr. med. U. Rasenack und Prof. Dr. med. J. Meyer absolvierte. Im Anschluss folgte im April 2006 der Abschluss des Studiums mit dem dritten Abschnitt der Ärztlichen Prüfung (3. Staatsexamen) an der Universität Göttingen.

Die Erteilung der Approbation als Arzt erlangte ich am 24.05.2006. Seit Juni 2006 bin ich als wissenschaftliche Angestellte mit ärztlichen Aufgaben an der Universitätsklinik Göttingen in der Abteilung für Neurochirurgie unter der Leitung von Prof. Dr. med. V. Rohde tätig.

Göttingen, 22.12.2009 